UNIVERSIDADE DE SÃO PAULO

ESCOLA DE ENFERMAGEM

FABIO JOSÉ DA SILVA

CAPACIDADE PARA O TRABALHO E PRESENTEÍSMO EM TRABALHADORES DE ENFERMAGEM: PROPOSTAS DE INTERVENÇÕES GERENCIAIS

SÃO PAULO

2016 

FABIO JOSÉ DA SILVA

\section{CAPACIDADE PARA O TRABALHO E PRESENTEÍSMO EM TRABALHADORES DE ENFERMAGEM: PROPOSTAS DE INTERVENÇÕES GERENCIAIS}

Tese apresentada ao Programa de Pós-Graduação em Gerenciamento em Enfermagem da Escola de Enfermagem da Universidade de São Paulo, para obtenção do título de Doutor em Ciências.

Área de Concentração: Fundamentos e Práticas de Gerenciamento em Enfermagem e em Saúde.

Orientadora: Prof. ${ }^{\text {a }}$ Dr. ${ }^{\text {a }}$ Vanda Elisa Andres Felli

VERSÃO CORRIGIDA

A versão original encontra-se disponível na Biblioteca da Escola de Enfermagem da Universidade de São Paulo e na Biblioteca Digital de Teses e Dissertações da Universidade de São Paulo.

\section{SÃO PAULO}

2016 
AUTORIZO A REPRODUÇÃO E DIVULGAÇÃO TOTAL OU PARCIAL DESTE TRABALHO, POR QUALQUER MEIO CONVENCIONAL OU ELETRÔNICO, PARA FINS DE ESTUDO E PESQUISA, DESDE QUE CITADA A FONTE.

Assinatura:

Data:

Silva, Fábio José

Capacidade para o trabalho e presenteísmo em trabalhadores de enfermagem: propostas de intervenções gerenciais / Fábio José da Silva. São Paulo, 2016.

$171 \mathrm{p}$.

Tese (Doutorado) - Escola de Enfermagem da Universidade de São Paulo.

Orientadora: Prof. ${ }^{a}$ Dr. ${ }^{a}$ Vanda Elisa Andres Felli

Area de concentração: Fundamentos e Fráticas de Gerenciamento em Enfermagem e em Saúde

1. Enfermagem. 2. Saúde ocupacional. 3. Avaliação da capacidade de trabalho. I. Título. 
FABIO JOSÉ DA SILVA

CAPACIDADE PARA O TRABALHO E PRESENTEÍSMO EM TRABALHADORES DE ENFERMAGEM; PROPOSTAS DE INTERVENÇÕES GERENCIAIS

Tese apresentada ao Programa de Pós-Graduação em Gerenciamento em Enfermagem da Escola de Enfermagem da Universidade de São Paulo, para obtenção do título de Doutor em Ciências.

Aprovado em:

\section{BANCA EXAMINADORA}

Prof. Dr.

Instituição:

Julgamento:

Assinatura:

Prof. Dr.

Instituição:

Julgamento:

Assinatura:

Prof. Dr.

Instituição:

Julgamento:

Assinatura:

Prof. Dr.

Instituição:

Julgamento:

Assinatura:

Prof. Dr.

Instituição:

Julgamento:

Assinatura: 



\section{DEDICATÓRIA}

Aos meus pais e avós que sempre me incentivaram na busca de meus ideais e me deram exemplos de bondade e amor ao próximo.

Ao Paulo, meu companheiro de todos os momentos, pela compreensão e carinho ao longo do período de elaboração deste trabalho.

Aos trabalhadores de enfermagem do Hospital Universitário da USP. 



\section{AGRADECIMENTOS}

À minha querida orientadora, Profa. Dra. Vanda Elisa Andres Felli, pelo carinho, competência e dedicação em seus ensinamentos.

À Profa. Dra. Patrícia Campos Pavan Baptista, pelo companheirismo, motivação e reconhecimento.

Às Profas. Dras. Elizabete Maria Neves Borges e Cristina Maria Leite Queirós pela parceria em pesquisa e carinho no acolhimento em meu estágio na cidade do Porto - Portugal.

À Dra. Maria Carmen Martinez, pelas contribuições no tratamento estatístico desta pesquisa.

Às pesquisadoras Ana Paula Pelegrini Ratier, Renata Santos Tito e Silmar Maria Silva, minhas grandes companheiras de estudo.

Às gerentes de enfermagem do Hospital Universitário da Universidade de São Paulo.

Às equipes de enfermagem do HU-USP que, mesmo nos plantões mais difíceis, sempre me trataram com todo respeito e carinho me motivando ao longo trajeto da coleta de dados.

Aos meus familiares e amigos, que sempre me deram apoio para continuar nessa difícil jornada.

Aos colegas e funcionários Universidade de São Paulo, por todo profissionalismo, carinho e prontidão com que atendem aos alunos. 

Comece onde você está.

Use o que você tem.

Faça o que você pode!

(Arthur Ashe) 

Silva FJ. Capacidade para o trabalho e presenteísmo em trabalhadores de enfermagem; propostas de intervenções gerenciais [tese]. São Paulo (SP), Brasil: Escola de Enfermagem, Universidade de São Paulo: 2016.

\section{RESUMO}

Introdução: $O$ aperfeiçoamento das políticas de saúde e segurança no trabalho requer inovação no gerenciamento de recursos humanos, demandando ações direcionadas para boas condições de trabalho e saúde. Objetivo: Analisar a associação da capacidade para o trabalho e do presenteísmo entre trabalhadores de enfermagem e propor intervenções para a prevenção do presenteísmo e das incapacidades para o trabalho. Método: Estudo epidemiológico de recorte transversal, com abordagem quanti-qualitativa dos dados, desenvolvido no Hospital Universitário da Universidade de São Paulo (HU-USP), com todos os trabalhadores assistenciais da equipe de enfermagem e seus respectivos gerentes. Os dados foram coletados por meio de quatro instrumentos: formulário contendo dados sociodemográficos e profissionais, questionário Índice de Capacidade para o Trabalho (ICT), Escala de Presenteísmo de Stanford (SPS-6) e entrevista coletiva (grupo focal) com os gerentes de enfermagem. O projeto foi submetido ao Comitê de Ética em Pesquisa da Escola de Enfermagem da Universidade de São Paulo e a coleta autorizada pelo HU-USP. Os dados foram coletados no período de fevereiro a novembro de 2015 , sendo que todos os participantes assinaram o Termo de Consentimento Livre e Esclarecido. O contato com os trabalhadores foi no próprio local e turno de trabalho, seguido da apresentação do projeto e do convite para participação no estudo. Foi usado o teste Qui quadrado para a análise bivariada dos fatores associados à capacidade para trabalho. As variáveis que apresentaram $\mathrm{p}<0,20$ foram incluídas na modelagem múltipla, por meio de análise de regressão logística stepwise forward. Os dados qualitativos foram transcritos e submetidos à análise de conteúdo temática. Resultados: Em relação aos dados quantitativos foram eleitos 516 sujeitos e desses $379(73,4 \%)$ participaram da pesquisa. A média etária foi de 41,6 anos ( $\mathrm{dp}=9,2$ anos), variando de 23,0 a 65,0 anos, sendo 331 (87,3\%) mulheres, casadas $(60,6 \%)$, com escolaridade de nível superior $(63,6 \%)$. O tempo médio de atuação na profissão de enfermagem era de 16,2 anos ( $d p=8,0$ anos) e $63,0 \%$ exerciam a função de técnico ou auxiliar de enfermagem. A jornada de trabalho semanal foi de 38,5 horas em média ( $\mathrm{dp}=8,6$ horas), sendo que a maioria $(55,6 \%)$ relatou mais de 01 hora diária de tempo de trajeto. A média do ICT foi considerada boa, com 39,1 pontos ( $\mathrm{dp}=5,9)$, variando de 20,0 a 49,0 pontos, porém $38.3 \%$ com ICT inadequado. O presenteísmo foi revelado por $39.8 \%$ dos participantes, desses $23.7 \%$ com desempenho mantido e $16,1 \%$ com desempenho reduzido. Dentre os problemas de saúde, os distúrbios musculoesqueléticos, gastrointestinais, respiratórios e emocionais foram os mais prevalentes. Observou-se associação estatisticamente significativa entre a capacidade para 0 trabalho e o presenteísmo $(p<0,001)$, sendo que entre os trabalhadores com melhor desempenho houve maior prevalência de capacidade para o trabalho adequada $(68,2 \%)$ do que entre aqueles com redução do desempenho $(27,9 \%)$. A análise dos dados qualitativos resultou em três categorias nas dimensões individual, gerencial e institucional com propostas de intervenções focadas nos temas de sensibilização para adesão às medidas de proteção, gestão e liderança para cultura de segurança no trabalho e os recursos disponíveis na universidade como estratégia de mudança. Conclusão: As intervenções gerenciais propostas para a saúde do trabalhador foram consideradas atributos para a qualidade de vida no trabalho, longevidade e garantia de segurança na assistência de enfermagem e melhora na acreditação hospitalar.

PALAVRAS-CHAVE: Enfermagem. Saúde Ocupacional. Avaliação da Capacidade de Trabalho. Presenteísmo. 

Silva FJ. Work ability and presenteeism among nursing workers: management intervention proposals [thesis]. São Paulo (SP), Brasil: Escola de Enfermagem, Universidade de São Paulo: 2016.

\section{ABSTRACT}

Introduction - The improvement of occupational health and safety policies requires innovation in human resource management, demanding actions directed at good working conditions and health. Objective - Analyze the association between work ability and presenteeism among nursing workers and propose interventions to prevent presenteeism and occupational disability. Method - Epidemiological cross-sectional study, with quantitative and qualitative data approach, developed at the University Hospital of the University of Sao Paulo (HU-USP), with all the nursing care workers and their respective managers. The data were collected through four instruments: sociodemographic and professional profile questionnaire, Work Ability Index (WAI), Stanford Presenteeism Scale (SPS-6) and nursing managers focus group discussion. The project was submitted to the Research Ethics Committee of the Nursing School of the University of Sao Paulo and the collection authorized by the HU-USP. The data were collected from February to November 2015, and all the participants signed the Informed Consent form. The contact with the workers was made at their own workplace and during their work shift. It was followed by the project presentation and the invitation to take part of the survey. The chi-square test was used for the bivariate analysis of the factors associated with the work ability. The variables presenting $p<0.20$ were included in the multivariate data modeling through a stepwise forward logistic regression analysis. The qualitative data were transcribed and submitted to a thematic content analysis. Results - Regarding quantitative data, 516 subjects were elected and 379 (73.4\%) of them participated in the survey. The average age was 41.6 years ( $S D=9.2$ years), ranging from 23.0 to 65.0 years old, $331(87.3 \%)$ were women, married $(60.6 \%)$, with an educational higher level (63.6\%).The average time of work in the nursing profession was 16.2 years $(\mathrm{SD}=8.0$ years) and $63.0 \%$ exercised as technicians or nursing assistants. The average weekly working hours were 38.5 (SD=8.6 hours), and the majority $(55.6 \%)$ reported spending more than 01 hour a day commuting. The WAl average score was considered good, with 39.1 points $(\mathrm{SD}=5.9)$, ranging from 20.0 to 49.0 points, but $38.3 \%$ presented an inadequate WAI. Presenteeism was revealed by $39.8 \%$ of the respondents, $23.7 \%$ of them maintaining their work performance, while $16.1 \%$ reducing it. The most prevalent health problems reported were musculoskeletal, gastrointestinal, respiratory and emotional disorders. A statistically significant association between work ability and presenteeism $(p<0,001)$ could be noted. There was a higher prevalence of adequate work ability $(68.2 \%)$ among workers with a better work performance than among those with a reduced one $(27.9 \%)$. The qualitative data analysis resulted in three categories in the individual, managerial and institutional dimensions with intervention proposals focused on awareness issues for adherence to protective measures, management and leadership for safety culture at work and the resources available at the university as a strategy of change. Conclusion - The management interventions proposed for the worker's health were considered as attributes to the quality of working life, longevity and safety assurance in nursing care and to the hospital accreditation improvement.

KEYWORDS: Nursing. Occupational health. Work Capacity Evaluation. Presenteeism. 



\section{LISTA DE TABELAS}

Tabela 1 - Análise comparativa entre perdas e participantes, segundo características demográficas e ocupacionais dos trabalhadores de Enfermagem, São Paulo, 2015.

Tabela 2 - Análise comparativa entre perdas e participantes segundo características demográficas e ocupacionais dos trabalhadores de Enfermagem, São Paulo, 2015. 68

Tabela 3 - Valores do alpha de Cronbach por dimensão do Índice de Capacidade para o Trabalho - ICT, trabalhadores de Enfermagem, São Paulo, 2015. 69

Tabela 4 - Valores do alpha de Cronbach por dimensão da Escala de Presenteísmo de Stanford - SPS-6, trabalhadores de Enfermagem, São Paulo, 2015. 70

Tabela 5 - Distribuição dos trabalhadores de Enfermagem segundo variáveis demográficas, São Paulo, 2015 .71

Tabela 6 - Estatística descritiva das variáveis quantitativas contínuas, trabalhadores de Enfermagem, São Paulo, 2015

Tabela 7 - Distribuição dos trabalhadores de Enfermagem segundo variáveis ocupacionais, São Paulo, 2015.

Tabela 8 - Distribuição dos trabalhadores de Enfermagem segundo local de trabalho, São Paulo, 2015.

Tabela 9 - Estatística descritiva da Escala de Presenteísmo de Stanford - SPS-

6 e suas dimensões componentes, trabalhadores de Enfermagem, São Paulo, 2015 .75

Tabela 10 - Distribuição dos trabalhadores de Enfermagem segundo as doenças autorreferidas, São Paulo, 2015.

Tabela 11 - Distribuição dos trabalhadores de Enfermagem segundo classificação da capacidade para o trabalho, São Paulo, 2015. 
Tabela 12 - Distribuição dos trabalhadores $\left(\mathrm{n}^{\circ}\right)$ segundo pontuação das dimensões do Índice de Capacidade para o Trabalho, São Paulo, 2015.

Tabela 13 - Distribuição (no e \%) dos trabalhadores de Enfermagem segundo as principais doenças referidas, São Paulo, 2015.

Tabela 14 - Distribuição dos trabalhadores de Enfermagem segundo grupos de doenças citadas com diagnóstico médico, São Paulo, 2015. 82

Tabela 15 - Análise das associações entre presenteísmo e capacidade para o trabalho em trabalhadores de Enfermagem, São Paulo, 2015. 83

Tabela 16 - Análise das associações entre variáveis demográficas e capacidade para o trabalho em trabalhadores de Enfermagem, São Paulo, 2015

Tabela 17 - Análise das associações entre variáveis ocupacionais e capacidade para o trabalho em trabalhadores de Enfermagem, São Paulo, 2015 .... 85

Tabela 18 - Análise das associações entre local de trabalho e capacidade para o trabalho em Trabalhadores de Enfermagem, São Paulo, 2015. 86

Tabela 19 - Fatores associados à capacidade para o trabalho em trabalhadores de Enfermagem, identificados por meio da análise de regressão logística, São Paulo, 2015. 


\section{LISTA DE GRÁFICOS}

Gráfico 1 - Pontuação média dos componentes da Escala de Presenteísmo de Stanford - SPS-6, de trabalhadores de Enfermagem. São Paulo, 2015.

Gráfico 2 - Distribuição da população de estudo (\%) segundo classificação do presenteísmo, trabalhadores de Enfermagem, São Paulo, 2015.

Gráfico 3 - Distribuição (\%) dos trabalhadores de Enfermagem segundo classificação da capacidade para o trabalho, São Paulo, 2015. .78 



\section{LISTA DE APÊNDICES}

APÊNDICE A - Dados Sociodemográficos e Profissionais ...................................147

APÊNDICE B - Termo de Consentimento Livre e Esclarecido .................................149

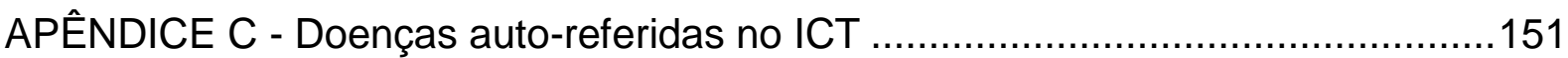





\section{LISTA DE ANEXOS}

ANEXO 1 - Índice de Capacidade para o trabalho ......................................... 161

ANEXO 2 - Escala de Presenteísmo de Stanford (SPS-6) ...............................167

ANEXO 3 - Parecer Consubstanciado do CEP - EEUSP ..................................168

ANEXO 4 - Aprovação do Comitê de Ética em Pesquisa do HU-USP ...................171 



\section{SUMÁRIO}

1 INTRODUÇÃO.

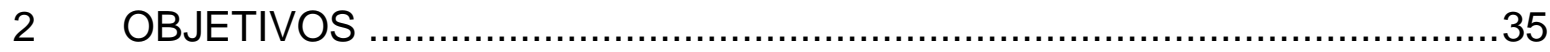

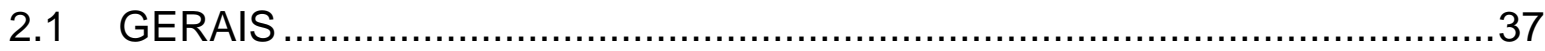

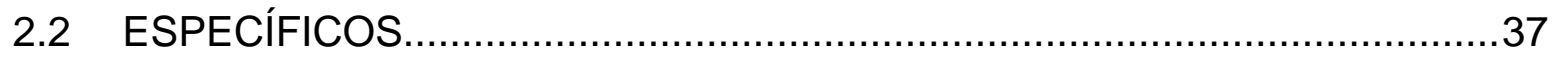

3 FUNDAMENTAÇÃO TEÓRICA ..................................................... 39

3.1 A AVALIAÇÃO CAPACIDADE PARA O TRABALHO NA ÁREA DA ENFERMAGEM

3.2 O PRESENTEÍSMO EM TRABALHADORES DE ENFERMAGEM 44

3.3 A PERSPECTIVA DO GERENCIAMENTO EM ENFERMAGEM NA BUSCA DE MELHOR CAPACIDADE PARA O TRABALHO E PREVENÇÃO DO PRESENTEÍSMO

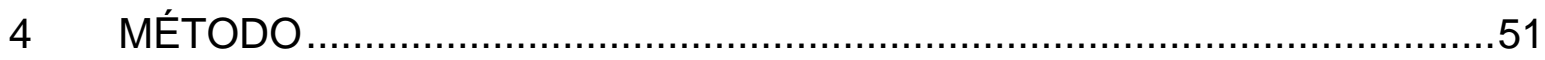

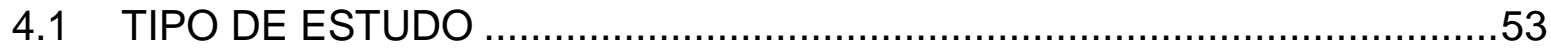

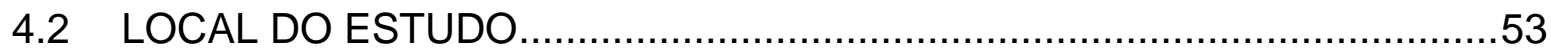

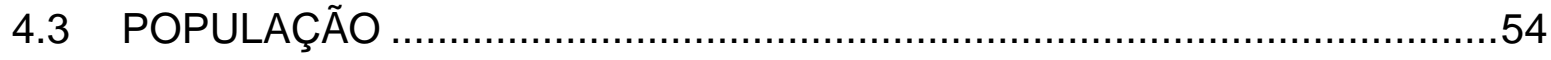

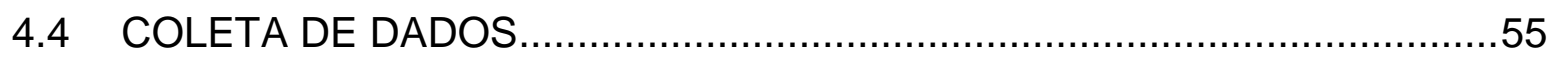

4.4.1 Instrumentos para coleta de dados.................................................. 55

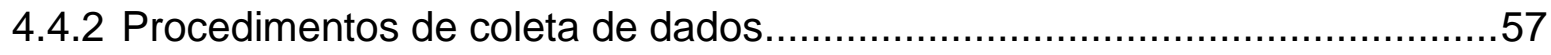

4.5 PROCEDIMENTOS DE ANÁLISE DOS DADOS QUANTITATIVOS ............59

4.6 PROCEDIMENTOS DE ANÁLISE DOS DADOS QUALITATIVOS..............63

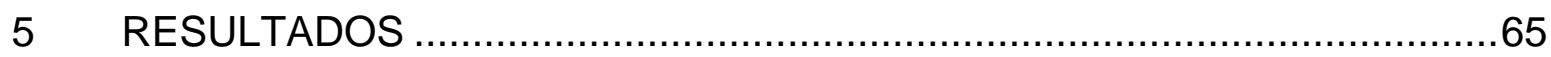

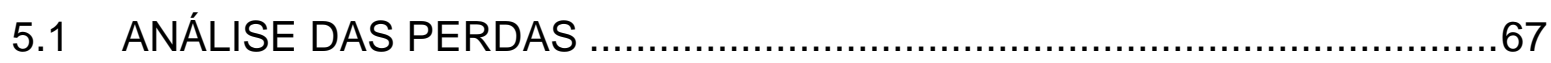

5.2 CONFIABILIDADE DOS QUESTIONÁRIOS UTILIZADOS .........................69

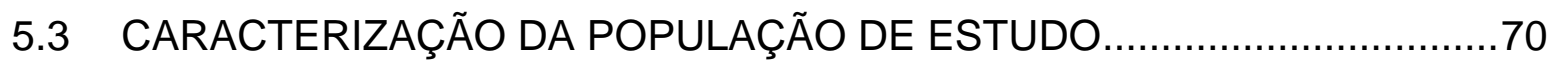

5.3.1 Características sociodemográficas e ocupacionais ................................70

5.3.2 Análise descritiva do presenteísmo.............................................. 75 
5.4 ANÁLISE DO ÍNDICE DE CAPACIDADE PARA O TRABALHO

5.5 ANÁLISE DAS ASSOCIAÇÕES ENTRE CAPACIDADE PARA O

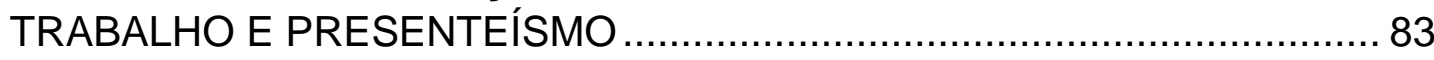

5.5.1 Análise dos fatores associados à capacidade para o trabalho .................... 83

5.5.2 Análise das associações entre capacidade para o trabalho e

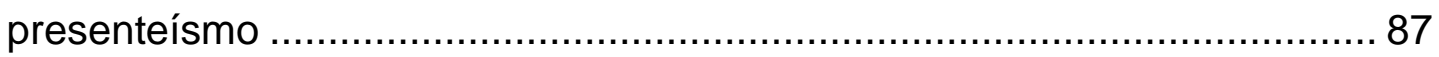

5.6 CONCLUSÃO DOS RESULTADOS QUANTITATIVOS ................................ 89

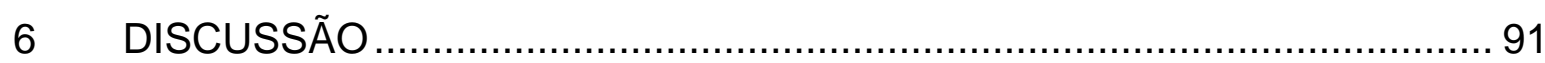

6.1 CARACTERIZAÇÃO DA POPULAÇÃO DE ESTUDO ….............................93

6.2 ANÁLISE DESCRITIVA DO PRESENTEÍSMO ......................................... 99

6.3 AVALIAÇÃO DA CAPACIDADE PARA O TRABALHO .............................103

6.4 A CAPACIDADE PARA O TRABALHO, O PRESENTEISMO E DEMAIS FATORES ASSOCIADOS .................................................. 108

7 ANÁLISE QUALITATIVA DAS PROPOSTAS DE INTERVENÇÃO ............113

7.1 AS PROPOSTAS DE INTERVENÇÃO VALIDADAS ................................. 124

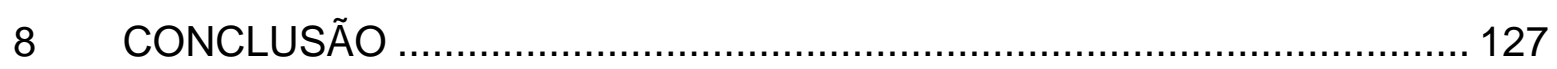

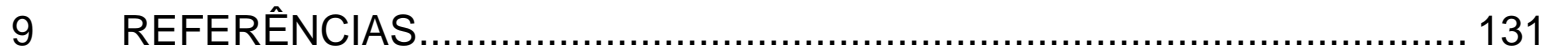

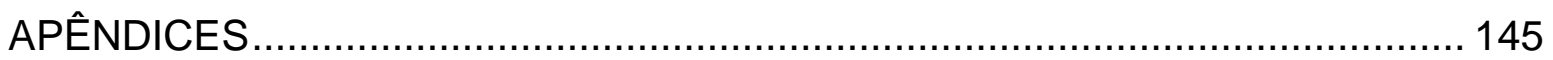

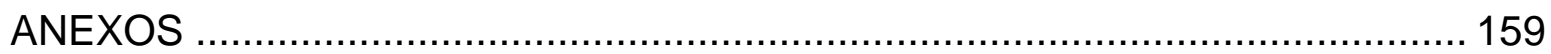


1 INTRODUÇÃO 



\section{INTRODUÇÃO}

O aperfeiçoamento das políticas de saúde e segurança do trabalho constou entre os desafios para a Década dos Recursos Humanos em Saúde, proposta pela Organização Panamericana de Saúde para 2006-2015. A proposta buscou superar sérios desafios em relação ao desenvolvimento desses recursos na região das Américas e dentre esses gerar relações laborais entre os trabalhadores e as organizações de saúde que promovam ambientes de trabalho saudáveis e permitam o compromisso com a missão institucional de garantir bons serviços de saúde para toda a população (PAHO, 2006).

Embora a década já tenha terminado, as ações continuam e a promoção da qualidade de vida no trabalho ainda é um desafio a ser vencido.

O combate ao absenteísmo e ao presenteísmo, bem como, a melhoria da capacidade para o trabalho são determinantes da qualidade de vida e da longevidade no trabalho, a fim de se prevenir o envelhecimento pelo trabalho (Ilmarinen, 2005; Brasil, 2008).

Com o aumento da expectativa de vida da população e a inversão da pirâmide populacional, os trabalhadores tendem a permanecer por mais tempo no mercado de trabalho, o que implica na sustentabilidade da economia do País e na redução dos déficits previdenciários. Portanto, demandas por boas condições de trabalho e saúde emergem, tanto no plano individual, como das organizações e da própria sociedade (Martinez, Latorre, Fischer, 2010).

Frente às exigências do mercado globalizado, a reestruturação produtiva requer dos trabalhadores maior flexibilidade para o desempenho de suas atividades, com melhores resultados e menor custo para as empresas (Antunes, Alves, 2004). Como consequência, observa-se o aumento da rotatividade, pela ausência de vínculos formais e a terceirização dos serviços de saúde, tornando o trabalho cada vez mais fragmentado (Franco, Druch, Seligmann-Silva, 2010). Com isso, torna-se um desafio para a gestão em saúde a manutenção das competências técnicocientíficas dos trabalhadores. Esses transitam no mercado de trabalho onde não encontram mais a estabilidade no emprego e nem os incentivos para a criação de vínculos com as instituições. Essa problemática impacta na satisfação profissional e na saúde física, mental e social dos trabalhadores, nos quais se observa 
desmotivação, elevados índices de fadiga e estresse crônico, comprometendo a qualidade vida no trabalho (Martins, Molinaro, 2013; Silva et al., 2016).

Mundialmente a perda da capacidade para o trabalho entre trabalhadores da área da saúde, principalmente, os de enfermagem que compõe o maior contingente da força de trabalho em saúde é uma preocupação (Fischer et al., 2005; Camerino et al., 2006). Isto se deve, às más condições de trabalho com jornadas extensas e, ao subemprego que são expoentes da precarização do trabalho (Felli, 2012).

A precarização do trabalho de enfermagem é evidenciada pela terceirização dos serviços, trabalho cooperativado, temporário, sem vínculo e com baixa remuneração, além de outros determinantes (Felli, Tronchin, 2010; Felli, 2012). As comprometidas relações interpessoais, estabelecidas durante o processo de trabalho, que já ocorre em ritmo acelerado e o clima organizacional prejudicado pela exposição intensa às cargas de trabalho são determinantes do processo saúdedoença, favorecendo a escassez dos recursos humanos nas instituições de saúde (Mauro et al., 2010; Felli, Tronchin, 2010).

A escassez de trabalhadores de enfermagem também se deve, além das ausências previstas e imprevistas, aos afastamentos prolongados e à falta de políticas institucionais para melhor dimensionamento de pessoal (Sancinetti et al., 2011; Costa et al., 2014).

Dentre os trabalhadores de enfermagem, alocados nas unidades assistenciais, encontram-se trabalhadores com restrições de atividades de trabalho, tanto de ordem física, quanto mental, diagnosticadas por médico por meio de atestado de saúde ocupacional (Silva, 2011).

Essa situação resulta em uma divisão de trabalho, em que são atribuídos aos trabalhadores que não possuem restrições de atividades, os cuidados de pacientes de alta dependência, semi-intensivos e intensivos. Assim, se por um lado são poupados os trabalhadores com restrições, por outro, ficam sobrecarregados os que assumem as atividades integralmente, os quais também podem sofrer comprometimentos de saúde. O exemplo dessa situação é a manipulação excessiva de peso por esses trabalhadores.

Além disso, as manifestações de insatisfação dos trabalhadores que assumem maior número de atividades aumentam os conflitos interpessoais, dada a desigualdade na distribuição de tarefas entre todos os trabalhadores da equipe, que 
devem exercer as mesmas funções dentro da instituição. Em decorrência, a capacidade para o trabalho da equipe de enfermagem é comprometida, tornando-se fator preocupante para o gerenciamento de recursos humanos em enfermagem nas unidades assistenciais.

As restrições de atividades de trabalho são, na maioria das vezes, definitivas e oriundas de distúrbios osteomusculares, limitando os trabalhadores às manipulações de peso, realização de movimentos repetitivos e ao trabalho em pé (Gurgueira, Alexandre, 2006). No entanto, não se tem observado programas de reabilitação e nem mudanças nos processos e postos trabalho para prevenção e controle dessa situação geradora de comprometimento da saúde e segurança no trabalho (Silva, 2012).

O estudo de Martins (2011) constatou sintomas musculoesqueléticos em todos os trabalhadores de enfermagem de unidade de terapia intensiva, em um período de doze meses, sendo os sítios corporais mais afetados a coluna vertebral e os ombros. Constatou, ainda, o fato preocupante de que, para continuaram trabalhando e poderem descansar após o turno de trabalho, fazem uso indevido da automedicação analgésica.

Neste contexto, estudos realizados com os trabalhadores de enfermagem evidenciam que esses têm sérios problemas de saúde física e mental, o que contribui para o aumento dos índices de absenteísmo e presenteísmo, prejudicando a assistência de enfermagem (Paschoalin et al., 2012; Costa et al., 2014; Silva et al., 2016).

As atividades realizadas pelos trabalhadores de enfermagem são consideradas insalubres e de difícil execução, pois geralmente são procedimentos que os expõem ao adoecimento, dado o manuseio inadequado de peso, materiais químicos perigosos e biológicos infectantes, além do comprometimento da saúde mental, pelo elevado nível de tensão nos ambientes intra e extra-hospitalares (Elias, Navarro, 2006; Felli, 2012).

Ademais, por ser a assistência de enfermagem um trabalho predominantemente feminino, a jornada se estende ao trabalho doméstico, aos cuidados dos filhos e, muitas vezes, a outros vínculos empregatícios e baixos salários (Elias, Navarro, 2006).

Essas condições expõem os trabalhadores de enfermagem à diversas cargas de trabalho, geradoras de diversos processos de desgaste, dos quais podem 
ocorrer incapacidades para o trabalho, com repercussões na qualidade de vida desses trabalhadores (Felli, Tronchin, 2010).

As cargas de trabalho são concebidas como os elementos do processo de trabalho que interatuam entre si e com o corpo do trabalhador, no momento de interação com o objeto, meios e instrumentos, formas de organização e divisão do trabalho, gerando processos de adaptação que se traduzem em desgastes. Estes, por sua vez, constituem a perda da capacidade corporal, física ou mental, potencial ou efetiva (Laurell, Noriega, 1989).

A exposição dos trabalhadores de enfermagem às cargas de trabalho, que foram classificadas por Silva (1996) como: biológicas, químicas, físicas, mecânicas, fisiológicas e psíquicas; são geradoras de diversos processos de desgaste. Os processos de desgaste que podem gerar incapacidades físicas e mentais estão, na maioria, relacionados aos distúrbios musculoesqueléticos, aos traumas por acidentes de trabalho, às doenças infecciosas e aos transtornos mentais e comportamentais (Mininel et al., 2013; Felli et al., 2015; Silva et al., 2016).

As doenças musculoesqueléticas têm sido apontadas como as principais redutoras da capacidade para o trabalho devido, tanto à sobrecarga física, quanto mental dos trabalhadores de enfermagem (Magnago et al., 2012). A alta frequência desses distúrbios, dentre os trabalhadores de enfermagem, constitui uma das principais causas de afastamento do trabalho (Felli et al., 2015).

Os transtornos mentais entre os trabalhadores de enfermagem vêm apresentando forte associação com o esgotamento no trabalho, levando estes trabalhadores ao afastamento e, até mesmo, ao abandono da profissão ao desenvolverem a síndrome de burnout (Baptista, Tito, Carvalho, 2015).

A prevalência de $52 \%$ de fadiga entre os trabalhadores de enfermagem e $35 \%$ de capacidade inadequada para o trabalho foi verificada por Silva et al. (2016). Com base nesses resultados, os autores recomendam a reorganização do processo de trabalho, bem como, a instituição de programas que privilegiem a alimentação balanceada; a prática de esporte e lazer, local adequado para descanso durante as pausas de trabalho; apoio emocional/psicológico aos trabalhadores; e a adequação ergonômica dos postos de trabalho.

O absenteísmo é definido como ausências ao trabalho que podem ser previstas ou imprevistas (Chiavenato, 2000). As previstas são caracterizadas pelas férias, folgas e feriados e as não previstas são exemplificadas pelas faltas justificas 
ou injustificadas, licenças médica ou aquelas amparadas por lei, como maternidade, gala, nojo e participação em eventos científicos (Gaidzinski, 1998).

Entretanto, considera-se que o absenteísmo por motivo de doença é decorrente dos processos de desgaste que comprometem a capacidade para trabalho e aumentam a fadiga dos trabalhadores de enfermagem. Também são geradores de conflito, o estresse e a desmotivação, sendo precursores, a médio e longo prazo, de outras formas de adoecimento deste grupo de trabalhadores (Silva et al., 2015).

Observa-se no cotidiano de trabalho que, muitas vezes, o trabalhador adoentado não tem apoio institucional e pessoal (chefias e colegas) para se afastar do trabalho, ou mesmo o próprio trabalhador opta por não se afastar, por causa do compromisso com o grupo e com os pacientes e, também, para evitar conflitos.

Esse fenômeno caracteriza o presenteísmo, situação que ocorre quando o trabalhador encontra-se no ambiente de trabalho, porém sem atingir a produtividade ideal por motivos de problemas de saúde física e/ ou mental (Hemp, 2004).

Diferentemente do absenteísmo, que é mais facilmente medido pelas ausências ao trabalho, o presenteísmo impacta em maior custo indireto às empresas, pela perda da produtividade e da qualidade dos serviços. No contexto da assistência à saúde, este fenômeno demanda estudo para sua mensuração, prevenção e controle, pois compromete os resultados na assistência, a segurança do paciente e, consequentemente, a acreditação da qualidade nas instituições de saúde (Umann, Guido, Grazziano, 2012).

Sendo assim, o presenteísmo limita a produtividade quantitativamente, pela redução do desempenho físico e mental e, qualitativamente, devido à dificuldade de concentração e possibilidade de erros (Silva et al., 2015).

Estudo realizado por Martinez e Ferreira (2011) entre enfermeiros portugueses demonstrou como maiores causas do presenteísmo, as lombalgias, infecções respiratórias, cefaleias e estresse. Evidenciam, assim, a relação entre as condições de saúde e o presenteísmo.

Na prática, percebe-se que o fenômeno do presenteísmo, ainda, não é reconhecido pelos gerentes de recursos humanos de enfermagem, sendo que os prejuízos para a qualidade da assistência são notórios e de difícil mensuração. Estudos que abordam o presenteísmo são recentes na área de enfermagem. Em 
uma revisão da literatura (Paschoalin, Griep, Lisboa, 2012) a respeito do presenteísmo em enfermagem, os autores revelam as consequências negativas, tanto para os trabalhadores e organizações, como para os usuários dos serviços de saúde.

O presenteísmo compromete a capacidade para 0 trabalho em trabalhadores de enfermagem, como apontam os estudos realizados por Silva (2011). Pesquisas sobre o presenteísmo na enfermagem estampam em seus resultados trabalhadores adoecidos em seus postos de trabalho, com níveis elevados de estresse e fadiga, com reduzido desempenho profissional e qualidade de vida comprometida (Flores-Sandi, 2006; Rojas, 2007; Letvak, Buck, 2008; Letvak, Ruhm, 2010; Umann, Guido, Grazziano, 2012).

A perda da capacidade para o trabalho é um forte indicador de presenteísmo, conforme aponta estudo com trabalhadores da indústria finlandesa (Vanni et al, 2012). No entanto, não se encontram estudos que relacionem a capacidade para o trabalho e o presenteísmo dentre trabalhadores de enfermagem, tanto no contexto internacional, como nacional, o que evidencia um vazio de conhecimento.

Assim, é importante e necessária a avaliação da capacidade para o trabalho de enfermagem e do presenteísmo para a elucidação desta problemática que impacta na saúde dos trabalhadores e na economia, comprometendo os indicadores de qualidade assistencial, gerencial e a acreditação hospitalar.

O estudo da relação entre os presenteísmo e a capacidade para o trabalho entre os trabalhadores de enfermagem hospitalares visa subsidiar propostas para o gerenciamento dos recursos humanos, que resulte em ações de vigilância e promoção da saúde no trabalho.

Portanto, considera-se como hipótese desse estudo, a existência de associação entre o presenteísmo e a capacidade inadequada para o trabalho e que essa problemática pode ser melhorada por meio de estratégias de gerenciamento de recursos humanos.

Assim, surge a motivação para desenvolver esse estudo, orientado pelos objetivos a seguir. 
2 OBJETIVOS 



\section{OBJETIVOS}

\section{$2.1 \quad$ GERAIS}

- Analisar a associação entre a capacidade para o trabalho e do presenteísmo entre os trabalhadores de enfermagem;

- Propor intervenções para a prevenção do presenteísmo e das incapacidades para o trabalho.

\subsection{ESPECÍFICOS}

- Verificar os índices de capacidade para o trabalho e de presenteísmo entre trabalhadores de enfermagem.

- Identificar, junto aos gerentes de enfermagem, estratégias para a prevenção do presenteísmo e de incapacidades para o trabalho.

- Construir propostas de intervenção para a melhoria da capacidade de trabalho e prevenção do presenteísmo dos trabalhadores de enfermagem 

3 FUNDAMENTAÇÃO TEÓRICA 



\section{FUNDAMENTAÇÃO TEÓRICA}

\subsection{A AVALIAÇÃO CAPACIDADE PARA O TRABALHO NA ÁREA DA ENFERMAGEM}

$\mathrm{Na}$ busca da prevenção de doenças, da consequente invalidez dos trabalhadores próximos da aposentadoria e, com foco na longevidade no trabalho, pesquisadores do Finish Occupational Health Institute $(\mathrm{FIOH})$ construíram base teórica para avaliação, promoção e manutenção da capacidade para o trabalho (Ilmarinen et al., 1991).

A capacidade para o trabalho é produto da relação dos recursos humanos com as características do trabalho, evidenciada pela capacidade física, cognitiva e social, bem como, o resultado do envolvimento com o trabalho, por meio de atitudes, motivação e interesse pelo trabalho. Os índices de capacidade para o trabalho são determinados pela avaliação das exigências das atividades, das condições do ambiente de trabalho e adaptação do trabalhador e suas condições de saúde, fatores sociodemográficos, estilo de vida e envelhecimento (Ilmarinen, Tuomi, 2004).

O instrumento utilizado para a avaliação da capacidade para o trabalho é o questionário "Índice de Capacidade para o Trabalho" (ICT), que tem por finalidade saber: "Quão bem está, ou estará, um(a) trabalhador(a), presentemente ou num futuro próximo, e quão capaz ele ou ela pode executar seu trabalho, em função das exigências, de seu estado de saúde e de sua capacidade física e mental" (Fischer, 2005; p.9).

Desenvolvido pelos pesquisadores finlandeses (Ilmarinen et al., 1991) e traduzido para o português (Fischer, 2005) e validado por Martinez, Latorre e Fischer (2009), o ICT pode ser usado para avaliar, promover e manter a capacidade de trabalho, bem como, acompanhar trabalhadores que precisam lidar com deficiência ou doença no trabalho. Ele também pode ser usado no aconselhamento para a reabilitação e tratamento dos mesmos (Tuomi, et al., 2005).

As pesquisas realizadas através do ICT, envelhecimento e qualidade de vida, desenvolvidas em diversos países, alertam para a necessidade de mecanismos de apoio à longevidade no trabalho, devido ao aumento significativo da 
expectativa de vida na população mundial, podendo levar à escassez da força de trabalho (llmarinen, 2005; Costa, 2008).

Ao investigarem saúde e capacidade para o trabalho em trabalhadores da área administrativa, Martinez e Latorre (2006) constataram que, quanto melhor o estado de saúde, melhor é a capacidade para o trabalho. Isso mostra a importância do monitoramento da saúde do trabalhador, para que se identifique precocemente alterações e se aplique as medidas corretivas individuais e coletivas. Esse monitoramento, também, torna possível a melhoria da organização e do ambiente psicossocial do trabalho, promovendo a saúde mental dos trabalhadores (Ilmarinen, 2008).

Pesquisando trabalhadores holandeses da construção civil acima de 40 anos, Alavinia et al (2009), verificaram que os trabalhadores com capacidades inadequadas para o trabalho (moderada e baixa) possuem maior fator preditivo para as aposentadorias por invalidez. $O$ estudo sugeriu medidas que facilitem equilíbrio entre desempenho no trabalho e saúde.

Em estudo com trabalhadores de enfermagem de 10 países europeus, pesquisadores encontraram maior perda da capacidade para 0 trabalho entre os trabalhadores acima de 45 anos e expressiva intenção em deixar a profissão, pelos mais jovens, por apresentarem tempo hábil para a mudança de área profissional (Camerino et al., 2006).

A gestão do lazer, qualidade e segurança no ambiente de trabalho foram fatores associados à capacidade para o trabalho em pesquisa realizada com trabalhadores de enfermagem hospitalar em Taiwan, sendo recomendado apoio para o cumprimento das exigências físicas e mentais do trabalho (Chiu et al., 2007).

Dentre os estressores ocupacionais identificados que apresentaram significância estatística com a baixa capacidade para o trabalho entre trabalhadores de enfermagem croatas foram citados: organização do trabalho e das questões financeiras, os riscos no local de trabalho, os conflitos interpessoais, o trabalho em turnos e as exigências profissionais e intelectuais. Esse estudou revelou também que os técnicos de enfermagem apresentam maior carga de estresse comparado aos enfermeiros, recomendando desenvolvimento educacional e investimentos na carreira desta categoria profissional (Golubic et al., 2009). 
O maior comprometimento da capacidade para o trabalho dos técnicos de enfermagem pode ser explicado pelas atribuições que demandam maior esforço físico e menor autonomia sobre o cuidado dos pacientes, em relação aos enfermeiros (Magnago et al., 2012). No Brasil, os técnicos e auxiliares de enfermagem, enquanto membros da equipe de enfermagem executam atividades de cuidado direto aos pacientes, enquanto os enfermeiros assumem, preponderantemente, o gerenciamento desse cuidado.

Índices inadequados de capacidade para o trabalho, superiores a 30\%, foram evidenciados entre os trabalhadores de enfermagem nos estudos de Silva et al. (2016), Vasconcelos et al. (2011) e Vegian (2010), tendo suas variáveis associadas às precárias condições de trabalho com escassez de trabalhadores, jornadas extensivas, trajetos longos e demorados, acidentes de trabalho, morbidades sem diagnóstico médico e altos níveis de fadiga.

Avaliando a capacidade para o trabalho e a sua relação com a morbidade entre os trabalhadores de enfermagem, Viero et al. (2011) referem que esses trabalhadores convivem com desconforto e dor no desempenho de suas atividades laborais, podendo acarretar-Ihes perda acentuada da capacidade para o trabalho. Os autores apontam que as morbidades mais observadas foram: as musculoesqueléticas (dores nas costas e pescoço), as de origem respiratória (infecções repetidas e sinusite), varizes, distúrbio emocional leve, colesterol alto e hipertensão arterial.

Estudos nacionais e internacionais sobre a capacidade para o trabalho dentre os trabalhadores de enfermagem mostram que estes encontram-se submetidos às condições de trabalho com exigências físicas e mentais desgastantes, o que conduz às capacidades inadequadas para o trabalho. Com isso, evidencia-se a necessidade de investimentos na saúde do trabalhador como parte do planejamento estratégico da gestão de pessoas em saúde (Camerino et al., 2006; Chiu et al., 2007; Golubic et al., 2009; Vasconcelos et al., 2012; Silva et al., 2016).

Ao pressupor que existe relação entre a capacidade para o trabalho e o presenteísmo torna-se importante contextualizá-lo. 


\subsection{O PRESENTEÍSMO EM TRABALHADORES DE ENFERMAGEM}

O termo presenteísmo surgiu na década de 50 , após o consenso da importância da participação do capital humano na competitividade das empresas, com vistas aos resultados de produtividade nas organizações (Isma, 2010). A sua abordagem ressurge fortemente, na década de 1990, por Cary Cooper, psicólogo especialista em administração organizacional da Universidade de Manchester. Esse ressurgimento foi devido à instabilidade no emprego e a necessidade da compreensão da permanência do trabalhador no trabalho, mesmo sem condições de saúde suficientes. Visto como chave para o negócio, o capital humano passa a ser de grande interesse para as empresas que vem incentivando investimentos em gestão integrada da saúde e produtividade, motivação e cultura corporativa (Clark, 1994).

O presenteísmo é conceituado como a presença do trabalhador em seu local de trabalho, sem atingir a produtividade ideal (Hemp, 2004). Os fatores causais do presenteísmo podem variar desde o pessimismo e desmotivação até o adoecimento de ordem física e/ou mental (Johns, 2010; Flores-Sandi, 2006).

Segundo Calzaretta (2007), também o fato de estar presente no trabalho, mas sem estar trabalhando adequadamente, foi denominado de presenteísmo e caracteriza um neologismo por significar o oposto ao absenteísmo. Ainda, é assegurado ser um fenômeno associado aos problemas de saúde e, mais abrangentemente, aos fatores biopsicossociais, com repercussões no clima organizacional, como desmotivação e insatisfação laboral, fadiga, burnout, mal estar subjetivo com apoio social negativo.

Nos estudos de administração em saúde o presenteísmo foi recentemente apontado como problema comprometedor da qualidade dos serviços de saúde pela ameaça causada à saúde dos trabalhadores, bem como, aumento dos riscos de eventos adversos e incidentes que reduzem a segurança do paciente durante os cuidados de saúde (Umann, Guido, Grazziano, 2012; Johns, 2010; Vineburgh, 2007).

Estudos realizados por Letvak e Ruhm (2010) apontam o presenteísmo como problema mais preocupante que o absenteísmo, pois como o trabalhador não está afastado, não pode ser substituído, impactando negativamente os resultados de toda equipe de trabalho. Os autores enfatizam que o reconhecimento da 
problemática do presenteísmo entre os gerentes de enfermagem é de suma importância para a revisão dos processos de trabalho e melhoria, tanto do ambiente físico de trabalho, como também do clima organizacional.

O tema presenteísmo é relativamente recente e, ainda, escasso na literatura, principalmente no que se refere aos trabalhadores de enfermagem, tanto no contexto nacional como internacional. Os achados de revisão de literatura (Paschoalin, Griep, Lisboa, 2012) alertam sobre as consequências do presenteísmo para a qualidade da assistência prestada à população exposta aos riscos de erros graves e até mesmo fatais, recomendando mais investigações, dada a relevância dessa problemática identificada entre os trabalhadores de enfermagem.

Estudo sueco com 3801 trabalhadores de diversas categorias profissionais apontou a área da educação e da saúde como as de maior risco para o presenteísmo. E, dentre os trabalhadores presenteístas, os sintomas de fadiga, depressão leve e dores nas costas e pescoço foram os mais relatados. O estudo também revelou associação entre o presenteísmo, absenteísmo doença e os baixos salários (Aronsson, Gustafsson, Dallner, 2000).

Em estudo americano sobre o presenteísmo na enfermagem, Pilette (2005) refere a sua alta prevalência na enfermagem, como problema econômico significativo, dado pela redução da produtividade. No estudo, a depressão foi destacada como a maior causa deste fenômeno, podendo ser percebida pelo aumento da irritabilidade com pacientes, familiares e colegas; fadiga, distração, atrasos, desmotivação e isolamento social no trabalho; bem como, execução lenta e/ou inacabada das tarefas, podendo ser seguida de erros e acidentes.

$\mathrm{Na}$ Costa Rica, os trabalhadores de enfermagem também foram enquadrados no grupo de risco para o presenteísmo, no qual foi observada a relação com a exposição às cargas psíquicas, durante extensas jornadas de trabalho, somadas ao compromisso da enfermagem em manter a assistência de enfermagem ininterrupta e com os melhores resultados. O estudo aponta também os riscos de erros graves que, muitas vezes, iniciam de forma latente, porém com consequências irreparáveis para pacientes, família e toda a sociedade (FloresSandi, 2006).

Para o início de um processo de mudança dessa realidade, os gestores devem reconhecer as dimensões de presenteísmo e investir na criação da cultura de 
segurança nas instituições de saúde e incentivar amudança de comportamento. Isto, para que também os trabalhadores se motivem a diminuir a exposição às cargas de trabalho, utilizando-se da padronização da assistência segura e dos equipamentos de proteção, disponíveis para facilitar os procedimentos (Flores-Sandi, 2006).

O presenteísmo é de difícil mensuração e ocorre no dia-dia das atividades de trabalho, podendo ser administrado nas relações de trabalho, pela aproximação dos lideres junto as suas equipes. Para tanto, é importante a participação dos trabalhadores na construção de estratégias de intervenção, sendo os trabalhadores ouvidos em rodas de conversas e conversas individuais (Middaught, 2007).

A vontade dos trabalhadores de enfermagem em continuar atuando na profissão e as características individuais do trabalho influenciam a produtividade demonstrando crescente preocupação entre os gestores de recursos humanos (Rojas, 2007; Letvak, Buck, 2008),

Estudo americano realizado por Letvak e Rhum (2010) refere que os problemas crônicos de saúde, também, são responsáveis pelo presenteísmo e apontam a problemática como desafio para a gestão de pessoas. Haja vista, que o presenteísmo representa maior risco de eventos adversos, quando comparado ao absenteísmo, pois o trabalhador não sendo substituído e com problemas de saúde apresenta sua capacidade laborativa reduzida.

Considerando a revisão da literatura a respeito do presenteísmo na enfermagem, depara-se com uma força de trabalho que se esforça para manter sua capacidade laborativa mesmo adoecida, com forte exposição às cargas de trabalho geradoras de processos de desgastes, ameaçando a produtividade e proporcionando riscos de eventos adversos aos usuários dos serviços de saúde.

Quanto à avaliação do presenteísmo, muitos aspectos de mensuração merecem atenção especial, principalmente no que diz respeito às medidas para quantificar resultados econômicos (Brooks et al., 2010), mediante produtos parcialmente realizados e com risco de retrabalho, o que evidentemente aumenta os custos assistenciais (Letvak, Rhum, 2010).

Outro aspecto a considerar é que a baixa produtividade caracterizada pelo presenteísmo pode também, impactar na reduzida capacidade para o trabalho e conduzir o trabalhador ao absenteísmo (Johns, 2010).

Dentre os instrumentos utilizados para a avaliação do presenteísmo, destaca-se o Health and Work Questionnarie (HWQ), o Work Productivity and 
Activity Impairment Questionnarie (WPAIQ) e o Stanford Presenteeism Scale (SPS$6)$.

O Health and Work Questionnarie é um instrumento desenvolvido para avaliar a produtividade no local de trabalho em relação à saúde do trabalhador e não tem domínio público, possui 24 questões e seu período recordatório é de uma semana (Shikiar et al, 2004).

De domínio público, traduzido para o português e validado no Brasil (Ciconelli et al, 2006), o Work Productivity and Activity Impairment Questionnarie investiga o quanto os problemas de saúde afetaram a produtividade, enquanto estava trabalhando e quanto esses problemas afetaram as atividades diárias realizadas pelo trabalhador ao longo dos últimos sete dias (Reilly, Zbrozek, Dukes, 1993).

No Stanford Presenteeism Scale (SPS-6) a perda de produtividade, relacionada às condições de saúde, é referida pelo próprio trabalhador, quando são questionadas as influências de seu estado de saúde em suas atividades de trabalho. Desenvolvido por pesquisadores da Stanford School of Medicine, avalia os aspectos cognitivos, emocionais e comportamentais da saúde e seus efeitos no trabalho (Koopman et al., 2002).

Dentre os instrumentos utilizados para avaliar o presenteísmo, o SPS-6 foi traduzido e validado no Brasil por Paschoalin (2012) e vem sendo mais comumente utilizado em pesquisas internacionais, por possuir excelentes propriedades psicométricas na avaliação das relações de saúde e produtividade. Por esse motivo foi selecionado para captar o presenteísmo dos trabalhadores de enfermagem deste estudo. 


\subsection{A PERSPECTIVA DO GERENCIAMENTO EM ENFERMAGEM NA BUSCA DE MELHOR CAPACIDADE PARA O TRABALHO E PREVENÇÃO DO PRESENTEÍSMO}

O gerenciamento dos trabalhadores de enfermagem é imprescindível para a prevenção do presenteísmo e da incapacidade para o trabalho.

$O$ processo de gerenciamento em enfermagem tem por finalidade a da organização do trabalho e dos recursos humanos e, para tanto, o planejamento, dimensionamento e seleção de pessoal, educação permanente e avaliação de desempenho são instrumentos desse processo; além dos recursos físicos e ambientais do local de trabalho (Felli, Peduzzi, 2010).

A prática social desenvolvida pela enfermagem no atendimento às necessidades de saúde, demandas pelo processo saúde-doença, constitui-se na transformação dos sujeitos envolvidos (clientes e profissionais) por meios e instrumentos numa atividade que se organiza de forma específica. Portanto, atua na perspectiva tanto da promoção como na recuperação da saúde, proporcionando a emancipação dos sujeitos (Felli, Peduzzi, 2010).

A dinâmica do trabalho da enfermagem envolve relação de interação social intensa à medida que lida com vida e morte, sofrimento e prazer. As ações são sempre conjuntas e, multiprofissional necessitando de organização por meio do trabalho em equipe com saberes específicos e hierarquizados (Felli, Peduzzi, 2010).

Felli (2002) sugere estratégias para o gerenciamento da saúde do trabalhador, apontando a necessidade de implantação de ações de intervenção, com vistas à melhoria da qualidade de vida no trabalho. Para tanto, a autora sugere a reorganização do processo de trabalho em enfermagem, com base nas dimensões gerenciais técnica, política, administrativa e de desenvolvimento da cidadania. Sugere a discussão da relação saúde-trabalho em todas as oportunidades, de ensino e de serviço, desde a formação profissional à educação permanente nos serviços. Aponta, ainda, estratégias inovadoras direcionadas para investimentos nas relações interpessoais e que incentivem os trabalhadores a cuidar da sua saúde através de hábitos de vida saudáveis, ao mesmo tempo em que são também assistidos pela instituição. 
Também, segundo Rocha e Felli (2004), em estudo da saúdo do trabalhador de enfermagem sob a ótica da gerência, além da reorganização do processo de trabalho, se faz necessário maior investimento em educação permanente para avançar o conhecimento gerencial sobre os aspectos conceituais e instrumentais em saúde do trabalhador, que ainda é restrito e limita-se à avaliação das condições de saúde. Estudos realizados com trabalhadores de enfermagem europeus sugerem aos gerentes de enfermagem investimentos estratégicos para promoção da capacidade para o trabalho. Esta deve ser combinada com a melhoria das relações interpessoais, com foco na prevenção da rotatividade e abandono da profissão, situação comumente encontrada no continente Europeu (Camerino et al., 2006; Rongen et al., 2013).

Os gerentes de enfermagem reconhecem a necessidade de intervenção para a melhoria da saúde do trabalhador de enfermagem, pela sobrecarga de trabalho, pouca autonomia na tomada de decisão e a inexistência de política institucional para a promoção da qualidade de vida no trabalho (Mininel, Felli 2007).

Segundo Baptista et al. (2015), o absenteísmo e o presenteísmo, decorrentes do adoecimento e das incapacidades para o trabalho, são motivos de grande preocupação para os gerentes de enfermagem, dada às repercussões que podem causar à qualidade e segurança dos pacientes. Para Balsanelli e Jericó (2005) a participação democrática dos trabalhadores para a gestão de qualidade total é motivo de satisfação e incentivo para a melhoria da produtividade e redução do absenteísmo.

Agregar valores e aprimorar o conhecimento subsidia a criação de potencial de emancipação dos sujeitos e garantem relações mais saudáveis nas relações interpessoais. Essas ações conduzem a gestão para os paradigmas das políticas de gestão educativa, podendo alcançar os trabalhadores com postura de agentes de mudanças e de transformação das condições de trabalho (Rocha, Felli, 2004; Balsanelli, Jericó, 2005).

Assim, reconhecida a relevância do gerenciamento de recursos humanos para transformar a realidade da saúde dos trabalhadores de enfermagem, evidenciase a necessidade dos gerentes serem sujeitos ativos na proposição de estratégias intervenção, para a promoção da qualidade de vida desses trabalhadores. 




\section{MÉTODO}

\subsection{TIPO DE ESTUDO}

Trata-se de um estudo epidemiológico de recorte transversal, com abordagem quanti-qualitativa dos dados.

\subsection{LOCAL DO ESTUDO}

O estudo foi desenvolvido no Hospital Universitário da Universidade de São Paulo (HU-USP), situado na zona oeste do município de São Paulo, do estado de São Paulo.

O HU-USP é unidade complementar da Universidade de São Paulo (USP), integrante do Sistema Único de Saúde (SUS), inserido na Coordenadoria Regional de Saúde Centro-Oeste. Tem como objetivos o ensino, a pesquisa e a assistência à saúde de média complexidade, multidisciplinar e integral, à população da área de abrangência, bem como os funcionários da USP e seus dependentes (Gaidzinski et al., 2008).

Localizado no campus da USP Capital, região oeste da cidade de São Paulo, o HU-USP conta atualmente com 178 leitos, distribuídos nas áreas de especialidades Médica, Cirúrgica, Obstetrícia e Ginecologia, Pediatria e Ortopedia. É campo de Ensino e Pesquisa de seis unidades de ensino da USP: Faculdade de Medicina, Faculdade de Saúde Pública, Escola de Enfermagem, Faculdade de Ciências Farmacêuticas, Faculdade de Odontologia e Instituto de Psicologia (Universidade de São Paulo, 2015).

O Departamento de Enfermagem reporta-se diretamente à Superintendência do HU-USP e tem como finalidade a coordenação, supervisão e controle das ações executadas pela enfermagem (Gaidzinski et al., 2008) 


\subsection{POPULAÇÃO}

A população estudada foi composta por todos os trabalhadores da assistência de enfermagem (enfermeiros, técnicos e auxiliares). $\mathrm{Na}$ ocasião o quadro total de pessoal de enfermagem era de 668 trabalhadores o departamento de enfermagem contava com um Chefe do Departamento de Enfermagem, cinco Chefes de Divisão de Enfermagem, 14 Chefes de Seção Enfermagem, um Chefe de Serviço de Educação e Qualidade, três Enfermeiros do Serviço de Educação e Qualidade, um Enfermeiro de Gestão de Materiais, 174 Enfermeiros Assistenciais, 372 Técnicos de Enfermagem, 94 Auxiliares de Enfermagem. Ainda, desse quadro também compunham três Enfermeiros alocados no Departamento Administrativo, sendo: um Chefe de Divisão de Gestão de Pessoas, um Chefe de Serviço de Higienização Especializada, um Enfermeiro da Comissão de Infecção Hospitalar.

Os critérios de inclusão dos sujeitos no estudo foram:

- Trabalhadores com pelo menos seis meses de trabalho na instituição e que não tenham se afastado nos últimos trinta dias que antecederam a coleta de dados;

- Estar trabalhando na assistência direta aos pacientes no momento da coleta de dados, nos três turnos de trabalho (manhã, tarde e noite);

- Ser enfermeiro-chefe de seção das unidades assistenciais $(n=13)$, pois estes foram convidados a participar da parte qualitativa do estudo no de grupo focal.

Os critérios de exclusão dos sujeitos no estudo foram:

- Enfermeiros lotados nas áreas administrativas.

- Os Enfermeiros, técnicos e auxiliares de enfermagem que trabalham na central de material e esterilização e os alocados junto ao gerenciamento de materiais nas unidades assistenciais.

- Os atendentes de enfermagem por não prestarem assistência direta aos pacientes.

- O pesquisador por fazer parte da equipe de enfermagem 


\subsection{COLETA DE DADOS}

\subsubsection{Instrumentos para coleta de dados}

Foram utilizados três instrumentos para a coleta de dados.

O primeiro instrumento foi um formulário elaborado pelo próprio pesquisador (Apêndice A) contendo dados sociodemográficos e profissionais para caracterizar a população de estudo.

O segundo instrumento foi o questionário Índice de Capacidade para o Trabalho (ICT), de autoria de Ilmarinen et al (1991) com a validade e confiabilidade da versão brasileira verificada por Martinez, Latorre e Fischer (2009), no qual foram encontradas propriedades psicométricas satisfatórias quanto à validade de construto, de critério e confiabilidade (Anexo 1).

O ICT apresenta 10 questões ponderadas em sete itens com escore numérico: capacidade para o trabalho atual e comparado com a melhor da vida, com escore de zero a 10 pontos; Capacidade para o trabalho em relação às exigências do trabalho, fornecidas por duas questões com número de pontos ponderados de natureza do trabalho que fornecem escore de seis a 10 pontos, sendo contadas apenas doenças diagnosticadas por médico; número de doenças autorreferidas e diagnosticas por médico com uma questão contendo lista de 51 doenças, sendo consideradas apenas as doenças diagnosticadas por médico na contagem dos pontos que variam de um ponto (cinco ou mais doenças) e sete pontos (nenhuma doença); perda estimada para o trabalho devido a doenças, com uma questão valendo de um a seis pontos marcados no questionário; faltas ao trabalho por doenças nos últimos 12 meses, com uma questão, com escore variando de um a cinco pontos; prognóstico próprio sobre a capacidade para o trabalho daqui a dois anos, com uma questão e pontuação de um, quatro ou sete pontos; recursos mentais, obtidos por três questões ponderadas e que somados apresentam escore de um a quatro pontos.

O ICT foi calculado pela soma dos pontos ponderados obtidos para cada um dos sete itens. Os resultados variam em escore de sete a 49 pontos e classificado em quatro categorias de capacidade para o trabalho com as seguintes medidas propostas para trabalhadores maiores de 35 anos: 
- $\quad$ Baixa (de 7 a 27 pontos) - restaurar a capacidade para o trabalho.

- Moderada (28 a 36 pontos) - melhorar a capacidade para o trabalho.

- $\quad$ Boa (de 37 a 43 pontos) - apoiar a capacidade para o trabalho.

- $\quad$ Ótima (de 44 a 49 pontos) - manter a capacidade para o trabalho.

É sugerida a pontuação diferenciada para trabalhadores menores de 35 anos: Baixa: de 7 a 36 pontos; Moderada: 37 a 40 pontos; Boa: 41 a 44 pontos e Ótima: 45 a 49 pontos (Kujala et al., 2005).

O terceiro instrumento foi o Stanford Presenteeism Scale (SPS-6) construído por Koopman e col em 2002 (Anexo 2), que foi validado no Brasil por Paschoalin et al (2013). Este instrumento tem a função de identificar e classificar o presenteísmo.

Foi recomendado ao sujeito da pesquisa para responder a este questionário somente se ele esteve no trabalho com algum problema de saúde nos últimos trinta dias:

O SPS-6 é um instrumento que compõe seis itens mensurados através de uma escala likert com resposta: 1 - discordo totalmente, 2 - discordo parcialmente, 3 - não concordo nem discordo, 4 - concordo parcialmente, 5 - concordo totalmente.

O score total da SPS-6 é calculado pela soma dos itens respondidos com a pontuação conforme segue:

Quadro1 - Valor dos pontos dos itens da SPS - 6

\begin{tabular}{lcc}
\hline Opções de respostas & Itens $\mathbf{1 , 3}$ e $\mathbf{4}$ & Itens 2,5 e $\mathbf{6}$ \\
\hline Discordo totalmente & 5 & 1 \\
Discordo parcialmente & 4 & 2 \\
Não concordo nem discordo & 3 & 3 \\
Concordo parcialmente & 2 & 4 \\
Concordo totalmente & 1 & 5 \\
\hline Fone: Jointly owned by Merck \& Co., Stanford University School of Medicine
\end{tabular}
Jointly owned by Merck \& Co., Stanford University School of Medicine 
Por meio da soma dos pontos que variaram de seis a 30 foi encontrada a pontuação total do SPS-6. Fundamentados em Koopman et al (2002), a pontuação que variou entre seis e 18 pontos indicou score baixo e determinou a redução de desempenho e a pontuação mais próxima de 30 representou o trabalhador com melhor desempenho, embora apresentasse algum problema de saúde. Entendeu-se então, que os trabalhadores com menor pontuação na SPS-6 foram os mais afetados pelo presenteísmo (Martinez, Ferreira, 2011). A escala contempla duas dimensões do presenteísmo: trabalho finalizado por meio dos itens 2, 5 e 6, relativos aos sintomas físicos e concentração mantida, que está associada aos aspectos psicológicos do trabalho (Martinez, 2007).

\subsubsection{Procedimentos de coleta de dados}

A coleta de dados se iniciou após aprovação do projeto submetido ao Comitê de Ética em Pesquisa da Escola de Enfermagem da Universidade de São Paulo e autorização pelo Comitê de Ética em Pesquisa do HU-USP.

Uma lista de todos os trabalhadores de enfermagem do HU-USP foi fornecida pelo Serviço de Ensino e Qualidade e as escalas dos turnos de trabalho foram fornecidas pelos Enfermeiros-chefe de cada seção.

A coleta de dados quantitativos foi realizada entre fevereiro e junho de 2015 e, três reuniões de grupo focal entre outubro e novembro de 2015 e a última em junho de 2016, iniciando-se após aprovação e autorização pelos respectivos Comitês de Ética em Pesquisa e, por meio do agendamento de coleta, após reunião com os Enfermeiros-chefe das unidades para estabelecer um cronograma.

O contato com os trabalhadores foi feito no próprio local e turno de trabalho, quando o projeto foi apresentado e feito o convite para participação no estudo. Os participantes foram informados que a coleta teria duas fases: a primeira, com os trabalhadores de enfermagem das unidades assistenciais e, a segunda, com os gerentes de enfermagem (enfermeiros-chefe) por meio de reunião de grupo focal.

Após a leitura e assinatura do Termo de Consentimento Livre e Esclarecido pelos sujeitos que concordaram em participar do estudo, os instrumentos foram numerados, Após essa etapa foram entregues aos trabalhadores e recolhidos pelo pesquisador ao final do plantão quando também foram esclarecidas possíveis dúvidas. 
Após a coleta de dados e de posse da análise estatística, os enfermeiroschefe das 13 unidades assistenciais foram convidados para compor grupo focal, uma vez que são sujeitos com' governabilidade para implantar as propostas de intervenção construídas no grupo mediante a problemática exposta. $\mathrm{Na}$ impossibilidade de algum enfermeiro-chefe comparecer às reuniões, os respectivos enfermeiros substitutos de chefia também foram convidados para a composição do grupo.

O local, data, horário e regras para a participação dos encontros foram inicialmente estabelecidos de maneira que propiciasse melhor conforto e facilidade para a participação de maior número de enfermeiros-chefe possível. As reuniões ocorreram nos dias 27 de outubro, 03 e 10 de novembro de 2015 e em 07 de junho de 2016.

O grupo focal foi constituído de 10 participantes, dos 13 enfermeiroschefe convidados.

O pesquisador, após capacitação e com roteiro preparado, assumiu o papel de coordenador do grupo e convidou duas pesquisadoras com experiência na estratégia de pesquisa, sendo uma para assumir o papel de observadora, que fez os registros das ações de comunicação do grupo, inclusive os aspectos não verbais; e outra para realizar os registros de gravação das falas e as filmagens em vídeo da dinâmica do grupo, que foi filmada e, após, transcritas e codificadas numericamente para garantir o sigilo dos participantes (Minayo, 2014).

O coordenador considerou a manutenção de um ambiente favorável às expressões de todas as opiniões dos participantes em local confortável e livre de ruídos para não prejudicar os registros das falas dos sujeitos, assim como garantiu a boa interação entre todos os participantes (Chiesa, Ciampone; 1999).

Foram realizadas quatro reuniões: no primeiro encontro foi realizada a apresentação do projeto de pesquisa, do Termo de Consentimento Livre e Esclarecido para a leitura e, após a sua assinatura. Após, iniciou-se a apresentação dos resultados da análise descritiva de caracterização da população de estudo e da análise estatística dos dados de associação da capacidade de trabalho ao presenteísmo. 
Assim, foi sugerido aos participantes que fizessem uma reflexão a respeito daqueles resultados com foco aos setores de trabalho sob suas gerências.

De posse dos resultados foi iniciada a discussão por meio da questão norteadora: Que intervenções são indicadas para a melhoria da capacidade para o trabalho e da prevenção do presenteísmo entre os trabalhadores de enfermagem?

Após o intervalo de uma semana, iniciou-se o segundo encontro com a síntese dos resultados. Após, foi iniciado os debate sobre a problemática, de acordo com a realidade de cada cenário estudado e lançado o desafio para a elaboração de propostas de intervenção, oriundas do próprio grupo na perspectiva de compreensão e transformação da realidade.

No terceiro encontro foi dada continuidade à construção das propostas de intervenção e, mediante o consenso dos participantes, foram construídas segundo os planos: individual, gerencial e institucional. Ao final desta reunião foram expostos os relatórios de observação das três reuniões, sendo também disponibilizadas as imagens gravadas para que os participantes que tivessem interesse em conferi-las. E, para quaisquer dúvidas e esclarecimentos posteriores, os contatos dos pesquisadores participantes do grupo foram disponibilizados.

O quarto encontro foi realizado com o propósito de validar as propostas final de intervenção com os gerentes, subsidiadas pela construção no grupo focal e pela literatura científica.

\subsection{PROCEDIMENTOS DE ANÁLISE DOS DADOS QUANTITATIVOS}

Para a análise dos dados foram consideradas as seguintes variáveis quantitativas, relativas às características sociodemográficas e ocupacionais foram categorizadas para posterior análise estatística.

\section{Características Sociodemográficas}

Sexo: variável categorizada em feminino ou masculino. 
Idade: variável quantitativa contínua, em anos. Foi categorizada em faixas etárias de acordo com os tercis da distribuição de frequências: < 35,0 anos ( $1^{\circ}$ tercil); $\geq 35,0$ e $<45,0$ anos $\left(2^{\circ}\right.$ tercil); $\geq 45,0$ anos ( $3^{\circ}$ tercil).

Estado conjugal: variável qualitativa categorizada em: solteiro(a), casado(a), vive com companheiro(a), separado(a)/divorciado(a), viúvo(a).

Escolaridade: variável qualitativa categorizada em: Ensino Fundamental, Ensino Médio, Ensino Superior.

Renda familiar líquida: variável qualitativa categorizada em salários mínimos: $\geq 2 \mathrm{e}$ $<4$ salários mínimos; $\geq 4$ e $<6$ salários mínimos; $\geq 6$ e $<8$ salários mínimos e $\geq 8$ salários mínimos.

\section{Características ocupacionais}

Tempo de trabalho na instituição: variável quantitativa contínua, em anos, referente ao tempo de vínculo empregatício com a instituição. Foi categorizada em faixas de acordo com os tercis da distribuição de frequências: $\leq 9$ anos ( $1^{\circ}$ tercil); 10 a 18 anos ( $2^{\circ}$ tercil); $\geq 19$ anos ( $3^{\circ}$ tercil).

Tempo de trabalho na profissão: variável quantitativa contínua, em anos, referente ao tempo de atuação na Enfermagem. Foi categorizada em faixas de acordo com os tercis da distribuição de frequências: $\leq 12$ anos ( $1^{\circ}$ tercil); 13 a 19 anos $\left(2^{\circ}\right.$ tercil); $\geq$ 20 anos (3ำ tercil).

Função: variável qualitativa representando a categoria ocupacional no quadro de Enfermagem da instituição: Enfermeiro, Técnico de Enfermagem, Auxiliar de Enfermagem.

Total de horas trabalhadas na semana: variável quantitativa contínua, em horas, referente ao total de horas da jornada semanal. Foi categorizada em 36,0 horas (jornada de trabalho esperada de acordo com o contrato de trabalho) e $>36,0$ horas. 
Turno de trabalho: variável qualitativa categorizada em manhã, tarde e noite, sendo os turnos da manhã e tarde de 6 h diárias e o noturno em regime 12/36 horas; para cada 12 horas trabalhadas, 36 horas de descanso.

Número de vínculos empregatícios: variável quantitativa ordinal variando de 1 a 4 vínculos empregatícios.

Tempo de trajeto (ida e volta) para o trabalho: variável quantitativa contínua, em horas, referente ao tempo gasto no trajeto de ida e volta ao trabalho. Foi categorizada em faixas de acordo com os tercis da distribuição de frequências: $<1,0$ hora ( $1^{\circ}$ tercil); $\geq 1,0$ e $<2,0$ horas $\left(2^{\circ}\right.$ tercil); $\geq 2,0$ horas $\left(3^{\circ}\right.$ tercil).

Divisão de enfermagem: variável categórica representando a estrutura organizacional do serviço de enfermagem da instituição em termos de grandes blocos: Enfermagem Clínica (Unidade de Terapia Intensiva Adulto e Clínica Médica), Enfermagem Cirúrgica (Clínica Cirúrgica e Centro Cirúrgico), Pacientes Externos (Pronto Socorro Adulto, Ambulatório e Imagenologia), Enfermagem Pediátrica (Unidade de Terapia Intensiva Pediátrica, Pediatria, Pronto Socorro Infantil), Enfermagem Obstétrica e Ginecológica (Alojamento Conjunto, Centro Obstétrico e Berçário).

Setor de trabalho: variável categórica representando a estrutura organizacional do serviço de enfermagem da instituição em termos das unidades setoriais de trabalho: Alojamento Conjunto, Ambulatório, Berçário, Centro Cirúrgico, Centro Obstétrico, Clínica Cirúrgica, Clínica Médica, Imagenologia, Pediatria, Pronto Socorro Adulto, Pronto Socorro Infantil, Unidade de Terapia Intensiva Adulto, Unidade de Terapia Intensiva Pediátrica.

\section{Presenteísmo:}

Escore da Escala de Presenteísmo de Stanford - SPS-6: quando o sujeito nega manter-se trabalhando com algum problema de saúde nos últimos trinta dias a escala não é preenchida e, portanto, não há pontuação. Nos demais casos, quando a escala é preenchida, ela fornece um escore variando de 6,0 a 30,0 pontos, onde quanto maior a pontuação, mais alto o presenteísmo (melhor o desempenho). 
A escala é composta a partir de 06 questões que podem ser agrupadas em duas dimensões (Dimensão física - trabalho finalizado e Dimensão psicológica concentração mantida), variando de 3,0 a 15,0 pontos, onde quanto maior a pontuação, melhor o desempenho.

De acordo com as premissas de PASCHOALIN et al. (2013), o escore da SPS-6 foi categorizado em Alto presenteísmo - melhor desempenho ( $\geq 19,0$ pontos) e Baixo presenteísmo - redução do desempenho (6,0 a 18,0 pontos). Os sujeitos que não pontuaram a escala foram categorizados como Sem problemas de saúde.

\section{Capacidade para o trabalho:}

Escore do Índice de Capacidade para o Trabalho - ICT, variando de 7 a 49 pontos, onde quanto maior a pontuação, maior a capacidade para o trabalho.

A variável foi categorizada em ótima, boa, moderada e baixa. Para os trabalhadores com idade a partir de 35 anos foi utilizado o critério do Finnish Institute of Occupational Health - FIOH (TUOMI et al. 2005): Ótima (44,0 a 49,0 pontos); Boa (37,0 a 43,9 pontos); Moderada (28,0 a 36,9 pontos) e Baixa (7,0 a 27,9 pontos). Para os trabalhadores com idade inferior a 35 anos foi utilizado o critério do KUJALA et al (2005): Ótima (45,0 a 49,0 pontos); Boa (41,0 a 44,9 pontos); Moderada (37,0 a 40,9 pontos) e Baixa (7,0 a 36,9 pontos).

Posteriormente a variável foi dicotomizada em Adequada (ótima/ boa) e Inadequada (moderada/ baixa), adotando a classificação utilizada em outros estudos (Bethge et al., 2012; Vasconcelos et al., 2012; Martinez et al., 2015).

\section{Análise estatística:}

Foi utilizada planilha do Microsoft Excel para realização de dupla digitação e verificação da consistência dos dados. Em seguida os dados foram exportados para o programa Software Statistical Package for Social Sciences (SPSS) versão 22.0 para realização das análises estatísticas.

Para a análise de perdas foi feita a comparação entre a população participante no estudo e as perdas segundo sexo, idade, tempo de trabalho na instituição, Divisão e Setor de Trabalho. Foi utilizando o teste de associação pelo Qui-Quadrado para as variáveis categóricas. Para as variáveis quantitativas, após realização do teste de homogeneidade das variâncias de Levene $(p>0,05)$, foi aplicado o teste ANOVA. A análise da confiabilidade dos questionários utilizados foi 
avaliada utilizando o coeficiente alpha de Cronbach. A análise descritiva da população de estudo foi realizada por meio das médias, desvios-padrão, medianas, valores mínimos e máximos dos escores das variáveis quantitativas e proporções para as variáveis qualitativas.

A análise das associações entre capacidade para 0 trabalho e presenteísmo, como o escore do ICT e da SPS-6 não apresentou aderência à distribuição normal ( $p<0,05$ no teste de Kolmogorov-Smirnov), então optou-se por não utilizar testes paramétricos nesta etapa. Foi usado o teste Qui quadrado para a análise bivariada dos fatores associados à capacidade para trabalho.

As variáveis que apresentaram $\mathrm{p}<0,20$ foram incluídas na modelagem múltipla, por meio de análise de regressão logística binária pelo método stepwise forward. Inicialmente, foi verificada a associação entre capacidade para o trabalho e presenteísmo (desempenho no trabalho) e, em seguida, foram incluídas as demais variáveis, sendo que o valor do "p" na análise bivariada determinou a ordem de entrada na modelagem múltipla.

As variáveis qualitativas foram transformadas em variáveis indicadoras (Dummy). E, as variáveis independentes permaneceram no modelo múltiplo se $\mathrm{p}<0,05$ e/ou se fosse variável de ajuste. Foi utilizado o odds ratio (OR) como estimador do risco, com intervalo de $95 \%$ de confiança. Em todas as análises as associações foram consideradas significativas quando $p<0,05$.

\subsection{PROCEDIMENTOS DE ANÁLISE DOS DADOS QUALITATIVOS}

Os vídeos obtidos nas reuniões foram salvos e arquivados sigilosamente pelo pesquisador que os assistiu para compreensão do cenário e percepção comportamental, atitudinal e sentimentos expressos, que pudessem contribuir para a análise de compressão e interpretação dos dados.

Sequencialmente, o pesquisador realizou a transcrição das falas gravadas separando-as numericamente por participante do grupo. Procedeu, então, à análise temática segundo Minayo (2014) buscando núcleos de sentidos que definissem o caráter do discurso. 
A etapa pré-analítica dos resultados deu-se pela retomada das hipóteses e dos objetivos do estudo para a melhor compreensão do material. Então, realizouse a leitura flutuante e da apreciação das gravações em áudios e vídeos resultando em intenso envolvimento com o material para a organização inicial unidades de registro.

Essas unidades de registros foram apresentadas por recortes das falas de cada gerente, codificadas pela letra $G$ e numeradas sequencialmente para garantia do sigilo dos participantes. A seguir, foram sendo agrupadas pela frequência e representativa, suficientes para formar temas e categorias pertinentes para responder os objetivos do trabalho conforme a etapa de exploração do material analisado.

Contudo, procedeu-se a elaboração das categorias, dada pela redução do texto e organização das unidades de registros, seguindo a proposta de agrupá-las nas três dimensões: Individual, Gerencial e Institucional, a fim de se pensar as ações interventivas, direcionando-as de acordo com as respectivas governabilidades e com o objetivo futuro de viabilizar a sua execução.

E, após serem construídas as três categorias empíricas formulou-se, também, os respectivos temas: "Sensibilização para adesão às medidas de proteção", Gestão e liderança para cultura de segurança no trabalho" e "Os recursos disponíveis na universidade como estratégia de mudança".

Após a exploração do material, iniciou-se a etapa de interpretação com as inferências do pesquisador e à luz dos estudos científicos sobre a temática. 
5 RESULTADOS 



\section{$5 \quad$ RESULTADOS}

\subsection{ANÁLISE DAS PERDAS}

A população alvo foi composta pelos 668 trabalhadores do Departamento de Enfermagem do Hospital de estudo. Destes, 152 (22,8\%) estiveram enquadrados nos critérios de exclusão: estar afastado por licença médica (10 pessoas) ou em licença maternidade (11 pessoas), não pertencer ao quadro assistencial (72 pessoas), desligados no Programa de Demissão Voluntária - PDV durante o período da coleta de dados antes de preencherem o questionário (58 pessoas), e ser o pesquisador, que também compõe o quadro de trabalhadores (1 pessoa).

Restaram 516 pessoas elegíveis, das quais 379 (73,4\%) participaram do estudo. Os demais 137 recusaram participar do estudo, determinando uma taxa de perdas de $26,6 \%$. Os resultados da análise das perdas estão apresentados nas Tabelas 1 e 2 .

Tabela 1 - Análise comparativa entre perdas e participantes, segundo características demográficas e ocupacionais dos trabalhadores de Enfermagem, São Paulo, 2015.

(continua)

\begin{tabular}{|c|c|c|c|c|c|c|}
\hline \multirow{2}{*}{ Variável } & \multicolumn{2}{|c|}{ Participação } & \multicolumn{2}{|c|}{ Perdas } & \multirow{2}{*}{$\begin{array}{c}\text { Total } \\
\text { no }\end{array}$} & \multirow[t]{2}{*}{$p^{*}$} \\
\hline & no & $\%$ & no & $\%$ & & \\
\hline \multicolumn{7}{|l|}{ Sexo } \\
\hline Feminino & 331 & 73,1 & 122 & 26,9 & 453 & 0,599 \\
\hline Masculino & 48 & 76,2 & 15 & 23,8 & 63 & \\
\hline \multicolumn{7}{|l|}{ Função } \\
\hline Enfermeiro & 140 & 90,3 & 15 & 9,7 & 155 & $<0,001$ \\
\hline Técnico de Enfermagem & 204 & 67,5 & 98 & 32,5 & 302 & \\
\hline Auxiliar de Enfermagem & 35 & 59,3 & 24 & 40,7 & 59 & \\
\hline \multicolumn{7}{|c|}{ Divisão de Enfermagem } \\
\hline Enfermagem Clínica & 92 & 81,4 & 21 & 18,6 & 113 & 0,015 \\
\hline Enfermagem Cirúrgica & 70 & 79,5 & 18 & 20,5 & 88 & \\
\hline Pacientes Externos & 80 & 72,7 & 30 & 27,3 & 110 & \\
\hline Enfermagem Pediátrica & 68 & 62,4 & 41 & 37,6 & 109 & \\
\hline
\end{tabular}


(continuação)

\begin{tabular}{|c|c|c|c|c|c|c|}
\hline \multirow{2}{*}{ Variável } & \multicolumn{2}{|c|}{ Participação } & \multicolumn{2}{|c|}{ Perdas } & \multirow{2}{*}{$\begin{array}{c}\text { Total } \\
\text { no }\end{array}$} & \multirow[t]{2}{*}{$p^{*}$} \\
\hline & $\mathrm{n}^{\circ}$ & $\%$ & $\mathrm{n}^{\circ}$ & $\%$ & & \\
\hline $\begin{array}{l}\text { Enfermagem Obstétrica e } \\
\text { Ginecológica }\end{array}$ & 69 & 71,9 & 27 & 28,1 & 96 & \\
\hline \multicolumn{7}{|l|}{ Setor de trabalho } \\
\hline Alojamento Conjunto & 32 & 91,4 & 3 & 8,6 & 35 & $<0,001$ \\
\hline Ambulatório & 14 & 73,7 & 5 & 26,3 & 19 & \\
\hline Berçário & 21 & 70,0 & 9 & 30,0 & 30 & \\
\hline Centro Cirúrgico & 31 & 72,1 & 12 & 27,9 & 43 & \\
\hline Centro Obstétrico & 16 & 51,6 & 15 & 48,4 & 31 & \\
\hline Clínica Cirúrgica & 39 & 86,7 & 6 & 13,3 & 45 & \\
\hline Clínica Médica & 40 & 74,1 & 14 & 25,9 & 54 & \\
\hline Imagem e Endoscopia & 21 & 77,8 & 6 & 22,2 & 27 & \\
\hline Pediatria & 30 & 66,7 & 15 & 33,3 & 45 & \\
\hline Pronto Socorro Adulto & 45 & 70,3 & 19 & 29,7 & 64 & \\
\hline Pronto Socorro Infantil & 16 & 72,7 & 6 & 27,3 & 22 & \\
\hline Unidade de Terapia Intensiva Adulto & 52 & 88,1 & 7 & 11,9 & 59 & \\
\hline $\begin{array}{l}\text { Unidade de Terapia Intensiva } \\
\text { Pediátrica }\end{array}$ & 22 & 52,4 & 20 & 47,6 & 42 & \\
\hline Total & 379 & 73,4 & 137 & 26,6 & 516 & \\
\hline
\end{tabular}

* Teste de associação pelo Qui-Quadrado

Tabela 2 - Análise comparativa entre perdas e participantes segundo características demográficas e ocupacionais dos trabalhadores de Enfermagem, São Paulo, 2015.

\begin{tabular}{|c|c|c|c|c|c|c|}
\hline Variável & no & Média & $\begin{array}{l}\text { Desvio } \\
\text { padrão }\end{array}$ & Mínima & Máxima & $\mathbf{p}^{*}$ \\
\hline \multicolumn{7}{|c|}{ Idade (anos) } \\
\hline Participação & 379 & 42,1 & 9,1 & 23,7 & 66,0 & 0,003 \\
\hline Perdas & 137 & 44,9 & 9,2 & 27,0 & 68,9 & \\
\hline Total & 516 & 42,9 & 9,2 & 23,7 & 68,9 & \\
\hline \multicolumn{7}{|c|}{$\begin{array}{l}\text { Tempo de trabalho na instituição } \\
\text { (anos) }\end{array}$} \\
\hline Participação & 378 & 13,9 & 8,6 & 1,2 & 33,5 & 0,027 \\
\hline Perdas & 137 & 15,9 & 9,1 & 1,4 & 33,3 & \\
\hline Total & 515 & 14,5 & 8,7 & 1,2 & 33,5 & \\
\hline
\end{tabular}

* Teste ANOVA 
Não houve diferença estatisticamente significativa quanto ao sexo $(26,9 \%$ de perdas entre as mulheres e $23,8 \%$ de perdas entre os homens; $p=0,599)$. Houve diferença estatisticamente significativa $(p=0,003)$ em relação à idade, sendo que os participantes tiveram média etária (42,1 anos) menor do que os não participantes (44,9 anos). Também houve diferença $(p=0,027)$ quanto ao tempo de trabalho na instituição, com os participantes apresentando média (13,9 anos) inferior aos não participantes (15,9 anos).

Observou-se diferença no percentual de perdas quanto à função $(p<0,001)$, com os Enfermeiros apresentando taxa de perdas $(9,7 \%)$ menor do que os Técnicos de Enfermagem (32,5\%) e Auxiliares de Enfermagem (40,7\%). Também houve diferença estatisticamente significativa $(p=0,015)$ quanto à Divisão de Enfermagem, com maior taxa de participação na Divisão de Enfermagem Clínica. Quanto ao Setor de Trabalho, também ocorreu diferença estatisticamente significativa $(p<0,001)$, com grande variação entre os setores, sendo que os maiores percentuais de perdas foram no Centro Obstétrico, Unidade de Terapia Intensiva Pediátrica, Pediatria, Berçário e Pronto Socorro Adulto (respectivamente 48,4\%; $47,6 \% ; 30,2 \% ; 33,3 \% ; 29,7 \%)$.

\subsection{CONFIABILIDADE DOS QUESTIONÁRIOS UTILIZADOS}

Os dados de confiabilidade são apresentados nas tabelas 3 e 4.

Tabela 3 - Valores do alpha de Cronbach por dimensão do Índice de Capacidade para o Trabalho - ICT, trabalhadores de Enfermagem, São Paulo, 2015.

(continua)

\section{Dimensão}

Capacidade para o trabalho atual comparada com a melhor de toda a vida

Capacidade para o trabalho em relação às exigências do trabalho

Número atual de doenças diagnosticadas pelo médico (pontos)

Perda estimada para o trabalho devido às doenças

Faltas ao trabalho por doenças nos últimos 12 meses
Alpha de Cronbach se a questão for excluída

0,67

0,68

0,73

0,69

0,73 
(continuação)

\begin{tabular}{cc}
\multicolumn{1}{c}{ Dimensão } & $\begin{array}{c}\text { Alpha de Cronbach se a } \\
\text { questão for excluída }\end{array}$ \\
\hline $\begin{array}{l}\text { Prognóstico próprio sobre a capacidade para o trabalho daqui a } \\
\text { dois anos }\end{array}$ & 0,72 \\
Recursos mentais & 0,72 \\
\hline \multicolumn{1}{c|}{ ICT (com todas as dimensões) } & $\mathbf{0 , 7 4}$ \\
\hline
\end{tabular}

O ICT apresentou boa confiabilidade, obtendo alpha de Cronbach de 0,74 , sendo que a exclusão de qualquer das dimensões não acarretaria um melhor resultado (Tabela 3$)$.

Tabela 4 - Valores do alpha de Cronbach por dimensão da Escala de Presenteísmo de Stanford - SPS-6, trabalhadores de Enfermagem, São Paulo, 2015.

\begin{tabular}{lc}
\multicolumn{1}{c}{ Questão } & $\begin{array}{c}\text { Alpha de Crombach se } \\
\text { a questão for excluída }\end{array}$ \\
\hline Lidar com o estresse do trabalho & 0,65 \\
Terminar as tarefas difíceis do trabalho & 0,70 \\
Ter prazer no trabalho & 0,62 \\
Ter ânimo para terminar as tarefas & 0,62 \\
Ter concentração nas metas & 0,65 \\
Ter energia para terminar o trabalho & 0,67 \\
\hline \multicolumn{1}{c}{ SPS-6 (com todas as dimensões) } & $\mathbf{0 , 7 0}$ \\
\hline
\end{tabular}

O SPS-6 também apresentou boa confiabilidade, com alpha de Cronbach de 0,70 , sendo que a exclusão de qualquer das questões não representaria melhora no resultado (Tabela 4 ).

\subsection{CARACTERIZAÇÃO DA POPULAÇÃO DE ESTUDO}

\subsubsection{Características sociodemográficas e ocupacionais}

Os resultados relativos às características sociodemográficas podem ser visualizados na tabela 5 . 
Tabela 5 - Distribuição dos trabalhadores de Enfermagem segundo variáveis demográficas, São Paulo, 2015.

\begin{tabular}{|c|c|c|}
\hline Variável & no & $\%$ \\
\hline \multicolumn{3}{|c|}{ Sexo } \\
\hline Feminino & 331 & 87,3 \\
\hline Masculino & 48 & 12,7 \\
\hline \multicolumn{3}{|c|}{ Faixa etária } \\
\hline$<35,0$ anos & 108 & 28,5 \\
\hline$\geq 35,0$ e $<45,0$ anos & 114 & 30,1 \\
\hline$\geq 45,0$ anos & 157 & 41,4 \\
\hline \multicolumn{3}{|c|}{ Estado conjugal } \\
\hline Solteiro(a) & 88 & 23,2 \\
\hline Casado(a) & 184 & 48,5 \\
\hline Vive com companheiro(a) & 46 & 12,1 \\
\hline Separado(a)/divorciado(a) & 53 & 14,0 \\
\hline Viúvo(a) & 8 & 2,1 \\
\hline \multicolumn{3}{|c|}{ Escolaridade } \\
\hline Ensino Fundamental & 0 & 0,0 \\
\hline Ensino Médio & 138 & 36,4 \\
\hline Ensino Superior & 241 & 63,6 \\
\hline \multicolumn{3}{|c|}{ Renda familiar líquida mensal (R\$) } \\
\hline$\geq 2$ e $<4$ salários mínimos & 10 & 2,6 \\
\hline$\geq 4$ e $<6$ salários mínimos & 87 & 23,0 \\
\hline$\geq 6$ e $<8$ salários mínimos & 92 & 24,3 \\
\hline$\geq 8$ salários mínimos & 190 & 50,1 \\
\hline Total & 379 & 100,0 \\
\hline
\end{tabular}

Quanto às características sociodemográficas, mostradas na Tabela 5, observa-se que a população de estudo foi predominantemente feminina $(87,3 \%)$, casada ou com companheiro(a) (60,6\%), com escolaridade de nível superior $(63,6 \%)$ e renda familiar líquida mensal maior ou igual a oito salários mínimos do País (50,1\%). A maior proporção de trabalhadores (71,5\%) tinha idade a partir de 35,0 anos, sendo que $41,4 \%$ tinham 45,0 anos ou mais. A média etária foi de 41,6 anos ( $d p=9,2$ anos), variando de 23,0 a 65,0 anos, com mediana de 41,6 anos. 
A Tabela 6 apresenta a estatística descritiva das variáveis ocupacionais quantitativas e as Tabelas 7 e 8 apresentam as variáveis ocupacionais qualitativas.

Tabela 6 - Estatística descritiva das variáveis quantitativas contínuas, trabalhadores de Enfermagem, São Paulo, 2015.

\begin{tabular}{llllllll}
\hline \multicolumn{2}{c}{ Variável } & no & Média & Mediana & $\begin{array}{l}\text { Desvio } \\
\text { padrão }\end{array}$ & Mínimo & Máximo \\
\hline $\begin{array}{l}\text { Tempo de trabalho na instituição } \\
\text { (anos) }\end{array}$ & 379 & 14,0 & 14,0 & 8,6 & 1,0 & 34,0 \\
$\begin{array}{l}\text { Tempo de trabalho na profissão } \\
\text { (anos) }\end{array}$ & 379 & 16,2 & 15,0 & 8,0 & 1,0 & 40,0 \\
$\begin{array}{l}\text { Total de horas trabalhadas na } \\
\text { semana (horas) }\end{array}$ & 379 & 38,5 & 36,0 & 8,6 & 36,0 & 84,0 \\
$\begin{array}{l}\text { Tempo de trajeto para o trabalho } \\
\text { (horas) }\end{array}$ & 379 & 1,1 & 1,0 & 0,7 & 0,2 & 5,5 \\
\hline
\end{tabular}

Tabela 7 - Distribuição dos trabalhadores de Enfermagem segundo variáveis ocupacionais, São Paulo, 2015.

(continua)

\begin{tabular}{|c|c|c|}
\hline Variável & no & $\%$ \\
\hline \multicolumn{3}{|c|}{ Tempo de trabalho na instituição } \\
\hline$\leq 9$ anos $\left(1^{\circ}\right.$ tercil $)$ & 136 & 35,9 \\
\hline $10-18$ anos $\left(2^{\circ}\right.$ tercil $)$ & 128 & 33,8 \\
\hline$\geq 19$ anos $\left(3^{\circ}\right.$ tercil $)$ & 115 & 30,3 \\
\hline \multicolumn{3}{|c|}{ Tempo de trabalho na profissão } \\
\hline$\leq 12$ anos $\left(1^{\circ}\right.$ tercil $)$ & 138 & 36,4 \\
\hline $13-19$ anos ( $2^{\circ}$ tercil) & 118 & 31,1 \\
\hline$\geq 20$ anos $\left(3^{\circ}\right.$ tercil $)$ & 123 & 32,5 \\
\hline \multicolumn{3}{|c|}{ Função } \\
\hline Enfermeiro & 140 & 36,9 \\
\hline Técnico de Enfermagem & 204 & 53,8 \\
\hline Auxiliar de Enfermagem & 35 & 9,2 \\
\hline \multicolumn{3}{|c|}{ Total de horas trabalhadas na semana } \\
\hline 36,0 horas & 348 & 91,8 \\
\hline$>36,0$ horas & 31 & 8,2 \\
\hline
\end{tabular}

(continuação) 


\section{Variável}

no

\section{Turno de trabalho}

Manhã

Tarde

Noite

Único

Duplo

Triplo
131

123

125

№ de vínculos empregatícios

348

30

1
$\%$

34,6

32,5

33,0

91,8

7,9

0,3

Tempo de trajeto (ida e volta) para o trabalho

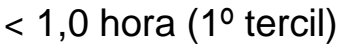

$\geq 1,0$ e $<2,0$ horas $(2$ - tercil)

$\geq 2,0$ horas $\left(3^{\circ}\right.$ tercil)
168

157

54
44,3

41,4 14,3

Nas Tabelas 6 e 7 observa-se que os trabalhadores tinham em média 14,0 anos ( $d p=8,6$ anos) de tempo de trabalho na instituição, sendo que 30,3\% tinha, 19 ou mais anos de casa. O tempo médio de atuação na profissão de enfermagem era de 16,2 anos ( $d p=8,0$ anos), com 32,5\% dos trabalhadores informando 20 ou mais anos na profissão.

Quanto à função exercida, observou-se maioria de trabalhadores de nível médio (63,0\%), sendo 53,8\% Técnicos de Enfermagem e 9,2\% Auxiliares de enfermagem. Os Enfermeiros totalizaram 36,9\% da amostra.

A jornada de trabalho total semanal informada foi de 38,5 horas em média ( $d p=8,6$ horas), sendo que 91,8\% informaram jornada de 36,0 horas semanais. Os trabalhadores estavam distribuídos em proporções semelhantes nos três turnos de trabalho, e a maioria deles $(91,8 \%)$ informou um único vínculo empregatício.

O tempo médio diário de trajeto (ida e volta) para o trabalho foi de 1,1 hora $(\mathrm{dp}=1,0$ hora), sendo que a maioria $(55,6 \%)$ relatou mais de 01 hora diária. 
Tabela 8 - Distribuição dos trabalhadores de Enfermagem segundo local de trabalho, São Paulo, 2015.

\begin{tabular}{|c|c|c|}
\hline Variável & no & $\%$ \\
\hline \multicolumn{3}{|c|}{ Divisão de Enfermagem } \\
\hline Enfermagem Clínica & 92 & 24,3 \\
\hline Enfermagem Cirúrgica & 70 & 18,5 \\
\hline Pacientes Externos & 80 & 21,1 \\
\hline Enfermagem Pediátrica & 68 & 17,9 \\
\hline Enfermagem Obstétrica e Ginecológica & 69 & 18,2 \\
\hline \multicolumn{3}{|c|}{ Setor de trabalho } \\
\hline Alojamento Conjunto & 32 & 8,4 \\
\hline Ambulatório & 14 & 3,7 \\
\hline Berçário & 21 & 5,5 \\
\hline Centro Cirúrgico & 31 & 8,2 \\
\hline Centro Obstétrico & 16 & 4,2 \\
\hline Clínica Cirúrgica & 39 & 10,3 \\
\hline Clínica Médica & 40 & 10,6 \\
\hline Imagem e Endoscopia & 21 & 5,5 \\
\hline Pediatria & 30 & 7,9 \\
\hline Pronto Socorro Adulto & 45 & 11,9 \\
\hline Pronto Socorro Infantil & 16 & 4,2 \\
\hline Unidade de Terapia Intensiva Adulto & 52 & 13,7 \\
\hline Unidade de Terapia Intensiva Pediátrica & 22 & 5,8 \\
\hline Total & 379 & 100,0 \\
\hline
\end{tabular}

A Tabela 8 evidencia a distribuição dos trabalhadores segundo a Divisão de Enfermagem e o Setor de Trabalho. As maiores proporções de trabalhadores estavam nas Divisões de Enfermagem Clínica (24,3\%) e Divisões de Pacientes Externos (21,1\%).

Os trabalhadores estavam distribuídos em 13 setores de trabalho, com as maiores proporções na UTI Adulto (13,7\%), Pronto Socorro Adulto (11,9\%), Clínica Médica (10,6\%) e Clínica Cirúrgica $(10,35)$. 


\subsubsection{Análise descritiva do presenteísmo}

Os resultados encontrados relativos ao presenteísmo são apresentados na tabela 9 e gráficos 1 e 2 .

Tabela 9 - Estatística descritiva da Escala de Presenteísmo de Stanford - SPS-6 e suas dimensões componentes, trabalhadores de Enfermagem, São Paulo, 2015.

\begin{tabular}{|c|c|c|c|c|c|c|}
\hline Variável & $\mathrm{n}^{\circ}$ & Média & Mediana & $\begin{array}{l}\text { Desvio } \\
\text { padrão }\end{array}$ & Mínimo & Máximo \\
\hline $\begin{array}{c}\text { Dimensão física (trabalho } \\
\text { finalizado) }\end{array}$ & 151 & 12,3 & 13,0 & 2,8 & 3,0 & 15,0 \\
\hline $\begin{array}{l}\text { Apesar do meu problema de saúde, } \\
\text { consegui terminar as tarefas difíceis } \\
\text { no trabalho }\end{array}$ & 151 & 4,3 & 5,0 & 1,1 & 1,0 & 5,0 \\
\hline $\begin{array}{l}\text { No trabalho, consegui me } \\
\text { concentrar em minhas metas apesar } \\
\text { de meu problema de saúde }\end{array}$ & 151 & 4,1 & 4,0 & 1,2 & 1,0 & 5,0 \\
\hline $\begin{array}{l}\text { Apesar de meu problema de saúde, } \\
\text { tive energia suficiente para terminar } \\
\text { o meu trabalho }\end{array}$ & 151 & 3,9 & 4,0 & 1,3 & 1,0 & 5,0 \\
\hline $\begin{array}{l}\text { Dimensão psicológica } \\
\text { (concentração mantida) }\end{array}$ & 151 & 7,5 & 7,0 & 3,5 & 3,0 & 15,0 \\
\hline $\begin{array}{l}\text { Devido ao meu problema de saúde, } \\
\text { foi muito difícil lidar com o estresse } \\
\text { no trabalho }\end{array}$ & 151 & 2,5 & 2,0 & 1,3 & 1,0 & 5,0 \\
\hline $\begin{array}{l}\text { Devido ao meu problema de saúde, } \\
\text { não pude ter prazer no trabalho }\end{array}$ & 151 & 2,5 & 2,0 & 1,4 & 1,0 & 5,0 \\
\hline $\begin{array}{l}\text { Me senti sem ânimo para terminar } \\
\text { algumas tarefas no trabalho devido } \\
\text { ao problema de saúde }\end{array}$ & 151 & 2,5 & 2,0 & 1,5 & 1,0 & 5,0 \\
\hline Escore do EPS-6 & 151 & 19,9 & 20,0 & 4,9 & 6,0 & 30,0 \\
\hline
\end{tabular}


Gráfico 1 - Pontuação média dos componentes da Escala de Presenteísmo de Stanford - SPS-6, de trabalhadores de Enfermagem. São Paulo, 2015.

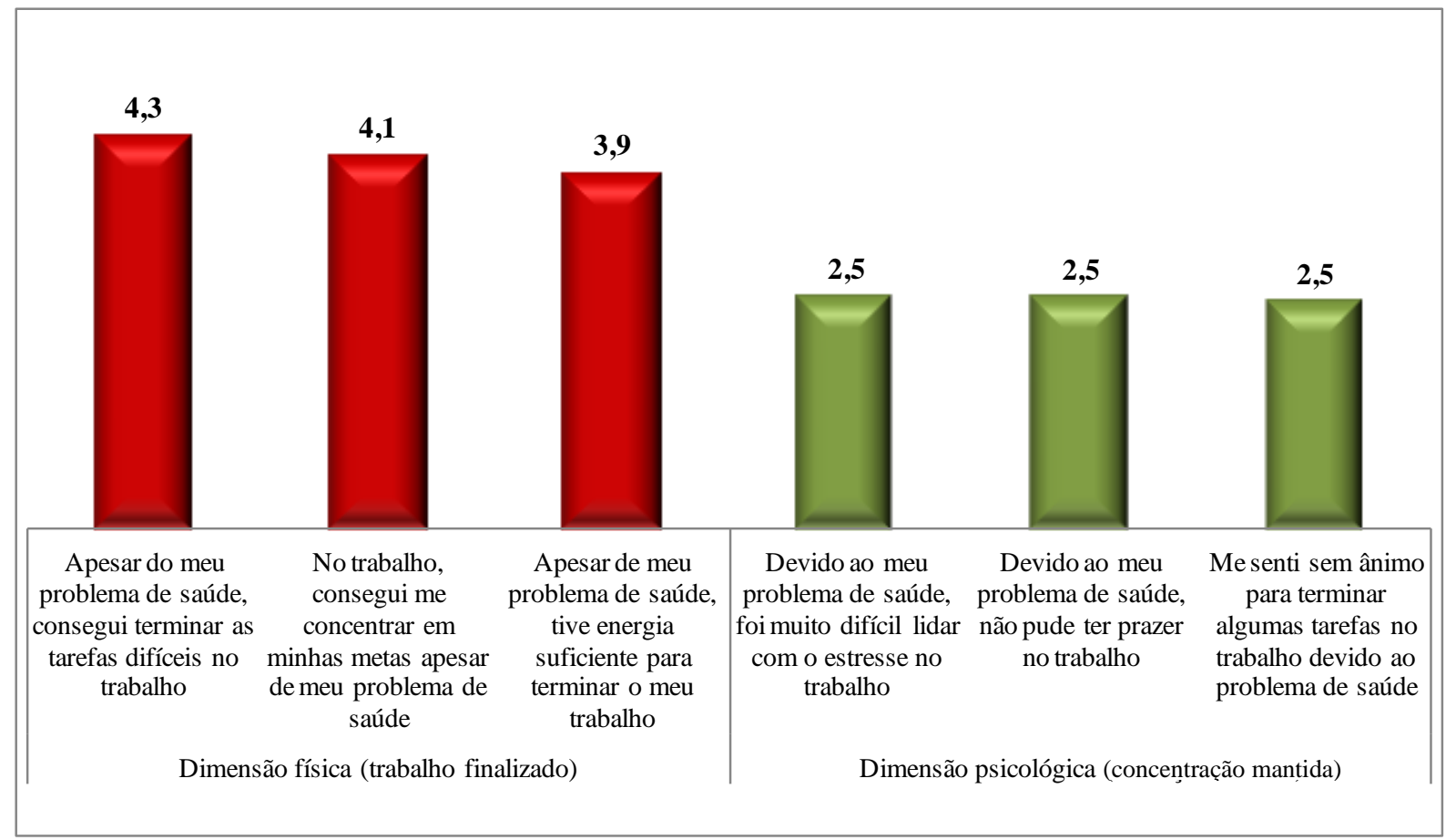

Entre os trabalhadores que participaram do estudo, $228(60,2 \%)$ relataram que não trabalharam na vigência de algum problema de saúde nos 30 dias anteriores à coleta de dados e, portanto, não preencheram o complemento da SPS6. A Tabela 9 e o Gráfico 1 apresentam os resultados da avaliação dos demais 151 $(39,8 \%)$ trabalhadores que responderam o questionário de presenteísmo. Observase que o escore médio do presenteísmo foi de 19,9 pontos $(\mathrm{dp}=4,9)$, variando de 6,0 a 30,0 pontos e mediana de 20,0 pontos.

A dimensão física (trabalho finalizado) apresentou média de 12,3 pontos $(\mathrm{dp}=2,8)$, variando de 3,0 a 15,0 pontos e mediana de 13,0 pontos. A dimensão psicológica (distração evitada) apresentou média de 7,5 pontos $(\mathrm{dp}=3,5)$ variando de 3,0 a 15,0 pontos, com mediana de 7,0 pontos.

Observa-se que os itens que compõem a dimensão física apresentaram maior pontuação média do que os itens que compõem a dimensão psicológica, indicando melhor desempenho (alto presenteísmo) sob o aspecto físico do que o psicológico. 
Gráfico 2 - Distribuição da população de estudo (\%) segundo classificação do presenteísmo, trabalhadores de Enfermagem, São Paulo, 2015.

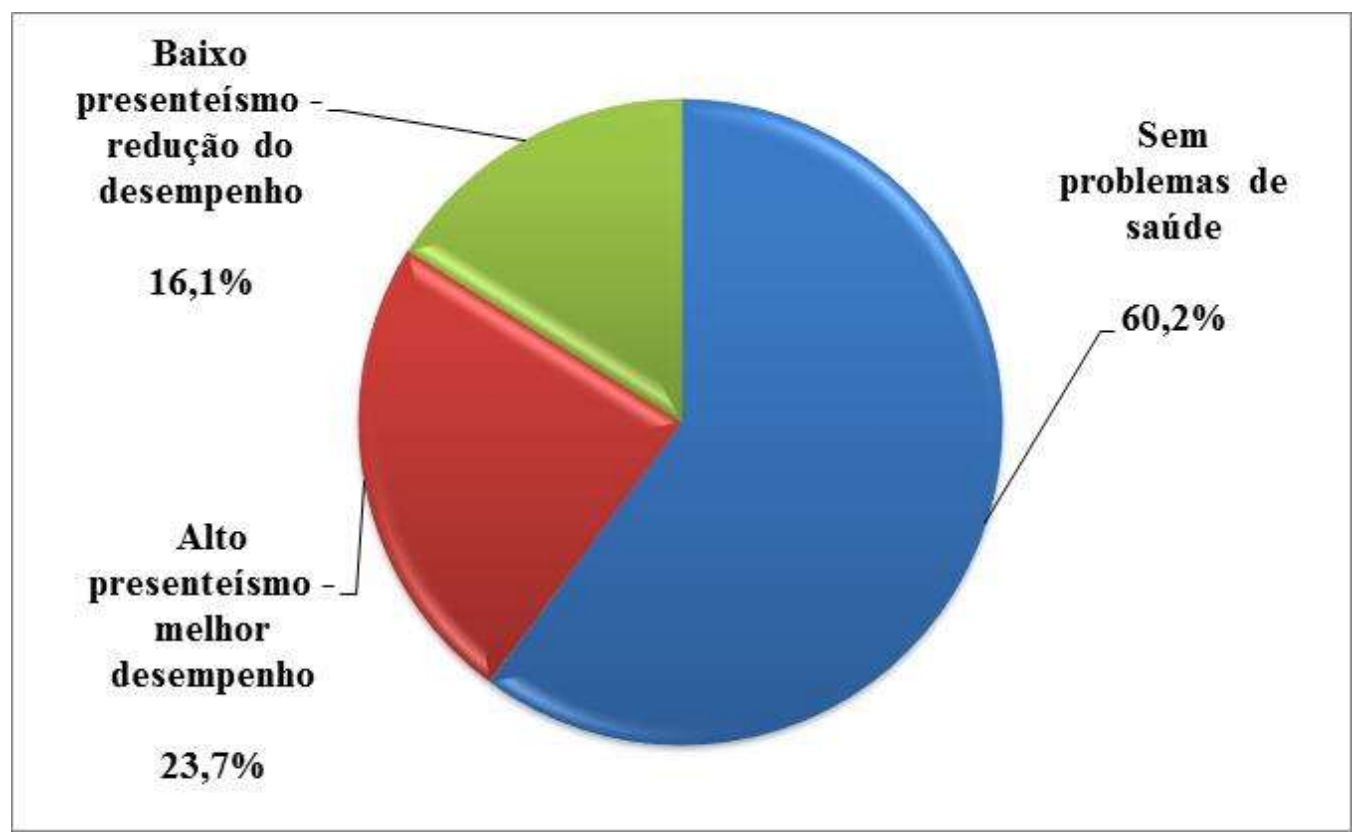

O Gráfico 2 mostra que, quando os resultados da SPS-6 são categorizados, além dos 60,2\% que se declararam sem problemas de saúde, 23,7\% são classificados com alto presenteísmo (melhor desempenho) e 16,1\% com baixo presenteísmo (redução de desempenho).

$\mathrm{Na}$ Tabela 10 observa-se que as doenças/agravos referidas com maior frequência pelos trabalhadores de enfermagem.

Tabela 10 - Distribuição dos trabalhadores de Enfermagem segundo as doenças autorreferidas, São Paulo, 2015.

\begin{tabular}{lccc}
\hline & Variável & no & $\%$ \\
\hline Distúrbios musculoesqueléticos & 92 & 60,9 \\
Cefaleias e enxaquecas & 21 & 13,9 \\
Distúrbios gastrointestinais & 19 & 12,6 \\
Gripes e resfriados & 14 & 9,3 \\
Sinusite & 6 & 4,0 \\
Infecção urinária & 4 & 2,6 \\
Transtorno mental & 2 & 1,3 \\
Hipertensão arterial & 2 & 1,3 \\
Outros & 20 & 13,2 \\
\hline
\end{tabular}


As doenças/agravos mais frequentemente referidos pelos trabalhadores de enfermagem foram os distúrbios musculoesqueléticos, cefaleias e enxaquecas, e distúrbios gastrointestinais, respectivamente com prevalências de 60,9, 13,9\% e $12,6 \%$.

\subsection{ANÁLISE DO ÍNDICE DE CAPACIDADE PARA O TRABALHO}

Os resultados relativos ao ICT são apresentados na Tabela 11 e no Gráfico 3.

Tabela 11 - Distribuição dos trabalhadores de Enfermagem segundo classificação da capacidade para o trabalho, São Paulo, 2015.

\begin{tabular}{ccc}
\hline Capacidade para o trabalho & $\mathbf{n}$ - & \% \\
\hline Ótima & 89 & 23,5 \\
Boa & 145 & 38,3 \\
Moderada & 105 & 27,7 \\
Baixa & 40 & 10,6 \\
\hline Total & $\mathbf{3 7 9}$ & $\mathbf{1 0 0 , 0}$
\end{tabular}

Gráfico 3 - Distribuição (\%) dos trabalhadores de Enfermagem segundo classificação da capacidade para o trabalho, São Paulo, 2015.

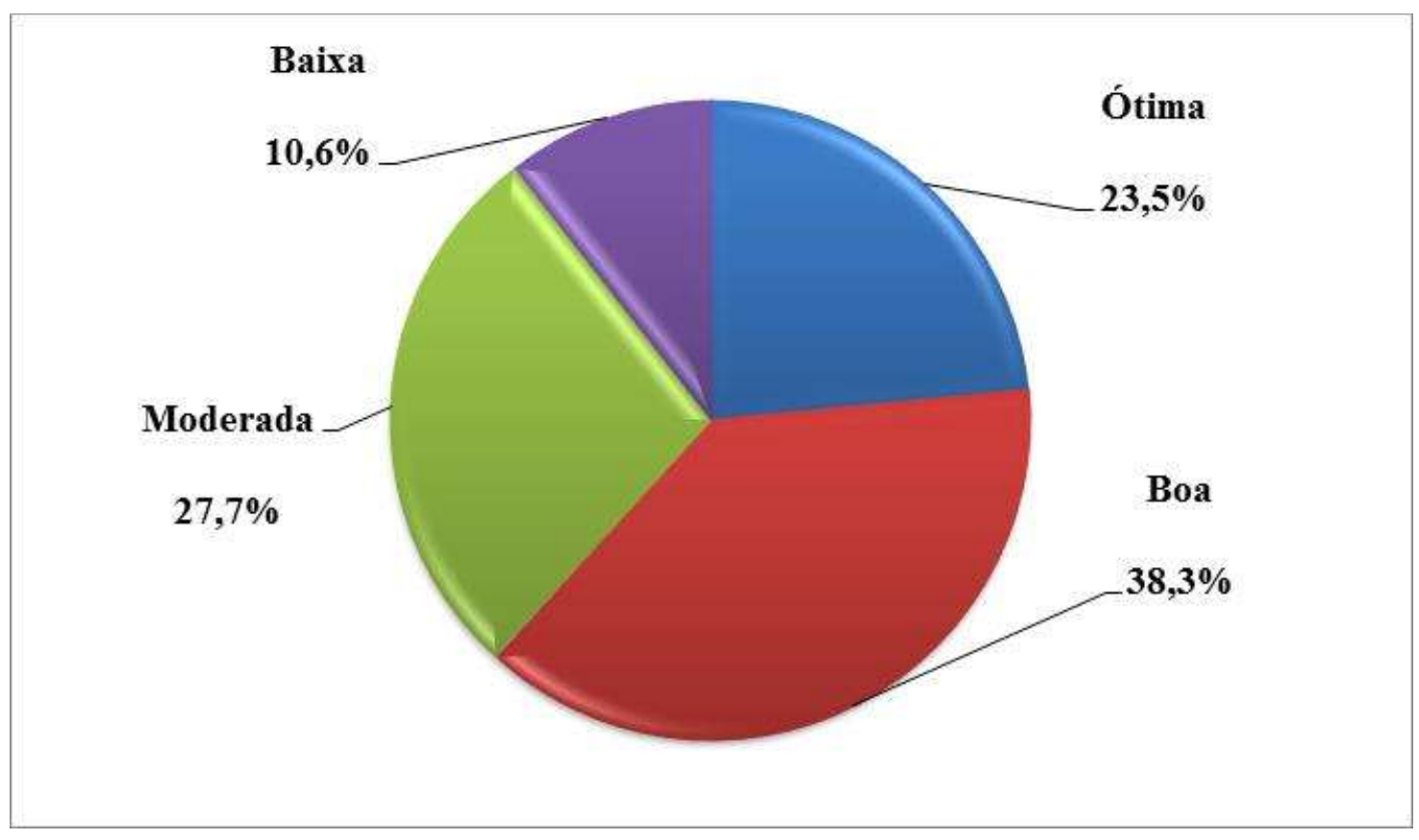


A média do ICT foi de 39,1 pontos ( $d p=5,9)$, variando de 20,0 a 49,0 pontos e mediana de 40,0 pontos. Conforme apresentado na Tabela 11 e no Gráfico $3,38,3 \%$ dos trabalhadores apresentaram capacidade para o trabalho comprometida (moderada ou baixa).

A Tabela 12 apresenta os resultados em cada uma das dimensões que compõe o ICT.

Tabela 12 - Distribuição dos trabalhadores $\left(\mathrm{n}^{\circ}\right)$ segundo pontuação das dimensões do Índice de Capacidade para o Trabalho, São Paulo, 2015.

\begin{tabular}{|c|c|c|c|c|c|c|c|c|c|c|c|}
\hline \multirow{2}{*}{ Dimensão } & \multicolumn{11}{|c|}{ Pontuação } \\
\hline & 0 & 1 & 2 & 3 & 4 & 5 & 6 & 7 & 8 & 9 & 10 \\
\hline $\begin{array}{l}\text { Capacidade para o trabalho } \\
\text { atual comparada com a } \\
\text { melhor de toda a vida }\end{array}$ & 0 & 0 & 0 & 1 & 5 & 8 & 19 & 57 & 126 & 87 & 76 \\
\hline $\begin{array}{l}\text { Capacidade para o trabalho } \\
\text { em relação às exigências do } \\
\text { trabalho }\end{array}$ & 0 & 0 & 0 & 0 & 2 & 9 & 25 & 91 & 124 & 72 & 56 \\
\hline $\begin{array}{l}\text { Número atual de doenças } \\
\text { diagnosticadas pelo médico } \\
\text { (pontos) }\end{array}$ & .. & 65 & 19 & 41 & 69 & 86 & .. & 99 &.. & .. & .. \\
\hline $\begin{array}{l}\text { Perda estimada para o } \\
\text { trabalho devido às doenças }\end{array}$ & .. & 0 & 4 & 8 & 87 & 158 & 122 & .. & .. & .. & .. \\
\hline $\begin{array}{l}\text { Faltas ao trabalho por } \\
\text { doenças nos últimos } 12 \\
\text { meses }\end{array}$ & .. & 7 & 14 & 28 & 135 & 195 & .. & .. & .. & .. & .. \\
\hline $\begin{array}{l}\text { Prognóstico próprio sobre a } \\
\text { capacidade para o trabalho } \\
\text { daqui a dois anos }\end{array}$ & .. & 19 & .. & .. & 91 & .. & .. & 269 & .. & .. & .. \\
\hline Recursos mentais & 0 & 3 & 56 & 170 & 150 & .. & .. & .. & .. & .. & .. \\
\hline
\end{tabular}

Dimensão 1 - Capacidade para o trabalho atual comparada com a melhor de toda a vida: observa-se que 289 (76,3\%) trabalhadores declararam-se entre os 3 pontos superiores (8 a 10) da dimensão.

Dimensão 2 - Capacidade para o trabalho em relação às exigências do trabalho: observa-se que $252(66,5 \%)$ trabalhadores declararam-se entre os 3 pontos superiores (8 a 10) da dimensão. 
Dimensão 3 - Número atual de doenças diagnosticadas pelo médico: 99 (26,1\%) dos trabalhadores não informaram doenças (pontuação = 7) e 86 (22,7\%) informaram 1 doença (pontuação = 5). Os 51,2\% restantes informaram 2 ou mais doenças.

Dimensão 4 - Perda estimada para o trabalho devido às lesões/doenças: 280 $(73,9 \%)$ dos trabalhadores informaram que, apesar do trabalho causar alguns sintomas, eles eram capazes de realizar seu trabalho ou negaram qualquer impedimento/doença para realizar seu trabalho (pontuação $=5$ e 6). Isso significa que os $26,1 \%$ restantes reportaram algum tipo de limitação para executar o trabalho em função de lesão ou doença.

Dimensão 5 - Faltas ao trabalho por doenças nos últimos 12 meses: 195 (51,5\%) dos trabalhadores relataram não estarem ausentes ao trabalho por doenças nos últimos 12 meses (pontuação = 5).

Dimensão 6 - Prognóstico próprio sobre a capacidade para o trabalho: 269 (71,0\%) dos trabalhadores reportaram ser bastante provável estar capaz de fazer o trabalho atual daqui a 2 anos (pontuação $=7$ ).

Dimensão 7 - Recursos mentais: 320 (84,4\%) dos trabalhadores ocuparam as duas melhores posições (pontuação = 3 e 4) nos recursos mentais (capacidade para apreciar as atividades diárias, percepção de estar ativo e alerta, sentimento de esperança para o futuro).

$\mathrm{Na}$ Tabela 13 estão apresentadas as doenças/agravos referidas com maior frequência pelos trabalhadores tanto em sua própria opinião como com relato de diagnóstico médico. Nesta Tabela estão apresentadas somente as situações com prevalência acima de 4,0\% (exceto distúrbio emocional severo). A apresentação detalhada de todas as doenças/agravos está no Apêndice C - Tabela 20. 
Tabela 13 - Distribuição (no e \%) dos trabalhadores de Enfermagem segundo as principais doenças referidas, São Paulo, 2015.

\begin{tabular}{lcccc}
\hline \multicolumn{1}{c}{ Doença/agravo } & \multicolumn{3}{c}{ Opinião própria } & \multicolumn{2}{c}{ Diagnóstico médico } \\
& no & $\%$ & no & $\%$ \\
\hline Lesão nos braços/mãos & 79 & 20,8 & 77 & 20,3 \\
Lesão nas costas & 98 & 25,9 & 61 & 16,1 \\
Lesão nas pernas/pés & 57 & 15,0 & 41 & 10,8 \\
Distúrbio emocional leve & 138 & 36,4 & 38 & 10,0 \\
Hipertensão arterial & 21 & 5,5 & 36 & 9,5 \\
Doença da parte inferior das costas & 66 & 17,4 & 32 & 8,4 \\
Infecções repetidas no trato respiratório & 33 & 8,7 & 32 & 8,4 \\
Doença musculoesquelética afetando os membros & 54 & 14,2 & 31 & 8,2 \\
Gastrite ou irritação duodenal & 34 & 9,0 & 31 & 8,2 \\
Obesidade & 46 & 12,1 & 30 & 7,9 \\
Dor nas costas que se irradia para a perna & 56 & 14,8 & 29 & 7,7 \\
Doença na parte superior das costas & 75 & 19,8 & 28 & 7,4 \\
Doença ou lesão da visão & 23 & 6,1 & 27 & 7,1 \\
Infecção das vias urinárias & 24 & 6,3 & 27 & 7,1 \\
Alergia, eczema & 21 & 5,5 & 27 & 7,1 \\
Sinusite crônica & 28 & 7,4 & 25 & 6,6 \\
Bócio ou outra doença da tireoide & 15 & 4,0 & 24 & 6,3 \\
Lesão em outras partes do corpo & 20 & 5,3 & 23 & 6,1 \\
Doença neurológica & 22 & 5,8 & 23 & 6,1 \\
Distúrbio emocional severo & 10 & 2,6 & 16 & 4,2 \\
\hline
\end{tabular}

Nessa tabela observa-se que as 03 situações com maior prevalência foram as lesões nos braços/mãos, lesões nas costas e lesões nas pernas/pés. Outras doenças musculoesqueléticas também foram reportadas com frequência (doença na parte inferior das costas, doenças afetando os membros, dores nas costas e lesões em outras partes do corpo). Agravos crônicos também foram frequentes (hipertensão arterial, obesidade, alergias, doenças da tireoide e neurológica), bem como infecções (respiratórias e urinárias) e afecções gastroduodenais. Os distúrbios emocionais leves ocuparam a $4^{a}$ posição e foram reportados com mais frequência na opinião própria do que com diagnóstico médico. 
Já os distúrbios emocionais severos foram citados com maior frequência no diagnóstico médico do que na opinião própria.

$\mathrm{Na}$ Tabela 14 as doenças/agravos aparecem agrupadas segundo sistema ou categoria de doenças.

Tabela 14 - Distribuição dos trabalhadores de Enfermagem segundo grupos de doenças citadas com diagnóstico médico, São Paulo, 2015.

\begin{tabular}{|c|c|c|}
\hline \multirow{2}{*}{ Grupo de doença / lesão } & \multicolumn{2}{|c|}{ Diagnóstico médico } \\
\hline & no & $\%$ \\
\hline Lesão decorrente de um acidente & 202 & 53,3 \\
\hline $\begin{array}{l}\text { Doença musculoesquelética nas costas, braços, pernas } \\
\text { ou outra parte }\end{array}$ & 135 & 35,6 \\
\hline Doença cardiovascular & 46 & 12,1 \\
\hline Doença respiratória & 84 & 22,2 \\
\hline Distúrbio mental & 54 & 14,2 \\
\hline Doença neurológica ou dos órgãos dos sentidos & 63 & 16,6 \\
\hline Doença ou problema digestivo & 75 & 19,8 \\
\hline Doença geniturinária & 56 & 14,8 \\
\hline Doença da pele & 43 & 11,3 \\
\hline Tumor ou câncer & 17 & 4,5 \\
\hline Doença metabólica ou endócrina & 78 & 20,6 \\
\hline Doença do sangue & 18 & 4,7 \\
\hline Defeitos de nascimento & 5 & 1,3 \\
\hline Outro distúrbio ou doença & 11 & 2,9 \\
\hline
\end{tabular}

Observa-se que este agrupamento traduz as prevalências das doenças isoladas, com as maiores frequências nas lesões decorrentes de acidentes (53,3\%), doenças musculoesqueléticas $(35,6 \%)$, doenças respiratórias $(22,2 \%)$ e doenças metabólicas ou endócrinas (20,6\%). 


\subsection{ANÁLISE DAS ASSOCIAÇÕES ENTRE CAPACIDADE PARA O TRABALHO E PRESENTEÍSMO}

\subsubsection{Análise dos fatores associados à capacidade para o trabalho}

Na Tabela 15 observa-se associação entre a capacidade para o trabalho e o presenteísmo.

Tabela 15 - Análise das associações entre presenteísmo e capacidade para o trabalho em trabalhadores de Enfermagem, São Paulo, 2015.

\begin{tabular}{lccccccc} 
& \multicolumn{2}{c}{ Adequada } & \multicolumn{2}{c}{ Inadequada } & Total & *ariável \\
& № & $\%$ & № & $\%$ & № & * \\
& 217 & 68,2 & 101 & 31,8 & 318 & $<0,001$ \\
Melhor desempenho & 17 & 27,9 & 44 & 72,1 & 61 & \\
Redução do desempenho & $\mathbf{2 3 4}$ & $\mathbf{6 1 , 7}$ & $\mathbf{1 4 5}$ & $\mathbf{3 8 , 3}$ & $\mathbf{3 7 9}$ & \\
\hline Total & & & & &
\end{tabular}

* Teste de associação pelo Qui-Quadrado

Os resultados mostrados na tabela apresentam associação estatisticamente significativa entre a capacidade para o trabalho e o presenteísmo $(p<0,001)$, sendo que entre os trabalhadores com melhor desempenho houve maior prevalência de capacidade para o trabalho adequada $(68,2 \%)$ do que entre aqueles com redução do desempenho (27,9\%).

A Tabela 16 mostra que as variáveis demográficas associadas à capacidade para o trabalho 
Tabela 16 - Análise das associações entre variáveis demográficas e capacidade para o trabalho em trabalhadores de Enfermagem, São Paulo, 2015.

\begin{tabular}{|c|c|c|c|c|c|c|}
\hline \multirow{2}{*}{ Variável } & \multicolumn{2}{|c|}{ Adequada } & \multicolumn{2}{|c|}{ Inadequada } & \multirow{2}{*}{$\begin{array}{c}\text { Total } \\
\quad \text { № }\end{array}$} & \multirow{2}{*}{$p^{*}$} \\
\hline & № & $\%$ & № & $\%$ & & \\
\hline \multicolumn{7}{|l|}{ Sexo } \\
\hline Feminino & 200 & 60,4 & 131 & 39,6 & 331 & 0,165 \\
\hline Masculino & 34 & 70,8 & 14 & 29,2 & 48 & \\
\hline \multicolumn{7}{|l|}{ Faixa etária } \\
\hline$<35$ anos & 52 & 48,1 & 56 & 51,9 & 108 & 0,001 \\
\hline$\geq 35,0$ e $<45,0$ anos & 82 & 71,9 & 32 & 28,1 & 114 & \\
\hline$\geq 45,0$ anos & 100 & 63,7 & 57 & 36,3 & 157 & \\
\hline \multicolumn{7}{|l|}{ Estado conjugal } \\
\hline $\begin{array}{l}\text { Casado(a)/companheiro(a) / Vive com } \\
\text { companheiro(a) }\end{array}$ & 145 & 63,0 & 85 & 37,0 & 230 & 0,517 \\
\hline $\begin{array}{l}\text { Solteiro(a) / Separado(a) / Divorciado(a) } \\
\text { / Viúvo(a) }\end{array}$ & 89 & 59,7 & 60 & 40,3 & 149 & \\
\hline \multicolumn{7}{|l|}{ Escolaridade } \\
\hline Ensino Médio & 83 & 60,1 & 55 & 39,9 & 138 & 0,628 \\
\hline Ensino Superior & 151 & 62,7 & 90 & 37,3 & 241 & \\
\hline \multicolumn{7}{|l|}{ Renda familiar líquida } \\
\hline$\geq 8$ salários mínimos & 128 & 67,4 & 62 & 32,6 & 190 & 0,024 \\
\hline Até 8 salários mínimos & 106 & 56,1 & 83 & 43,9 & 189 & \\
\hline Total & 234 & 61,7 & 145 & 38,3 & 379 & \\
\hline
\end{tabular}

* Teste de associação pelo Qui-Quadrado

A Tabela 16 mostra que as variáveis demográficas associadas à capacidade para o trabalho foram a faixa etária $(p=0,001)$ e a renda familiar líquida $(p=0,024)$ : os trabalhadores mais jovens e aqueles com menor renda familiar apresentaram maiores percentuais de capacidade para o trabalho inadequada do que os demais, respectivamente em cada variável. Sexo $(p=0,165)$, estado conjugal $(p=0,517)$ e escolaridade $(p=0,628)$ não estiveram associados à capacidade para 0 trabalho.

Quanto às variáveis ocupacionais, são mostradas na Tabela 17. 
Tabela 17 - Análise das associações entre variáveis ocupacionais e capacidade para o trabalho em trabalhadores de Enfermagem, São Paulo, 2015.

\begin{tabular}{|c|c|c|c|c|c|c|}
\hline \multirow{2}{*}{ Variável } & \multicolumn{2}{|c|}{ Adequada } & \multicolumn{2}{|c|}{ Inadequada } & \multirow{2}{*}{$\begin{array}{c}\text { Total } \\
\text { № }\end{array}$} & \multirow{2}{*}{$p^{*}$} \\
\hline & № & $\%$ & № & $\%$ & & \\
\hline \multicolumn{7}{|c|}{ Tempo de trabalho na instituição } \\
\hline$\leq 9$ anos $\left(1^{\circ}\right.$ tercil $)$ & 79 & 58,1 & 57 & 41,9 & 136 & 0,430 \\
\hline $10-18$ anos ( $2^{\circ}$ tercil) & 79 & 61,7 & 49 & 38,3 & 128 & \\
\hline$\geq 19$ anos $\left(3^{\circ}\right.$ tercil) & 76 & 66,1 & 39 & 33,9 & 115 & \\
\hline \multicolumn{7}{|c|}{ Tempo de trabalho na profissão } \\
\hline$\leq 12$ anos $\left(1^{\circ}\right.$ tercil $)$ & 78 & 56,5 & 60 & 43,5 & 138 & 0,267 \\
\hline $13-19$ anos ( $2^{\circ}$ tercil) & 75 & 63,6 & 43 & 36,4 & 118 & \\
\hline$\geq 20$ anos $\left(3^{\circ}\right.$ tercil) & 81 & 65,9 & 42 & 34,1 & 123 & \\
\hline \multicolumn{7}{|l|}{ Função } \\
\hline Enfermeiro & 86 & 61,4 & 54 & 38,6 & 140 & 0,879 \\
\hline Técnico de Enfermagem & 125 & 61,3 & 79 & 38,7 & 204 & \\
\hline Auxiliar de Enfermagem & 23 & 65,7 & 12 & 34,3 & 35 & \\
\hline \multicolumn{7}{|c|}{$\begin{array}{c}\text { Total de horas trabalhadas na } \\
\text { semana }\end{array}$} \\
\hline 36,0 horas & 218 & 62,6 & 130 & 37,4 & 348 & 0,226 \\
\hline$>36,0$ horas & 16 & 51,6 & 15 & 48,4 & 31 & \\
\hline \multicolumn{7}{|c|}{ Turno de trabalho } \\
\hline Manhã & 77 & 58,8 & 54 & 41,2 & 131 & 0,083 \\
\hline Tarde & 70 & 56,9 & 53 & 43,1 & 123 & \\
\hline Noite & 87 & 69,6 & 38 & 30,4 & 125 & \\
\hline \multicolumn{7}{|c|}{ № de vínculos empregatícios } \\
\hline Único & 218 & 62,6 & 130 & 37,4 & 348 & 0,226 \\
\hline Duplo & 16 & 51,6 & 15 & 48,4 & 31 & \\
\hline \multicolumn{7}{|c|}{ Tempo de trajeto para o trabalho } \\
\hline$<1,0$ hora & 111 & 66,1 & 57 & 33,9 & 168 & 0,216 \\
\hline$\geq 1,0$ e $<2,0$ horas & 89 & 56,7 & 68 & 43,3 & 157 & \\
\hline$\geq 2,0$ horas & 34 & 63,0 & 20 & 37,0 & 54 & \\
\hline Total & 234 & 61,7 & 145 & 38,3 & 379 & \\
\hline
\end{tabular}

* Teste de associação pelo Qui quadrado

Quanto às variáveis ocupacionais, a Tabela 17 mostra que nenhuma delas apresentou associação estatisticamente significativa com a capacidade para o trabalho: tempo de trabalho na instituição $(p=0,430)$, tempo de trabalho na profissão 
$(p=0,267)$, função $(p=0,879)$, total de horas trabalhadas na semana $(p=0,226)$, turno de trabalho $(p=0,083)$, quantidade de vínculos empregatícios $(0,226)$ e tempo de trajeto para o trabalho $(p=0,216)$.

A Tabela 18 mostra resultados da associação estatística entre a capacidade para o trabalho e a Divisão de Enfermagem.

Tabela 18 - Análise das associações entre local de trabalho e capacidade para o trabalho em Trabalhadores de Enfermagem, São Paulo, 2015.

\begin{tabular}{ccccccc}
\hline \multirow{2}{*}{ Variável } & \multicolumn{2}{c}{ Adequada } & \multicolumn{2}{c}{ Inadequada } & Total & \multirow{2}{*}{ * } \\
& № & $\%$ & № & $\%$ & № & \\
\hline
\end{tabular}

Divisão de Enfermagem

\begin{tabular}{|c|c|c|c|c|c|c|}
\hline Enfermagem Clínica & 52 & 56,5 & 40 & 43,5 & 92 & 0,196 \\
\hline Enfermagem Cirúrgica & 48 & 68,6 & 22 & 31,4 & 70 & \\
\hline Pacientes Externos & 43 & 53,8 & 37 & 46,3 & 80 & \\
\hline Enfermagem Pediátrica & 44 & 64,7 & 24 & 35,3 & 68 & \\
\hline Enfermagem Obstétrica e Ginecológica & 47 & 68,1 & 22 & 31,9 & 69 & \\
\hline \multicolumn{7}{|l|}{ Setor de trabalho } \\
\hline $\begin{array}{l}\text { Centro Cirúrgico, Centro Obstétrico, } \\
\text { Pediatria }\end{array}$ & 58 & 75,3 & 19 & 24,7 & 77 & 0,001 \\
\hline $\begin{array}{l}\text { Alojamento Conjunto, Berçário, Clínica } \\
\text { Cirúrgica, Imagem e Endoscopia, UTI } \\
\text { Adulto, UTI Pediátrica }\end{array}$ & 120 & 64,2 & 67 & 35,8 & 187 & \\
\hline $\begin{array}{l}\text { Ambulatório, Clínica Médica, Pronto } \\
\text { Socorro Adulto, Pronto Socorro Infantil }\end{array}$ & 56 & 48,7 & 59 & 51,3 & 115 & \\
\hline Total & 234 & 61,7 & 145 & 38,3 & 379 & \\
\hline
\end{tabular}

* Teste de associação pelo Qui quadrado

Observa-se que não houve associação estatisticamente significativa entre a capacidade para o trabalho e a Divisão de Enfermagem $(p=0,196)$. Em função da pequena quantidade de indivíduos em cada casela, os setores de trabalho foram agrupados considerando a prevalência de capacidade para o trabalho adequada. Os setores Ambulatório, Clínica Médica, Pronto Socorro Adulto e Pronto Socorro Infantil apresentaram menor prevalência de capacidade para o trabalho adequada $(48,7 \%)$ do que os demais e esta diferença foi estatisticamente significativa $(p=0,001)$. 


\subsubsection{Análise das associações entre capacidade para o trabalho e presenteísmo}

Os resultados finais da análise de regressão logística bivariada e múltipla estão apresentados na Tabela 19 e a modelagem passo a passo está apresentada no Apêndice D.

Tabela 19 - Fatores associados à capacidade para o trabalho em trabalhadores de Enfermagem, identificados por meio da análise de regressão logística, São Paulo, 2015.

(continua)

\begin{tabular}{|c|c|c|c|c|c|c|}
\hline \multirow[b]{2}{*}{ Variável } & \multicolumn{3}{|c|}{ Bivariada } & \multicolumn{3}{|c|}{ Múltipla } \\
\hline & OR & $\begin{array}{c}\text { IC } 95 \% \\
\text { (OR) }\end{array}$ & $\mathbf{p}^{*}$ & $\begin{array}{l}\text { OR } \\
\text { aj }\end{array}$ & $\begin{array}{l}\text { IC 95\% } \\
\text { (OR aj) }\end{array}$ & $p^{*}$ \\
\hline \multicolumn{7}{|l|}{ Presenteísmo } \\
\hline Melhor desempenho & 1,00 & & & 1,00 & & \\
\hline Redução do desempenho & 5,56 & $\begin{array}{l}{[3,03} \\
20,21]\end{array}$ & $\begin{array}{c}<0,00 \\
1\end{array}$ & 5,18 & $\begin{array}{l}{[2,75} \\
9,77]\end{array}$ & $<0,001$ \\
\hline \multicolumn{7}{|l|}{ Faixa etária } \\
\hline$\geq 35,0$ e $<45,0$ anos & 1,00 & & & 1,00 & & \\
\hline$<35$ anos & 2,76 & {$[1,58 ; 4,81]$} & $\begin{array}{c}<0,00 \\
1\end{array}$ & 2,25 & $\begin{array}{l}{[1,37} \\
3,71]\end{array}$ & 0,001 \\
\hline$\geq 45,0$ anos & 1,46 & {$[0,87 ; 2,46]$} & 0,155 & -- & -- & -- \\
\hline \multicolumn{7}{|l|}{ Setor de trabalho } \\
\hline $\begin{array}{l}\text { Centro Cirúrgico, Centro } \\
\text { Obstétrico, Pediatria }\end{array}$ & 1,00 & & & 1,00 & & \\
\hline $\begin{array}{l}\text { Alojamento Conjunto, Berçário, } \\
\text { Clínica Cirúrgica, Imagem e } \\
\text { Endoscopia, UTI Adulto, UTI } \\
\text { Pediátrica }\end{array}$ & 1,70 & {$[0,94 ; 3,10]$} & 0,081 & -- & -- & -- \\
\hline $\begin{array}{l}\text { Ambulatório, Clínica Médica, } \\
\text { Pronto Socorro Adulto, Pronto } \\
\text { Socorro Infantil }\end{array}$ & 3,22 & {$[1,71 ; 6,06]$} & $\begin{array}{c}<0,00 \\
1\end{array}$ & 2,02 & $\begin{array}{l}{[1,24 ;} \\
3,27]\end{array}$ & 0,005 \\
\hline \multicolumn{7}{|l|}{ Renda familiar líquida } \\
\hline 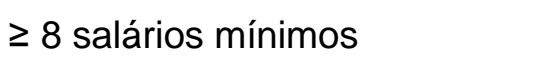 & 1,00 & & & 1,00 & & \\
\hline Até 8 salários mínimos & 1,62 & {$[1,07 ; 2,46]$} & 0,024 & 2,08 & $\begin{array}{l}{[1,30 ;} \\
3,31]\end{array}$ & 0,002 \\
\hline
\end{tabular}


(continuação)

\begin{tabular}{|c|c|c|c|c|c|c|}
\hline \multirow[b]{2}{*}{ Variável } & \multicolumn{3}{|c|}{ Bivariada } & \multicolumn{3}{|c|}{ Múltipla } \\
\hline & OR & $\begin{array}{c}\text { IC 95\% } \\
\text { (OR) }\end{array}$ & $p^{*}$ & $\begin{array}{l}\text { OR } \\
\text { aj }\end{array}$ & $\begin{array}{l}\text { IC } 95 \% \\
\text { (OR aj) }\end{array}$ & $p^{*}$ \\
\hline \multicolumn{7}{|l|}{ Turno de trabalho } \\
\hline Noite & 1,00 & & & & & \\
\hline Manhã & 1,61 & {$[0,96 ; 2,67]$} & 0,072 & -- & -- & -- \\
\hline Tarde & 1,73 & {$[1,03 ; 2,92]$} & 0,039 & -- & -- & -- \\
\hline \multicolumn{7}{|l|}{ Sexo } \\
\hline Feminino & 1,00 & & & 1,00 & & \\
\hline Masculino & 0,63 & $\begin{array}{c}{[0,325} \\
1,22]\end{array}$ & 0,168 & 0,54 & $\begin{array}{r}{[0,26} \\
1,11]\end{array}$ & 0,093 \\
\hline \multicolumn{7}{|c|}{ Divisão de Enfermagem } \\
\hline Enfermagem Cirúrgica & 1,00 & & & & & \\
\hline Enfermagem Clínica & 1,68 & $\begin{array}{c}{[0,875} \\
3,22]\end{array}$ & 0,119 & -- & -- & -- \\
\hline Pacientes Externos & 1,88 & $\begin{array}{c}{[0,961} \\
3,67]\end{array}$ & 0,065 & -- & -- & -- \\
\hline Enfermagem Pediátrica & 1,19 & {$[0,59 ; 2,42]$} & 0,630 & -- & -- & -- \\
\hline $\begin{array}{l}\text { Enfermagem Obstétrica e } \\
\text { Ginecológica }\end{array}$ & 1,02 & {$[0,50 ; 2,09]$} & 0,954 & -- & -- & -- \\
\hline
\end{tabular}

${ }^{*} \mathrm{p}$ da categoria $\mathrm{aj}=$ ajustada

Quanto à associação entre capacidade para o trabalho e presenteísmo, observa-se que os trabalhadores com redução do desempenho apresentaram maior chance de terem a capacidade para o trabalho inadequada quando comparados aos trabalhadores com melhor desempenho, e esta associação permaneceu independente das demais variáveis $\left(\mathrm{OR}_{\mathrm{aj}}=5,18 ; \mathrm{IC} 95 \%=2,75\right.$ a 9,77; $\left.\mathrm{p}<0,001\right)$.

Além do presenteísmo, no modelo múltiplo permaneceram associadas à capacidade para o trabalho as variáveis faixa etária, setor de trabalho e renda familiar. A variável sexo foi mantida como variável de ajuste. O teste de HosmerLemeshow $\left(\chi^{2}=4,091 ; p=0,769\right)$ mostrou bom ajuste do modelo.

Quando comparados aos demais trabalhadores, aqueles na faixa etária de até 35 anos tiveram maior chance de apresentaram a capacidade para o trabalho comprometida $\left(\mathrm{OR}_{\mathrm{aj}}=2,25 ; \mathrm{IC} 95 \%=1,47\right.$ a 3,71; $\left.\mathrm{p}=0,001\right)$, independente das demais variáveis. 
O grupo de setores composto pelo Ambulatório, Clínica Médica, Pronto Socorro Adulto e Pronto Socorro Infantil mostrou-se associado de forma independente ao comprometimento da capacidade para 0 trabalho quando comparado aos demais grupos $\left(\mathrm{OR}_{\mathrm{aj}}=2,02 ; \mathrm{IC} 95 \%=1,24\right.$ a 3,$\left.27 ; \mathrm{p}=0,005\right)$.

A renda familiar líquida também esteve associada de forma independente ao comprometimento da capacidade para o trabalho, com os trabalhadores com renda até 8 salários mínimos apresentando maior chance de comprometimento $\left(\mathrm{OR}_{\mathrm{aj}}=2,08 ; \mathrm{IC} 95 \%=1,30\right.$ a 3,$\left.31 ; \mathrm{p}=0,002\right)$.

\subsection{CONCLUSÃO DOS RESULTADOS QUANTITATIVOS}

Quanto à caracterização sociodemográfica, a média etária foi de 41,6 anos, variando de 23,0 a 65,0 anos. Observou-se a predominância a feminina com destaque entre casadas e com nível superior de escolaridade. Os ocupacionais revelam trabalhadores com tempo médio de atuação de 16,2 anos, sendo a maioria de trabalhadores exercendo função com exigência de nível médio de escolaridade, com único vínculo empregatício em jornadas de 36 horas semanais.

Quanto à análise do presenteísmo, a maioria relatou que não trabalharam na vigência de algum problema de saúde nos 30 dias anteriores à coleta de dados. Dentre os que responderam o questionário de presenteísmo, observa-se que os itens que compõem a dimensão física apresentaram maior pontuação média do que os itens que compõem a dimensão psicológica, indicando melhor desempenho (alto presenteísmo) sob o aspecto físico do que o psicológico. Dentre os problemas de saúde, os distúrbios musculoesqueléticos, gastrointestinais, respiratórios e emocionais foram os mais prevalentes.

A média do índice de capacidade para o trabalho foi avaliada como boa, porém os $38,4 \%$ trabalhadores com capacidade inadequada para o trabalho foram considerados como alerta aos gestores para as medidas de restauração da capacidade para o trabalho com intervenções prioritárias à esta população. 
A análise de associação entre o ICT e o presenteísmo apresentou associação estatisticamente significativa, sendo que entre os trabalhadores com melhor desempenho houve maior prevalência de capacidade para o trabalho adequada do que entre aqueles com redução do desempenho.

Os dados quantitativos evidenciaram que o presenteísmo e os declínios dos índices de capacidade para o trabalho decorrem da sobrecarga de trabalho gerando elevados níveis de estresse e fadiga que conduzem ao adoecimento. No entanto, percebeu-se o esforço dos trabalhadores em manterem-se produtivos em virtude da apreciação e comprometimento com a profissão de enfermagem. 
6 DISCUSSÃO 



\section{DISCUSSÃO}

Os resultados desta pesquisa serão discutidos segundo a caracterização da população de estudo, na análise descritiva do presenteísmo e da capacidade para o trabalho, bem como, suas respectivas análises de associações. Em sequência, será discutida a análise qualitativa relativa aos resultados do grupo focal.

Com relação à participação no estudo, observou-se menor participação nas unidades pediátricas e pronto socorro adulto, nas quais o acesso para a abordagem dos trabalhadores foi mais difícil, devido à tensão no clima organizacional percebido pelo pesquisador.

A dinâmica de trabalho intensificada nas unidades assistenciais foi ocasionada pelo período de readequações nos processos de trabalho decorrente das exonerações de cargos advindas do Programa de Incentivo de Demissão Voluntária - PIDV que ocorreu ao final da coleta de dados dessa pesquisa. O PIDV ofereceu prioritariamente maiores vantagens para a saída dos trabalhadores com mais idade e mais tempo de serviço (Universidade de São Paulo, 2015).

\subsection{CARACTERIZAÇÃO DA POPULAÇÃO DE ESTUDO}

A caracterização dos sujeitos do estudo buscou identificar o perfil sociodemográfico e ocupacional.

Em conformidade com o cenário nacional, os resultados apontam predominância feminina na equipe de enfermagem, embora a categoria venha demonstrando aumento gradativo de profissionais do sexo masculino nas últimas décadas. A maioria dos participantes é casada e/ou vive com companheiro, enfatizando as características específicas do trabalho feminino, em que se observa maior privação social familiar da mulher trabalhadora (Machado et al., 2016, Elias, Navarro, 2006).

Percebe-se, no entanto, um esforço maior do gênero feminino no trabalho devido ao acúmulo de atividades atribuídas a mulher, pois quando a mesma inserese mercado de trabalho, muitas vezes acrescenta mais uma jornada a sua rotina diária. No caso de mulheres profissionais de enfermagem, a maioria submete-se ao 
trabalho em turnos diurnos e noturnos, finais de semana e feriados na área hospitalar, maior empregador do setor saúde, sendo que geralmente não se encontram serviços de creches e escolas disponíveis (Versa, Matsuda, 2014).

Outro fator de destaque, na relação de gênero e o mercado de trabalho, é a menor valorização do trabalho feminino. Constata-se que a maioria é empregada em ocupações de menor reconhecimento social e econômico, com trabalho informal e remunerações inferiores aos dos homens. Essa posição de desigualdade de gênero deixa a mulher em maior suscetibilidade aos riscos de adoecimento físico e mental pela sobrecarga de trabalho e, consequentemente, maior insatisfação (Versa, Matsuda, 2014; Instituto Brasileiro de Geografia e Estatística, 2013; Felli, Tronchin, 2010).

O perfil de faixa etária apresentado neste estudo, em que se encontrou 28,5\% dos participantes com até 35 anos de idade, diferencia-se do cenário nacional, pois atualmente nota-se o rejuvenescimento da força de trabalho da enfermagem no Brasil com 45,6\% do contingente de pessoal em idade até 35 anos. Esse perfil de rejuvenescimento também é observado pela formação, haja vista que um auxiliar e/ou técnico de enfermagem pode ingressar no mercado de trabalho aos 18 anos de idade, quando completa o nível médio de escolaridade (Machado et al., 2016).

No entanto, essa média de idade demanda por investimentos de promoção e manutenção da capacidade para o trabalho, pois após os 45 anos são observados declínios da capacidade funcional dos trabalhadores (Prochnow et al., 2013; Araújo, 2012). Os hábitos de vida saudável, o suporte familiar, os eventos socioculturais e a satisfação no trabalho melhoram a capacidade para o trabalho, promovendo a qualidade de vida após a aposentadoria (Helleshein, Lautert, 2012).

As variáveis relativas à renda familiar, escolaridade e algumas variáveis ocupacionais como: tempo de trabalho na instituição, na profissão de enfermagem, função exercida e jornada de trabalho, diferenciam-se do perfil da enfermagem no cenário nacional. Observa-se que os trabalhadores do cenário de estudo possuem níveis salariais e tempo de permanência na instituição e profissão maiores em relação à média nacional (COFEN, 2015).

O diferencial de perfil sociodemográfico e ocupacional pode ser explicado pelo excelente nível qualificação profissional desses trabalhadores, por exemplo, a maioria mesmo exercendo cargos com exigência de nível médio, possui formação 
de nível superior na área e, até mesmo, pós-graduação lato e stricto sensu. Assim, por meio de programa de acesso à carreira na instituição, alcançam melhores remunerações por meio de avaliação de desempenho profissional (acesso vertical) e, também, por tempo de serviço (acesso horizontal).

Nota-se que esses trabalhadores com alta qualificação, preferem permanecer em seus cargos de nível médio pelo incentivo financeiro, estabilidade no emprego e, muitas vezes, por proximidade de tempo para a aposentadoria, configurando segurança econômica (Chinelli, Vieira, Menezes, 2014). No entanto, há que se questionar a satisfação profissional desses trabalhadores e as políticas institucionais internas de promoção e readequação de função por mérito. Essa readequação é resultante dos avanços em formação/qualificação obtidos pela educação permanente.

Estudo realizado por Prochnow et al (2013) verificou que $45,6 \%$ dos técnicos/ auxiliares de enfermagem possuem nível superior de formação (graduação/ pós-graduação). Esses resultados se devem aos incentivos salarias advindos do plano de carreira da instituição em estudo, porém somente aumento de salário não é suficiente. É recomendável a alteração na função para que esses trabalhadores que investiram em melhor qualificação profissional possam atuar com maior autonomia e controle sobre o trabalho. Isso reduziria o desgaste psicológico, gerado pelo sentimento de indignação em executar atividades aquém de sua qualificação e pela falta de participação na tomada de decisão na equipe de trabalho (Prochnow et al., 2013, Hilleshein, Lautert, 2012).

Com características diferenciadas de emprego e carreira é possível inferir que melhores condições de vida e satisfação no trabalho são promotoras de saúde, fato este confirmado pela variável vínculo empregatício, em que 91,8\% dos sujeitos declararam ter apenas um vínculo. Esse resultado é muito distante do que observa no cenário nacional, conforme estudo a respeito da satisfação no trabalho entre técnicos de enfermagem apresentou maiores índices de insatisfação relacionados à baixa remunerarão, justificando a necessidade de procurar por mais de um emprego (Cofen, 2015; Renner et al., 2014).

O tempo de trajeto para o trabalho de mais de uma hora revelado pela maioria dos trabalhadores, característica comum nos grandes centros urbanos, demonstra aumento significativo de até 30\% da jornada de trabalho. Assim, quando um trabalhador atinge a metade do seu expediente pode apresentar sintomas de 
fadiga, redução dos níveis de atenção e consequente aumento dos riscos de acidentes de trabalho (Silva et al., 2016).

Pesquisa com trabalhadores de enfermagem, em diferentes instituições de saúde da Europa, revelou que a equipe de enfermagem prefere trabalhar em turnos alternados para ter mais dias em casa. No entanto, foi percebido o aumento da fadiga e redução da capacidade para aqueles que executam suas atividades profissionais em turnos prolongados. Tal pesquisa, recomenda a implementação de medidas gerenciais, com o objetivo de amenizar o impacto desse regime de trabalho na qualidade da vida desses trabalhadores ao longo dos anos e, também, para melhor garantir a segurança na assistência prestada à população (Estryn-Béhar et al., 2012).

No Brasil, tramita no Congresso Nacional, o projeto de lei 2.295/00, que há 15 anos vem aguardando votação para redução da jornada de trabalho da enfermagem para trinta horas semanais. $O$ controle da insalubridade, periculosidade e penosidade do trabalho em enfermagem se faz necessário para que a garantia da força de trabalho saudável e produtiva (Felli 2012).

No estado do Rio de Janeiro, já foi aprovada lei de descanso intrajornada para a equipe de enfermagem nos plantões de doze horas, com garantia de local apropriado nas dependências das unidades assistenciais (Rio de Janeiro, 2012). Em 2015, o Conselho Federal de Enfermagem propôs ao Senado Federal, projeto de lei que amplia esse direito de descanso para plantonista de enfermagem em todo o território nacional (Cofen, 2015).

Quanto a variável função, observou-se maior participação de pessoal de nível médio (técnicos e auxiliares de enfermagem) no trabalho assistencial que requer maior força física e aproximação dos pacientes. Os trabalhadores de enfermagem de nível médio foram os que apresentaram as maiores taxas de morbidades nos estudos de capacidade para o trabalho, presenteísmo e absenteísmo-doença nos estudos de Silva et al (2016); Oliveira et al (2014) e Vasconcelos et al (2012). Esses resultados são explicados pela intensa exposição desses trabalhadores às cargas de trabalho, pois executam a assistência direta ao paciente caracterizando, além de maior manipulação de peso em posições incômodas, um convívio muito próximo com os conflitos psicoemocionais, advindos das dinâmicas do cuidado de pessoas em situação de sofrimento (Karino et al., 2015). A exposição às cargas de trabalho geradores dos processos de desgaste 
pode gerar acidentes de trabalho e, também de forma gradativa, no adoecimento desses trabalhadores (Mininel et al., 2013).

Em relação ao setor de trabalho dos sujeitos, a maior participação neste estudo concentrou-se nos setores de UTI Adulto, Pronto Socorro Adulto, Clínicas Médica e Cirúrgica. Nas unidades de terapia intensiva, a assistência de enfermagem exige técnicas avançadas, observação constante, capacidade de julgamento e decisões precisas em curto espaço de tempo, além da alta exigência psicoemocional para tratar de pacientes em risco de parada cardiorrespiratória e morte. Observa-se, também, uma intensificação de exposição aos riscos de acidentes com agentes biológicos, químicos e ergonômicos (Frota et al., 2013). Devido à complexidade e dependência de cuidados de enfermagem a pacientes de terapia intensiva, o riscos ergonômicos para os trabalhadores são maiores nessas unidades e requer atenção especial quanto à movimentação e remoção desses pacientes para prevenir acidentes e lesões osteomusculares causadas durante esses procedimentos, necessitando de equipamentos especiais, trabalho em equipe, bem como, treinamentos permanentes quanto ao uso correto e posicionamentos adequados (Pasa et al., 2015).

Todavia, nas unidades de emergência, a superlotação faz com que os pacientes permanecem internados em macas nas unidades de pronto socorro de todo o País. Situação esta, muitas vezes, causada por falhas de comunicação entre as equipes multiprofissionais, dificuldades nas tomadas de decisões por ausência de padronização da assistência e, principalmente, pelo déficit de leitos hospitalares causando lentidão no fluxo de encaminhamento desses pacientes para as unidades de internação. Com base nessa realidade, é notória a sobrecarga de trabalho nessas unidades e inevitável repercussão na saúde do trabalhador, que se desdobra no atendimento da demanda reprimida de pacientes, que aguardam por transferência para as unidades de internação ou serviços de nível atendimento à saúde em alta complexidade das emergências. É comum no cotidiano desses trabalhadores, que são escalados para as emergências, se depararam com a necessidade de assumir também a assistência dessa demanda alocada em regime de internação, mas sem infraestrutura de acomodação para o paciente e muito menos, condições ergonômicas os profissionais (Mendes et al., 2012; Pai, Lautert, krug, 2011). 
Ademais, nas unidades de internação de adultos é cada vez mais frequente a intensidade de exposição às cargas de trabalho, devido ao grau de dependência dos pacientes, em decorrência do aumento da demanda de internações de pacientes idosos que passam, a cada ano, a consumir mais serviços hospitalares. Essa demanda tem tendência progressiva, dada à mudança do perfil demográfico e epidemiológico da população brasileira, em quese prevê maioria de idosos nas próximas décadas (Mendes et al., 2012).

Estudos alertam a respeito da sobrecarga dos trabalhadores de enfermagem em unidades emergenciais e de internação. As consequências dessa sobrecarga são mais evidentes na medida em que se observa aumento dos níveis de fadiga e comprometimento da produtividade. Ainda, essa sobrecarga evidenciaa baixa qualidade dos resultados da assistência prestada, que podem ser comprovadas pelos indicadores, tanto assistenciais, como gerenciais (Silva et al., 2016; Paschoalin et al., 2013; Vasconcelos et al., 2011).

Pesquisas a respeito de avaliação de riscos ocupacionais, mensuração de cargas de trabalho e análise de eventos adversos são cada vez mais frequentes no intuito de amenizar esse impacto, tanto na saúde do trabalhador, quanto na segurança dos pacientes (Pasa et al., 2015; Sancinetti et al., 2011). Estudo realizado no estado Pensilvânia, Estados Unidos da América, revelou associação entre a Síndrome de Burnout na equipe de enfermagem e as infecções de sítio cirúrgico e de trato urinário em pacientes de unidades de terapia intensiva. Os resultados do estudo demonstraram queda nos índices de infecção nos serviços e as intervenções em saúde do trabalhador conseguiram reduzir a Síndrome de Burnout em até 30\%, perfazendo economia hospitalar em até 69 milhões de dólares em um ano (Cimiotti et al., 2012).

Contudo, percebeu-se pela caracterização da população de estudo, que embora haja tendência de aumento entre a população masculina, a predominância do trabalho feminino na enfermagem, atrelado ao acúmulo de jornada pelas tarefas doméstica, cuidados dos filhos, elevado tempo de trajeto, trabalho em turnos e noturno. A média de idade 41.6 anos também chamou a atenção por diferenciar-se do perfil de rejuvenescimento desta categoria no cenário nacional e alertou para a necessidade de investimentos para a manutenção da capacidade para o trabalho. 


\subsection{ANÁLISE DESCRITIVA DO PRESENTEÍSMO}

Dos 379 trabalhadores de enfermagem participantes deste estudo, 228 $(60,2 \%)$ declararam não trabalhar na vigência de algum problema de saúde nos últimos trinta dias, portanto, não responderam ao SPS-6. Já os respondentes do SPS-6 somaram 151 (39.8\%) participantes e, desses, 90 (23,7\%) foram classificados com alto presenteísmo (melhor desempenho) e 61 (16,1\%) com baixo presenteísmo (redução de desempenho).

Observando esses resultados do SPS-6, percebe-se que a maioria dos trabalhadores que se declaram em situação de presenteísmo, manteve-se produtiva. Esses resultados podem ser explicados por estratégias de coping, nas situações em que os esforços cognitivos e comportamentais desses trabalhadores foram preservados, mesmo na vigência dos agentes estressores, que repercutiram em algum problema de saúde (Umann, Guido, Silva, 2014).

Os esforços dispendidos por essa parcela de presenteístas em permanecer no trabalho revela o comprometimento com 0 trabalho e a responsabilidade ética para manter a continuidade da assistência de enfermagem. Isto porque mesmo com estabilidade no emprego, não se afastaram do trabalho. Percebe-se, muitas vezes, a demonstração de maior preocupação com o paciente, em detrimento de seu próprio estado de saúde, fazendo o trabalhador permanecer no cumprimento de sua tarefa (Paschoalin, 2012).

No entanto, a longo prazo, trabalhar em situação de presenteísmo e estresse em ambientes desfavoráveis, conduz o trabalhador ao estado de fadiga crônica podendo evoluir para o esgotamento profissional e agravamento dos problemas de saúde. Esta situação os torna vulneráveis à redução do desempenho, ao absenteísmo por doença e até mesmo a aposentadoria por invalidez permanente (Demerout et al., 2009; Vasconcelos et al., 2012; Silva et al., 2016).

Os dados da investigação sobre presenteísmo realizada por Palha (2014), que aplicou o questionário SPS-6 em enfermeiros portugueses, corroboram com os resultados desse estudo. A autora destaca a dificuldade de concentração e o comprometimento psicológico dessa categoria profissional ao completar as tarefas de trabalho em situação presenteísmo. 
Quanto à avaliação das dimensões do presenteísmo, encontrou-se o melhor desempenho relacionado à dimensão física do presenteísmo e reduzido desempenho quanto à dimensão psicológica.

Os resultados deste estudo corroboram com os achados dos estudos recentes a respeito do presenteísmo em enfermagem, em similaridade ao resultado da avaliação das dimensões do presenteísmo, apontando para um maior desgaste psicológico dos trabalhadores ao conseguirem finalizar suas tarefas (Ferreira et al., 2010; Martinez, Ferreira, 2012; Paschoalin et al., 2013; Palha, 2014).

Segundo Flores-Sandi (2006), quando os trabalhadores encontram-se em dificuldade para manter os níveis de atenção necessária, os riscos de acidentes aumentam e a segurança dos pacientes fica comprometida. Ressalta, ainda, a responsabilidade dos gestores em saúde quanto à aplicação de medidas preventivas com vistas à reorganização dos serviços de saúde, tornando o ambiente e os processos de trabalho favoráveis a promoção da saúde do trabalhador e livre de riscos aos usuários.

O presenteísmo no cotidiano profissional da enfermagem configura situação alarmante em decorrência do aumento dos eventos adversos associados ao perfil de morbidade dos trabalhadores de enfermagem. Essa problemática afeta diretamente os indicadores de resultados dos serviços ameaçando a acreditação hospitalar nas instituições de saúde (Letvak, Ruhm, Gupta, 2012; Silva et al., 2015).

Em avaliação do presenteísmo em trabalhadores de enfermagem acometidos pela Síndrome de Burnout, foram percebidas interferências significativas na produtividade, com perdas que chegaram a até $27 \%$ das horas trabalhadas, em decorrência dos sintomas emocionais e dificuldade de concentração no trabalho (Hyeda, Handar, 2011). Os autores alertam que a problemática pode ser percebida nos conflitos interpessoais decorrentes do esgotamento profissional, porém ainda é pouco notada pela administração hospitalar, à medida que calculam a redução de produtividade pelo absenteísmo, verificada pela ausência no trabalho e calculada somente em dias de trabalho perdidos. 
Estudo americano revelou prevalência de depressão de 18\% nos trabalhadores de enfermagem e associação significativa com o aumento do número de quedas de pacientes, maior número de erros na administração de medicamentos e, consequentemente, poira na qualidade dos cuidados. Ainda, o custo totalizado com o presenteísmo por enfermeiro no ano aproximou-se de US\$ 9.000, com estimativa de custo de 13 bilhões de dólares para os Estados Unidos da América anualmente (Letvak, Ruhm, Gupta, 2012).

Todavia, pesquisa realizada no mesmo País, revelou associação entre a Síndrome de Burnout na equipe de enfermagem, as infecções de sítio cirúrgico e de trato urinário em pacientes de unidades de terapia intensiva. Os resultados deste estudo demonstraram queda nos índices de infecção de sítio cirúrgico e de trato urinário nos hospitais em que as intervenções em saúde do trabalhador conseguiram reduzir a Síndrome de Burnout em até 30\%, perfazendo economia para os hospitais participantes do estudo em de até 69 milhões de dólares em um ano (Cimiotti et al., 2012).

Em relação aos problemas de saúde apontados pelos participantes do presente estudo, os mais prevalentes e com grande destaque foram os distúrbios musculoesqueléticos referidos por $60.9 \%$ dos trabalhadores presenteístas, seguidos de: cefaleias e enxaquecas (13.9\%), distúrbios gastrointestinais (12.6\%), gripes e resfriados $(9,3 \%)$. Os transtornos mentais foram referidos por apenas $1.3 \%$ dos trabalhadores, o que demonstra dificuldade dos trabalhadores em revelar esses problemas, devido ao estigma que os problemas psicológicos causam. No entanto, os problemas de ordem mental aparecem em perda de produtividade na dimensão psicológica da SPS-6.

A relevância dos distúrbios musculoesqueléticos apresentados pode ser explicada pela sobrecarga de trabalho, já discutida no presente estudo. Resultados aproximados também foram encontrados em pesquisas recentes, nos contextos nacional e internacional (Paschoalin, 2012; Letvak, Ruhm, Gupta, 2012; Lima et al., 2014).

O estudo americano realizado na Carolina do Norte por Letvak, Ruhm e Gupta (2012) com 2500 trabalhadores de enfermagem revelou prevalência de dor musculoesquelética em $71 \%$ dos entrevistados. Os pesquisadores alertaram por maior atenção a saúde desses trabalhadores com vistas à manutenção qualidade assitência prestada. 
Estudo nacional encontrou dor musculoesquelética em $91.4 \%$ dos trabalhadores de enfermagem hospitalar, sendo as mulheres, técnicos e auxiliares de enfermagem e com mais de 14 anos na função, os trabalhadores que apresentararam dor em maior intensidade. Os autores sugerem participação ativa dos trabalhadores na reivindicação de melhorias nas condições de trabalho (Lima et al., 2013).

Em avaliação de sintomas osteomusculares relacionados ao trabalho em equipe de enfermagem de terapia intensiva, Martins (2011) relatou que todos os trabalhadores apresentaram dor algum momento laboral nos últimos doze meses e que realizavam prática de automedicação analgésica para conseguirem finalizar o trabalho e/ou conseguirem descansar após a jornada. Os entrevistados relacionaram os sintomas a manipulação excessiva de peso, posturas inadequadas e trabalho repetitivo. Esses sintomas se agravam à medida que não se encontra programação de pausas e descanso intra-jornada em ambientes adequados aumentando ainda mais a prevalência de fadiga no trabalho (Silva et al., 2016).

Todavia, a avaliação do presenteísmo nesse estudo revelou a sobrecarga de trabalho encontrada no ambiente laboral e os esforços desses trabalhadores para manter a produtividade no trabalho, em detrimento da saúde física e mental. A exemplo disso, revelou-se a prevalência dos distúrbios osteomusculares e esgotamento emocial com o problemas de saúde relacionados à queda de imunidade e distúrbios gastrointestinais.

A problemática do presenteísmo aqui exposta traduz sérias consequentências para a economia em saúde e, para com a qualidade de vida, tanto dos profissionais, quanto dos pacientes por eles assistidos. Portanto, a pesquisa avança na busca de melhor entender o fenêmeno do presenteísmo aplicando a avaliação do índice de capacidade no trabalho. 


\subsection{AVALIAÇÃO DA CAPACIDADE PARA O TRABALHO}

Os trabalhadores de enfermagem, sujeitos desse estudo, foram classificados com boa capacidade para o trabalho ao apresentar média do ICT de 39,1 pontos $(\mathrm{dp}=5,9)$, variando de 20,0 a 49,0 pontos e mediana de 40,0 pontos.

No entanto, ao dicotomizar a variável classificando-a como ICT Adequado (ótimo/ bom) e ICT Inadequado (moderado/ baixo), percebe-se que 38,3\% apresentaram ICT Inadequado. Assim, a discussão é focada no grupo de trabalhadores com ICT inadequado, segundo a recomendação do Finnish Institute of Occupational Health - FIOH (Tuomi et al., 2005) para investimentos em melhorias e recuperação da capacidade para o trabalho. Isto porque os trabalhadores incapacitados também comprometem a capacidade para o trabalho dos demais, pela sobrecarga de trabalho, suas repercussões negativas no ambiente laboral, além de contribuir para o aumento da rotatividade de pessoal (Prochnow, et al., 2013; Rongen et al., 2013; Silva et al., 2016).

A média de ICT, encontrada neste estudo, corrobora com pesquisas nacionais e internacionais e demonstra resultados limítrofes entre boa e moderada capacidade para o trabalho. Aponta assim riscos para o ICT inadequado, quando intervenções necessárias de acordo com os respectivos cenários, não são aplicadas corretamente (Vasconcelos et al., 2011; Hilleshein, Lautert, 2012; Magnago et al., 2013; Prochnow et al., 2013; Moreira, Silvino, Cortez, 2015; Silva et al., 2016).

O ICT inadequado foi encontrado no mesmo cenário por Silva et al (2016), em unidades de internação de clínica médica e cirúrgica, sendo este associado à fadiga, ao tempo de trabalho na instituição e à função de técnico de enfermagem. Os autores consideraram a necessidade de investimentos em melhorias nas condições de trabalho e monitoramento da saúde do trabalhador de enfermagem.

Pesquisa realizada em hospital de ensino da região metropolitana do Rio de Janeiro, também revelou valores na marca de ICT inadequado em trabalhadores de enfermagem com faixa etária entre 36 e 50 anos (média de 37,84 pontos). Considerando o declínio da capacidade laborativa após os 45 anos idade, foram propostas, além das ações de atenção à saúde do trabalhador, mudanças no 
processo de trabalho, embasadas no binômio saúde-trabalho (Moreira, Silvino, Cortez, 2015).

De acordo com os resultados encontrados por Mangnago et al (2013) em serviço hospitalar de emergência do interior do Rio Grande do Sul, 42,9\% dos trabalhadores de enfermagem apresentaram ICT inadequado. Os autores recomendam a utilização do ICT como um dos indicadores de saúde para avaliação e acompanhamento da capacidade para o trabalho, à medida que sinaliza à gerência a necessidade de tomada de decisões para intervir em condições trabalho. As autoras sugerem que medidas de promoção à saúde do trabalhador sejam aplicadas desde o início da formação profissional.

As altas exigências no trabalho aumentam as chances de redução da capacidade para o trabalho, segundo Prochnow et al (2013). Os autores encontraram alta demanda e baixo controle do trabalho em técnicos de enfermagem, que trabalham sobrecarregados e submetidos à pressão no cumprimento de suas tarefas, devido ao déficit de pessoal.

A avaliação da capacidade para o trabalho realizada por Hilleshein, Lautert (2012) somente com enfermeiros em hospital universitário demonstrou boa capacidade para o trabalho com 41.8 pontos, sendo que $88 \%$ apresentaram ICT bom ou ótimo e não houve ICT baixo. Esses valores elevados de ICT obtiveram correlação positiva com melhores condições ocupacionais, como melhor reconhecimento profissional e melhor convívio sócio familiar.

A prevalência de ICT inadequado em estudo com trabalhadores de enfermagem hospitalar na região norte brasileira foi de $40.8 \%$ e obteve como fatores associados: o sexo feminino, ter outro vínculo empregatício, número de funcionários insuficiente, tarefas repetitivas e monótonas, três ou mais morbidades sem diagnóstico médico e a percepção de fadiga elevada (Vasconcelos et al., 2011).

$\mathrm{Na}$ região nordeste, pesquisa de revisão da literatura a respeito da capacidade para o trabalho, desenvolvida na disciplina "Bases filosóficas e teóricas de enfermagem na atenção a saúde", do Programa de Pós-Graduação em Enfermagem da Universidade Federal do Rio Grande do Norte, contemplou periódicos entre os anos de 2005 a 2013. Os pesquisadores evidenciaram que, apesar de a maioria dos estudos a respeito do ICT em profissionais de enfermagem apresentar média de boa capacidade para o trabalho, ainda se faz relevante avaliar o grupo que compõe ICTs inadequados na busca de entender as características 
individuais e do trabalho, que podem afetar o grupo como um todo (Cossi et al., 2015).

No cenário internacional, na Ásia, pesquisa a respeito da capacidade para o trabalho e qualidade de vida realizada com 1534 trabalhadores de enfermagem de Taiwan referiu redução do ICT, relacionado às morbidades e às cargas mentais de trabalho entre os mais jovens e as cargas físicas entre os trabalhadores maiores de 45 anos. A capacidade de trabalho dos enfermeiros foi fortemente associada com a qualidade e segurança do ambiente de trabalho e gestão do tempo de lazer (Chiu et al, 2007).

Na Europa, o Nurse's early exity study (NEXT-Study), realizado por grupo interdisciplinar de pesquisadores que avaliou os motivos, circunstâncias e consequências pelo qual os trabalhadores tem deixado precocemente a profissão de enfermagem, observou em 10 países europeus, maior prevalência de ICT inadequado em trabalhadores acima de 45 anos. Porém, entre os jovens, esse mesmo estudo relatou intenção de abandono da profissão. A justificativa para esse abandono foi de que a idade lhes permitia maiores condições de readequação em outra profissão, bem como maiores oportunidades no mercado de trabalho. O estudo associou o impacto da reduzida capacidade para o trabalho aos problemas nos âmbitos da liderança e de relacionamento interpessoal, bem como valorização na carreira. Dada a escassez de trabalhadores de enfermagem na Europa, os pesquisadores alertam por melhoria da capacidade para o trabalho em todas as faixas etárias e maiores incentivos em evolução na carreira para a redução da rotatividade desses trabalhadores (Camerino et al, 2006).

A respeito da violência no trabalho em enfermagem, o NEXT-Study observou que dentre 39.894 trabalhadores de enfermagem, 22\% revelaram que, além de sofrer violência adivindas de pacientes e familiares, são também associados à violência, os altos níveis de pressão no tempo de exução do trabalho. $E$, consequemente, houve associação entre a violência e o esgotamento profissional, a intenção em deixar a profissão de enfermagem ou tentar exercê-la em outra instituição (Estryn-Behar et al, 2008).

Contudo, ao observar os resultados detalhadamente do presente estudo por meio das dimensões do ICT, nota-se que o declínio da capacidade para o trabalho se dá pelo adoecimento do trabalhador que, mesmo com queixas de limitações no desempenho, tenta evitar os afastamentos do trabalho. Dos agravos à 
saúde, 51,2\% revelaram duas ou mais doenças. Porém, a maioria desses trabalhadores revelou ter esperança em melhorias na capacidade para trabalho, buscando nos recursos mentais, a sustentação para manter-se apto ao trabalho, à medida demonstram apreciação pela profissão.

Esses dados também foram encontrados por Magnago et al (2013) ao avaliarem o ICT em trabalhadores de enfermagem em unidade de emergência. Revelam os autores que $33,3 \%$ dos trabalhadores declaram incerteza quanto à continuidade de suas aptidões, em decorrência do agravamento progressivo de suas condições de saúde e 25,4\% desses trabalhadores sentem a necessidade de diminuir o ritmo e/ ou mudar os métodos de trabalho.

Quanto aos agravos à saúde, 53,3\% apresentaram lesões por acidentes e as três situações com maior prevalência foram lesões nos braços/mãos, lesões nas costas e lesões nas pernas/pés. Além das lesões por acidentes identificou-se 35,6\% de doenças musculoesqueléticas, 22,2\% doenças respiratórias e 20,6\% doenças metabólicas ou endócrinas. Os distúrbios mentais perfizeram 14.2\% dos agravos à saúde.

De acordo com as doenças diagnosticadas, $26.1 \%$ apresentaram limitações na execução de suas atividades laborais e $48.5 \%$ precisaram ausentar-se do trabalho por motivo de doença. Dos que se ausentaram, 35.6\% obtiveram até nove dias de ausência, 7.3\% ausentaram-se num período entre 10 e 24 dias, 3.7\% entre 25 e 99 dias e 1.9\% entre 100 dias e um ano. As ausências por período indeterminado não foram contempladas, pois os trabalhadores nessas condições de afastamento não fizeram parte da pesquisa.

Os recentes estudos na mesma temática e que corroboram com os resultados da prevalência de doenças encontradas nesta pesquisa foram publicados por Sancinetti et al (2011); Carugno et al (2012); Ribeiro et al (2012); Vasconcelos et al (2012); Lima et al (2013); Silva et al (2015).

As lesões por acidentes, ocasionadas durante a dinâmica de trabalho da enfermagem, estão relacionadas com a exposição às cargas de trabalho. Os efeitos deletérios dessas traduzem-se em desgaste resultando em adoecimento nos relatos dos trabalhadores e, consequente na reduzida capacidade laborativa, queda da produtividade e afastamentos do trabalho (Laurel, Noriega, 1989; Sancinetti et al., 2011; Silva et al, 2015). 
Os achados de Lima et al (2013) também revelaram as doenças musculoesqueléticas entre as mais prevalentes em trabalhadores de enfermagem hospitalar. Estas doenças estão entre as principais causas de afastamentos por doença do trabalho e requerimento de auxílio-doença na previdência social brasileira.

Estudo de coorte desenvolvido na Suécia com trabalhadores jovens encontrou ICT inadequados associados ao baixo controle do trabalho e às influências negativas das demandas do trabalho na vida privada. Assim, o aumento do suporte social do trabalho entre os jovens apresentou-se como promotor do ICT (Bostrom, Sluiter, Hagberg, 2012). A reduzida capacidade para o trabalho entre os jovens prediz afastamentos por período prolongado no futuro fazendo-se necessário, além da avaliação do ICT, exames periódicos de saúde (Kujala et al, 2006).

Estudos nacionais e internacionais são apresentados majoritariamente em abordagens descritivas e, com frequência, destacam a necessidade de intervenções para a problemática da saúde do trabalhador. Todavia, ainda são incipientes os estudos que revelem fortes evidências de intervenções que mudem essa realidade (Ribeiro et al, 2012).

Segundo Vasconcelos et al (2012), são necessárias as intervenções pautadas na promoção da saúde e as com abordagem na reorganização do trabalho. A revisão dos processos de trabalho assistenciais da equipe de enfermagem e revisão da política institucional de gerenciamento de recursos humanos são propostos por Sancinetti et al (2011), que encontraram elevadas taxas de absenteísmo por doença no mesmo cenário do presente estudo.

Em síntese, os achados desse estudo demonstram boa capacidade para trabalho, porém um percentual de 38.3\% com ICT inadequado. E, nota-se que o declínio do ICT se dá pela sobrecarga de trabalho gerando elevados níveis de estresse e fadiga que conduzem ao adoecimento.

Todavia, percebe-se como fator preditivo de melhoria, o fato dos trabalhadores terem esperança na mudança dessa realidade e fazerem uso dos recursos mentais como o apreço pela profissão para manterem-se trabalhando sem presenteísmo.

Portanto, os achados apontados nessa discussão devem ser vistos como norteadores para a gestão e tomada de decisão, no que concerne às intervenções de melhoria das condições de trabalho. 


\subsection{A CAPACIDADE PARA O TRABALHO, O PRESENTEISMO E DEMAIS FATORES ASSOCIADOS}

A hipótese de associação entre a capacidade para 0 trabalho $\mathrm{e}$ presenteísmo foi comprovada nesse estudo. A melhor representação dessa associação estatisticamente significativa é comprovada pelos trabalhadores com melhor desempenho, que obtiveram maior prevalência de capacidade para o trabalho adequada do que entre aqueles com redução do desempenho comprovando associação.

Conforme apresentado na avaliação do ICT, a reduzida capacidade para o trabalho é percebida pelo desgaste físico e mental dos trabalhadores, em decorrência das características sociodemográficas e ocupacionais a que estão expostos.

Neste contexto, também na avaliação do ICT, verificou-se o absenteísmo, com afastamento significativo somente em curto período de tempo. A maior relevância dos achados sobre o presenteísmo revelam os esforços dos trabalhadores para completar as tarefas de trabalho, devido ao fato de estarem em exercício de suas atividades profissionais, mesmo com problemas de saúde.

Portanto, entende-se por esta análise que o fenômeno do presenteísmo é um sinal de alerta precoce para o declínio da capacidade. Também, sinaliza o aumento das chances de evolução para o absenteísmo e, até mesmo, para as situações incapacitantes que levam as aposentadorias por invalidez permanente (Silva et al., 2015).

$\mathrm{Na}$ indústria alimentícia foi relatada a perda de produtividade associada ao ICT inadequado com maior concentração nas linhas de produção do que nas áreas administrativas. Esse dado foi relacionado ao fato de que nas linhas de produção o trabalho é mais extenuante pela maior demanda física, trabalho mecanizado e repetitivo. Este estudo, considerado pioneiro ao relacionar ICT e presenteísmo, sugere este tipo de avaliação ocupacional como importante indicador para monitorar a produtividade no trabalho promovendo permanência saudável do trabalhador (Vanni et al., 2012). 
Os efeitos negativos do ICT inadequado sobre o desempenho no trabalho podem ser evitados com o maior controle do trabalho. Pesquisadores holandeses aconselham intervenções, entre os trabalhadores com doença crônica, dando-Ihes possibilidades de participação no planejamento do trabalho e no gerenciamento de suas próprias atividades no trabalho (Van den Berg et al., 2011).

No Brasil, estudo relacionando a capacidade para o trabalho, presenteísmo e absenteísmo realizado no setor bancário detectou a cultura do presenteísmo sustentada pela competividade no trabalho. A permanência no trabalho, mesmo em condições de saúde desfavoráveis, foi considerada pelos trabalhadores como forma de busca do reconhecimento profissional destacando-se pela assiduidade. Ademais, o presenteísmo foi relacionado à tentativa de assegurar o emprego em momentos de reestruturação produtiva, com demissões e recontratações por meio da terceirização da força de trabalho e que constituem a nova realidade do mercado de trabalho (Sasaki, 2013).

Em relação aos trabalhadores, aqueles com menor renda familiar e os mais jovens, apresentaram maiores percentuais de capacidade para o trabalho inadequada. Quanto menor a remuneração, piores são as condições sóciofamiliares, fato que leva os trabalhadores a submeterem-se, muitas vezes, a mais de um vínculo empregatício, elevando os níveis de fadiga e ameaçando a capacidade para o trabalho (Vanconcelos et al., 2011).

O perfil sociodemográfico da enfermagem com representatividade nacional, apresentado em recente estudo realizado pelo Conselho de Federal de Enfermagem, revelou o rejuvenescimento da categoria com 45,6\% em idade até 35 anos, 47,5\% em idade até 55 anos e, somente 6,9\% em idade acima de 56 anos (Machado et al., 2016).

Frente ao exposto, apesar do rejuvenescimento da enfermagem brasileira, tanto este estudo, quanto estudos no cenário internacional apresentaram resultados preocupantes relativos ao presenteísmo e aos ICTs inadequados associados ao estresse, à insatisfação, baixo controle e alta demanda de trabalho, além da demonstração da intenção de abandono da profissional por estas razões (Camerino et al., 2006; Chiu et al, 2007; Bostrom, Sluiter, Hagberg, 2012).

Observa-se, principalmente entre os trabalhadores mais jovens, que exercem a função de técnico e/ou auxiliar, mas que atingiram a formação superior e hoje são enfermeiros, ainda exercendo função abaixo de seu nível de qualificação 
profissional. Esta posição na carreira se traduz em insatisfação e desmotivação no trabalho e os trabalhadores nesta situação tem reivindicado programas nas instituições que os absorvam por meio de seleção interna tendo seus esforços reconhecidos (Bacha et al., 2015).

Estes trabalhadores investem parte seus salários e tempo de descanso e lazer para dar continuidade aos seus estudos. Muitos deles não têm interesse em deixar seus vínculos, pela segurança que a estabilidade do serviço público lhes oferece. É notório também, o desequilíbrio entre a falta de controle da abertura de vagas em faculdades privadas e a oferta de emprego no mercado de trabalho brasileiro (Bacha et. al, 2015; Fernandes, 2012).

No Brasil, dentre o contingente pessoal da saúde, a enfermagem atinge 1.804.535 profissionais de médio e superior, constituindo $50 \%$ da força de trabalho em saúde. Porém, percebe-se que apenas 6,9\% dos trabalhadores permanecem no mercado em idade superior a 55 anos. No tocante a escassez de trabalhadores com mais de 55 anos, se contradiz com as expectativas das políticas públicas de retenção dos trabalhadores por maior tempo de trabalho, em decorrência do aumento da expectativa de vida e na tentativa de sustentabilidade econômica do sistema previdenciário (Cofen, 2015).

Com relação ao comprometimento do ICT relacionado aos setores de trabalho no hospital, observou-se menor prevalência de capacidade para o trabalho adequada no ambulatório, clínica médica, pronto socorro adulto e pronto socorro infantil.

Em avaliação dos problemas de saúde da equipe de enfermagem alocada em ambulatório, Sápia, Felli e Ciampone (2009), encontraram alta frequência de exposição às cargas fisiológicas de trabalho, derivadas do esforço físico e associados à obesidade e problemas circulatórios. Já em setor de internação de clínica médica e cirúrgica, Silva et al (2016) verificaram ICT inadequados associados a fadiga no trabalho em $52 \%$ desses trabalhadores.

Nas unidades de emergência, o comprometimento do ICT foi observado por Magnago et al (2013) em 42.9 dos trabalhadores de enfermagem e as doenças diagnosticas mais prevalentes foram: infecções repetidas do trato respiratório, lesão nas costas; varizes; distúrbio emocional leve; problemas de visão e doença da parte superior das costas ou região do pescoço. As autoras sugeriram medidas de prevenção de incapacidades desde a formação profissional. 
Contudo, é notória a necessidade de se repenssar os rumos do desenvolvimento político da categoria Enfermagem no cenário mundial para a retenção e melhor compromentimento dos profissionais, de maneira que se contemple direitos trabalhistas mais equitativos frente ao mercado de trabalho em saúde.

As pesquisas, tanto a respeito da capacidade para o trabalho, quanto do presenteísmo, alertam a gestão dos serviços de saúde para monitoramento da saúde do trabalhador ressaltando, também, os investimentos em promoção da saúde dessa população, bem como melhorias nas condições de trabalho. Como resultados destes investimentos almeja-se melhor qualidade de vida e longevidade no trabalho e, consequentemente, a otimização da qualidade da assistência prestada à população.

Constatada a associação entre o ICT e o presenteísmo, assim como as consequências geradas na saúde dos trabalhadores e na assistência prestada, é imprescindível intervir nessa realidade. Para tanto, é importante que os gerentes de enfermagem conheçam essa realidade e sugiram intervenções, uma vez que são seus profundos conhecedores. Assim, inicia-se a discussão dos dados qualitativos do estudo com as propostas gerenciais de intervenção coletadas por meio do grupo focal. 

7 ANÁLISE QUALITATIVA DAS PROPOSTAS DE INTERVENÇÃO 



\section{ANÁLISE QUALITATIVA DAS PROPOSTAS DE INTERVENÇÃO}

A análise das falas dos gerentes permitiu conformar três categorias empíricas: Propostas relativas a dimensão Individual, Gerencial e Institucional, com os seus respectivos temas e unidades de registro selecionadas, conforme apresentamos no quadro abaixo.

Quadro 2 - Propostas relativas a dimensão individual, gerencial e Institucional.

(continua)

\begin{tabular}{|c|c|c|}
\hline Categorias & Temas & Unidade de Registro \\
\hline Individual & $\begin{array}{c}\text { Sensibilização } \\
\text { para adesão às } \\
\text { medidas de } \\
\text { proteção }\end{array}$ & $\begin{array}{l}\text { "... a gente tem que aperfeiçoar a utilização dos recursos e } \\
\text { isso nem sempre é bem aceito pela equipe." } \\
\text { "A utilização de alguns recursos como o "Jack" (elevador } \\
\text { de pacientes) para a gente fazer a transferência do } \\
\text { paciente (...) as camas elétricas que vieram e isso foi muito } \\
\text { favorável para todos porque a cama sobe na sua altura e } \\
\text { você não precisa ficar se abaixando." } \\
\text { "... tem que trabalhar essa questão com a equipe para } \\
\text { utilizar os recursos existentes da melhor forma porque o } \\
\text { passante é uma coisa simples e fácil, mas tem gente que } \\
\text { tem resistência e prefere arrastar o paciente." }\end{array}$ \\
\hline Gerencial & $\begin{array}{c}\text { Gestão e } \\
\text { liderança para } \\
\text { cultura de } \\
\text { segurança no } \\
\text { trabalho }\end{array}$ & $\begin{array}{l}\text { “... a gente tem que se organizar para haver cooperação e } \\
\text { não sobrecarregar o grupo." } \\
\text { "É importante o enfermeiro assistencial olhar se aquele } \\
\text { funcionário está sobrecarregado ou não (...) o que vejo } \\
\text { como importante no trabalho em equipe são as reuniões na } \\
\text { tentativa de pontuar as dificuldades." } \\
\text { "Depois dessa reunião, a gente tem que ter outra reunião } \\
\text { com os técnicos e falar olha, a gente tem discutido isso, a } \\
\text { gente quer melhorar e estamos juntos com vocês" } \\
\text { "Agente tem que buscar uma maneira diferente de fazer as } \\
\text { coisas (...) achar uma estratégia para mudar a cultura } \\
\text { organizacional." } \\
\text { "O líder tem influência para reverter essa situação, } \\
\text { mostrando outra forma de pensar... Ele tem condições de } \\
\text { levantar a equipe. Ė difícil, mas acho que seria um começo } \\
\text { e dá pra fazer em curto prazo e com baixo custo..." } \\
\text { "Capacitação dos enfermeiros para gerenciar os conflitos } \\
\text { gerados nas escalas de trabalho." }\end{array}$ \\
\hline
\end{tabular}


(continuação)

\begin{tabular}{|c|c|c|}
\hline Categorias & Temas & Unidade de Registro \\
\hline Institucional & $\begin{array}{l}\text { Os recursos } \\
\text { disponíveis na } \\
\text { universidade } \\
\text { como estratégia } \\
\text { de mudança }\end{array}$ & $\begin{array}{l}\text { "E, uma escala de trabalho com condições para tirar essa } \\
\text { pessoa, ter uma substituição para que naquele dia a } \\
\text { pessoa consiga fazer uma hora de alongamento ou uma } \\
\text { hora meditação..." } \\
\text { "Enquanto universidade, temos a faculdade de educação } \\
\text { física, há muitos recursos aqui." } \\
\text { "A gente tem educação física, fisioterapia, tem terapia } \\
\text { ocupacional, a gente tem tudo. Alguma coisa a gente tem } \\
\text { que fazer..." } \\
\text { "E, numa esfera mais elevada, trazer um programa aqui } \\
\text { seria bom para melhorar as condições no trabalho..." } \\
\text { "...mapeando as atividades, olhando manipulação de peso, } \\
\text { macas porque lá, meu pessoal está com quase } 30 \% \text { de } \\
\text { restrição" } \\
\text { "Obtivemos resultados grandiosos com a presença da } \\
\text { terapeuta ocupacional e poderia ser repetido em todos os } \\
\text { setores, né?" }\end{array}$ \\
\hline
\end{tabular}

Assim, passamos a discutir as categorias empíricas, segundo os temas e as unidades de registros.

Primeira categoria: Propostas relativas à dimensão Individual

Nessa categoria, o principal tema abordado pelos gerentes foi a necessidade dos trabalhadores mudarem as suas próprias atitudes e, portanto o tema: "Sensibilização para adesão às medidas de proteção"

Observou-se inicialmente um clima de receio ao expressar a própria opinião a respeito de uma situação que parecer ser velada nos setores. No entanto, o grupo foi se descontraindo e a maioria manteve-se participativa durante todas as reuniões. Todavia quando o grupo em fim desinibiu-se, por vários momentos e, em todas as reuniões pode ser percebido pelo pesquisador e seus observadores que os gerentes tinham a necessidade de falar em forma de desabafo quanto a postura dos trabalhadores. Os gerentes demonstraram que muitos dos trabalhadores quando se queixam de problemas de saúde relaciona-os somente com as condições de trabalho. Porém, segundo os gerentes, esses trabalhadores não apresentam soluções voltadas para mudanças em suas próprias atitudes, seja nos hábitos de 
vida saudável ou na dinâmica de trabalho. No entanto, percebe-se falta de atitude própria do trabalhador no enfrentamento da situação, acrescido da tentativa de sempre apontar a instituição como única culpada do seu adoecimento.

Em relação aos hábitos de vida, temos que:

...onde eu trabalho tem bastante gente com essas limitações por tendinite, LER, DORT. (...) são sedentárias, não fazem atividades físicas e elas querem que o médico vá lá e faça intervenções e, vá curá-las. Você precisa fazer caminhadas, alongamentos e elas acabam não indo, né! Acho mais difícil você mudar a cultura, como as pessoas pensam... (G1)

Eu tenho bastante gente com restrição por problemas posturais. (...) Antes elas até iam para uma academia depois do plantão, mas agora com essa coisa de prioridades umas de manhã, outras à tarde ou à noite, aí já nem vão mais e até pela sobrecarga que o pessoal tem tido, estão cansados mesmo, meio desmotivados... (G5)

Eu acho que essa mudança de comportamento é bem difícil, por que geralmente é isso que acontece, quando se fala que vai haver meditação, mesmo quando teve terapias florais achamos que a procura seria enorme, mas não... E o pessoal fala, eu dediquei tanto de trabalho aqui, me desgastei aqui e a instituição é que tem que restaurar e não é só isso, né? (G6)

$\mathrm{Na}$ perspectiva dos gerentes e em relação à dinâmica de trabalho é considerada a passividade dos trabalhadores frente aos problemas apresentados e a culpabilização da instituição, isentando-se de qualquer responsabilidade, a exemplo do uso dos equipamentos que evitam o desgaste do trabalhador, como denota a fala a seguir.

A utilização de alguns recursos como o Jack (elevador de pacientes) para a gente fazer a transferência do paciente..." (...) tem que trabalhar essa questão com a equipe para utilizar os recursos existentes da melhor forma porque o passante é uma coisa simples e fácil, mas tem gente que tem resistência e prefere arrastar o paciente". "(...) e, as camas elétricas que vieram isso foi muito favorável para todos porque a cama sobe na sua altura e você não precisa ficar se abaixando. (G2)

Em estudo de revisão integrativa da literatura sobre os distúrbios osteomusculares relacionados ao trabalho em profissionais de enfermagem, Lelis et al (2012), recomendam investimentos em programas preventivos e educação em saúde. A utilização de recursos da internet tem apresentado resultados satisfatórios em programas de promoção da saúde com os temas de bem estar, gestão do estresse, alimentação saudável e controle de peso, bem como, fomentar a prática de 
atividade física com recursos que poderiam ser disponibilizados pela própria instituição (Cook et al, 2007).

Quanto à utilização dos equipamentos disponíveis, estudo sobre os investimentos em ergonomia relatam a importância dos treinamentos periódicos e, incentivos diários à correção postural e à utilização desses equipamentos para a redução da exposição às lesões musculoesqueléticas (Tompa, Dolinschi, Natale, 2013).

A partir das falas dos gerentes e com vistas aos achados na literatura percebe-se a necessidade de enfrentamentos relativos à adoção de hábitos de vida saudável e, também, às mudanças na dinâmica de trabalho. É fato que esses postos de trabalho possuem ferramentas suficientes para o início da transformação dessa realidade. Entretanto, é reconhecida a demanda de um esforço coletivo para a transformação desse cenário, com base na percepção da necessidade de readequação comportamental dentro da própria equipe.

Segunda categoria: Propostas relativas à dimensão gerencial

Observou-se nas falas e expressões durante as reuniões, certa dificuldade dos gerentes em administrar esse conflito, sendo fortemente visível quando, ao invés de aparecerem mais propostas de intervenção aos problemas, obtiveram-se mais queixas dos desafios e dificuldades em gerenciar setores de trabalho com elevados índices de presenteísmo e de capacidade inadequada para o trabalho.

Vale ressaltar que houve também apontamentos entre alguns gerentes no tocante ao despertar de um perfil de liderança frente à prevenção do presenteísmo por meio da promoção da saúde do trabalhador e revisão dos processos de trabalho com tendência a liderança participativa. Muitos acreditam que trazendo o trabalhador a partilhar da busca de resolução para os problemas das condições de trabalho, também poderia facilitar o enfrentamento à medida que fossem notando suas próprias atitudes tanto dentro da dinâmica de trabalho, como na vida pessoal.

Ademais, foram reconhecidas pelos gerentes certas lacunas de comunicação entre as equipes interdisciplinares dentro da própria instituição podendo ser um elemento que dificulta a utilização de recursos da própria instituição para resolver a problemática posta em debate no grupo focal. 
Nessa categoria, os gerentes consideram a necessidade da gestão e liderança para formar uma cultura de segurança no trabalho, como revelam as propostas a seguir.

\begin{abstract}
O líder tem influência para reverter essa situação, mostrando outra forma de pensar... Ele tem condições de levantar a equipe (...) tem umas quatro ou cinco fazendo pilates lá, e elas já se conscientizaram que já tem idade e precisam fazer, e isso acaba de certa forma elevando a autoestima da equipe. (G3)
\end{abstract}

Depois dessa reunião, a gente tem que ter outra reunião com os técnicos e falar, olha, a gente tem discutido isso, a gente quer melhorar e estamos juntos com vocês. (G10)

O que vejo como importante no trabalho em equipe são as reuniões na tentativa de pontuar as dificuldades (...) o grupo fica mais tranquilo quando a gente se conversa (...) é importante o enfermeiro assistencial olhar se aquele funcionário está sobrecarregado ou não... (G4)

\footnotetext{
A gente precisa achar uma estratégia para mudar a cultura organizacional... capacitação dos enfermeiros para gerenciar os conflitos gerados nas escalas diárias de trabalho." (G4)

É muito importante que do enfermeiro líder a forma como ele supervisiona a equipe e lidera a equipe para distribuir as atividades (G7)
}

Diante da dificuldade dos trabalhadores assumirem alguns hábitos de vida que os ajudariam a enfrentar os problemas de saúde, os gerentes também consideram a que poderiam incentivá-los por meio da liderança. As ações de liderança visam a formação de equipes com todas as categoria de trabalhadores para reverter esse comportamento dos trabalhadores.

São encontrados nas bases de dados de literatura fatores de desencadeamento de doenças ocupacionais na profissão de enfermagem que permeiam a interdisciplinaridade e multidisciplinaridade. Os investimentos em ergonomia e melhoria do ambiente laboral devem ser revistos tanto pela gestão como pelo trabalhador que necessita sensibilizar-se no intuito do autocuidado da própria saúde que muitas vezes passa despercebido, focando-se no atendimento ao paciente e esquecendo-se de si próprio (Teixeira, Casanova, Silva, 2014).

Segundo Reinhardt e Fischer (2009) estudando as barreiras relativas às intervenções em saúde do trabalhador encontraram programas sem embasamentos teóricos adequados, falhas de comunicação e envolvimento insuficiente da gestão dos serviços. As autoras recomendaram educação permanente para a prevenção de 
acidentes e doenças, com treinamentos específicos de acordo com a realidade de cada setor. Ainda, reforçam que um programa em saúde do trabalhador, para ser eficaz, necessita ser parte integrante da própria gestão.

É reconhecida a liderança do enfermeiro nas redes de relacionamento da equipe de saúde. Esta característica é potencializada no planejamento, incentivo e direcionamento de ações interventivas na dinâmica de trabalho multiprofissional (Lanzoni, Meirelles, 2013).

Assim, o enfermeiro líder, em suas unidades de trabalho pode interferir na reorganização dos processos de trabalho, reeducando sua própria equipe quanto à correção da mecânica corporal e, fazendo também a supervisão do uso correto dos equipamentos durante a assistência, haja vista, que já pratica supervisão no que concerne a execução das técnicas dos procedimentos de enfermagem.

Segundo Rocha e Felli (2004), a gestão participativa e os investimentos em educação, de maneira que proporcione a emancipação dos trabalhadores, são contributos para reorganização dos processos gerenciais a ponto de atingir a melhorias nas condições de trabalho.

Pesquisa baseada em evidência identificou que as melhores intervenções em programas de promoção da saúde no ambiente de trabalho apontam a liderança e o gerenciamento de riscos à saúde como as mais bem sucedidas no combate ao presenteísmo. Os fatores de risco mais identificados estavam relacionados ao sedentarismo, a má alimentação, manipulação excessiva de peso, elevados níveis de estresse e aos problemas de relacionamento interpessoal (Cancelliere et al, 2011).

Ademais, é considerado como elementos de formação de indicadores de qualidade do gerenciamento de recursos humanos em enfermagem, a satisfação e a motivação, resultantes do reconhecimento profissional, bem como, as situações intervenientes do trabalho que levam ao adoecimento e, consequentemente, ao aumento da rotatividade e do absenteísmo doença (Kurcgant et al, 2009).

Os programas de intervenção com foco na promoção da saúde do trabalhador e as melhorias nas condições de trabalho requerem seguimento de avaliação longitudinal. Essas intervenções devem atingir como resultado, trabalhadores sensibilizados quanto às mudanças de comportamento, relativos aos hábitos de vida saudáveis e a adesão às medidas de proteção individual no ambiente laboral (Alvares, Figueira Júnior, Deliberato, 2010). 
Além dos investimentos em intervenções implantados coletivamente, segundo Fischer et al (2005), faz necessário a acompanhamento individual para aqueles trabalhadores com reduzido desempenho. A aplicação de uma avalição do ICT poderá ser realizada por meio de encaminhamento para consulta de enfermagem ambulatorial.

Os trabalhadores encaminhados para o ambulatório requerem avaliação sigilosa e detalhada de todas as dimensões do ICT para que se possa estabelecer junto ao próprio trabalhador um plano individualizado de ação para melhorar e até mesmo restaurar a capacidade para o trabalho e, muitas vezes, são requisitados acompanhamentos da equipe multiprofissional. São também recomendadas ações que devem ser executadas pelo próprio trabalhador ou dirigidas à readaptação das atividades de trabalho que podem ser temporárias ou definitivas (Fischer et al, 2005).

Contudo, é possível apreender, tanto nas falas dos gerentes como na literatura, o quão importante e impreterível é participação do líder para que a implementação de intervenções para que os programas de saúde do trabalhador sejam eficazes. Haja vista que a incorporação do conhecimento recebido nos treinamentos, em quaisquer modalidades dos procedimentos de enfermagem, a ergonomia e a prevenção de acidentes devem ser contempladas, preservando-se assim a cultura de segurança.

Terceira categoria: Propostas relativas à dimensão Institucional

Nessa categoria, os gerentes consideram que existem recursos da instituição que podem ser acionados, visando a melhoria da saúde dos trabalhadores. As propostas dos gerentes para esta categoria foram construídas na intenção de serem encaminhadas aos superiores hierárquicos por considerarem-se estes, com governabilidade suficiente para implantação, controle e avaliação.

E, numa esfera mais elevada, trazer um programa aqui seria bom para melhorar as condições no trabalho..." "Enquanto universidade. (...) há muitos recursos aqui." "A gente tem educação física, fisioterapia, tem terapia ocupacional, a gente tem tudo. Alguma coisa a gente tem que fazer... (G3) 
Obtivemos resultados grandiosos com a presença da terapeuta ocupacional e poderia ser repetido em todos os setores, né? (G7)

Acho que o primeiro ponto seria identificar essas pessoas e ter apoio para um programa na saúde do trabalhador com estratégias efetivas como as oficinas. E, uma escala de trabalho com condições para tirar essa pessoa, ter uma substituição. (G4)

O suporte de uma equipe de especialistas com seu embasamento técnico-científico, bem como as parcerias com as demais unidades de ensino da universidade, muito podem contribuir para programas de êxito. Em contrapartida essas unidades de ensino poderiam usufruir de um cenário mais propício como campo de prático para os estágios de seus alunos.

Com relação ao suporte necessário para os gerentes, nota-se a necessidade de maior vigilância na saúde do trabalhador e controle do ambiente de trabalho. Segundo Carneiro (2006), os esforços do serviço de medicina ocupacional são diminutos e seus recursos se detêm preferencialmente às consultas médicas nos processos de exame admissional e demissional, consultas médicas periódicas obrigatórias e, pouco se vê a atuação do serviço de saúde ocupacional juntamente às estações de trabalho.

Estudo realizado por Santana (2013) inclui a consulta de enfermagem dentre as estratégias de intervenções à saúde do trabalhador. A autora enaltece o meio do monitoramento saúde do trabalhador para a construção de indicadores de saúde que orientem as intervenções no ambiente de trabalho.

Com base no exposto, os gerentes consideram que é pertinente 0 empenho dos trabalhadores em mudanças dos hábitos de vida; melhora da supervisão e da liderança relativas à adoção de posturas corretas no exercvício das atividades, no uso adequado dos equipamentos que economizam forço físico na manipulação de peso; e da instituição na implantação de um programa de saúde e segurança no trabalho.

No entanto, a governabilidade para o firmamento de tal compromisso caberia aos dirigentes das instituições envolvidas. De acordo com seus respectivos departamentos, é sugerida pelos gerentes a formação de parcerias para implantação e ações interinstitucionais efetivas entre faculdades da área da saúde como: Fisioterapia, Psicologia, Educação Física, Terapia Ocupacional, Nutrição, Enfermagem e Medicina e, a plataforma de ensino, hospital universitário. É fato que 
as tais faculdades elencadas já utilizam o hospital universitário como campo de estágio, mas é perceptível que nas propostas dos gerentes essa relação poderia ser ampliada e direcionada aos programas de segurança e saúde no trabalho.

A troca de experiência interdisciplinar e a identificação das necessidades de saúde e de reorganizações que envolvem o processo de trabalho e o ambiente são contributos acadêmicos de mais valia para as unidades assistenciais. Como resultado dessas parcerias, encontra-se a articulação entre universidades, o SUS e os movimentos sociais com fortes contribuições para o desenvolvimento dos trabalhadores, engajados na práxis da promoção saúde do trabalhador e saúde ambiental (Pontes, Rigotto, 2014).

Há que se considerar a contribuição das relações multiprofissionais na capacitação do enfermeiro em gerenciamento de recursos humanos. O gerente de enfermagem, além das interações estabelecidas com a própria equipe de enfermagem, está envolvido com os demais profissionais da área da saúde e da administração hospitalar. Esse convívio traduz-se em competências gerenciais que vão além da dimensão técnico-científica atingindo as dimensões ético-políticas e socioeducativas (Kurcgant, Massarolo, 2010).

Ademais, pesquisadores croatas reforçam a necessidade de incentivos referentes à comunicação saudável entre os enfermeiros e outros profissionais de saúde (Soric et al, 2013). Os autores sugerem a formação de equipe interdisciplinar para a gestão de conhecimento e competências para a melhoria das condições de trabalho.

A exemplo dessas parcerias multiprofissionais, Telles et al (2015) relata excelentes resultados da experiência com a realização de workshop para a promoção da qualidade de vida no trabalho. O evento foi idealizado por um grupo de estudo do hospital composto por profissionais de enfermagem, terapia ocupacional, fisioterapia, bem como, docentes e alunos de instituições parceiras. Destacou-se, as lacunas de conhecimento dos trabalhadores sobre o tema, a oportunidade de discussão da problemática e sensibilização dos trabalhadores para melhoria das condições de trabalho com o engajamento dos diversos atores sociais envolvidos nesse contexto.

Contudo, conforme acordo no grupo, pretende-se que a implantação das propostas de intervenção se dê por meio de oficinas de treinamento com simulação da realidade, formação de grupos de discussão da problemática por setor, para 
mudanças nos processo de trabalho e, encaminhamentos de propostas gerenciais e das reivindicações dos trabalhadores para os níveis hierárquicos competentes, de acordo com a seleção de intervenções por governabilidade.

Constatou-se que as reuniões do grupo focal foram consideradas a etapa inicial das estratégias gerenciais de intervenção por ter permitido o encontro inédito entre os gerentes para discutir especificamente a problemática do presenteísmo, realidade marcante nas unidades assistências de enfermagem. Os próprios gerentes expressaram a expectativa de continuidade desses encontros e, à medida que as intervenções sejam implementadas, poder-se-á avaliar também os resultados.

Estudo realizado por Minenel e Felli (2007), revelaram a preocupação, lacunas de conhecimento e dificuldades na tomada de decisão para a implantação de intervenções gerenciais oriundas de restrições de governabilidade no nível institucional. Ainda, as autoras recomendam disponibilização de recursos e empoderamento dos gerentes para a execução de medidas interventivas.

Contudo, segundo Camelo et al (2014), a gestão democrática proporciona a participação dos envolvidos e maior satisfação, aumentando as chances de êxito na reorganização dos processos de trabalho. Ressaltam, ainda, que para a redução do impacto dessa problemática na saúde dos trabalhadores é necessário o reconhecimento e comprometimento na reorganização do trabalho pelos dos gestores das instituições de saúde.

\subsection{AS PROPOSTAS DE INTERVENÇÃO VALIDADAS}

\section{Gestão de saúde e segurança no trabalho em enfermagem}

\section{Propostas gerenciais para implantação de intervenções}

A análise das propostas de intervenção, relativas à melhoria da saúde dos trabalhadores de enfermagem, construídas com os gerentes de enfermagem das unidades assistenciais do Hospital Universitário da USP e validadas pela literatura, são descritas a seguir. Essas propostas são apresentadas considerando as categorias empíricas do estudo, ou seja: propostas relativas às dimensões individual, gerencial e institucional. 


\section{Tema: Sensibilização para a adesão às medidas de proteção}

As propostas estão pautadas na conscientização da necessidade mudança comportamental, referente à promoção da saúde e segurança no trabalho como:

- Incentivar a adoção da prática de exercícios físicos; esporte e lazer;

- Motivar o ingresso aos programas de reeducação alimentar;

- Aplicar treinamento e supervisão para uso correto dos equipamentos disponíveis para a movimentação e transferência de pacientes;

- Encorajar o agendamento de consultas e exames periódicos na medicina do trabalho;

\section{Propostas relativas à dimensão gerencial}

\section{Tema: Gestão e liderança para cultura de segurança no trabalho}

Capacitação dos enfermeiros em gerenciamento de conflitos existentes frente ao presenteísmo:

- Incentivar os enfermeiros ao ingresso nos grupos de estudos sobre a temática da gestão de pessoas, qualidade de vida, saúde trabalhadores e afins.

- Agendar reuniões com reunião equipe de enfermagem de suas respectivas unidades para discussão dos problemas relativos ao processo de trabalho, captação de sugestões e encaminhamentos com base no planejamento estratégico situacional (PES);

- Formar grupos de terapias complementares para gerenciamento do estresse no trabalho e prevenção de DORT'S (Grupo de relaxamento, meditação, psicoterapia grupal, etc...);

- Treinar os enfermeiros para prevenção de incapacidades no ambiente laboral;

- Orientar os trabalhadores quanto à busca por tratamento de reabilitação nos casos de incapacidade para o trabalho;

- Capacitar os enfermeiros em consulta ambulatorial para de avaliação da capacidade para o trabalho em parceria com a Escola de Enfermagem. 


\section{Propostas relativas à dimensão institucional}

Tema: Os recursos disponíveis na universidade como estratégia de mudança

- Contratos interunidades de ensino

- Formalizar convites entre as faculdades de ciências da saúde que utilizam o Hospital Universitário como campo de estágio para a participação da elaboração, implantação e avaliação contínua de programa de intervenção em saúde e segurança no trabalho;

- Institucionalizar de programas de saúde e segurança do trabalhador do Hospital Universitário;

- Ampliar o Serviço Especializado em Engenharia de Segurança e em Medicina do Trabalho (SESMT);

- Readequar os postos de trabalho embasados nos aspectos da ergonomia;

- Aperfeiçoar a gestão de pessoas com vistas ao dimensionamento de pessoal que contemple a possibilidade de reabilitação de pessoal incapacitado;

- Fomentar pesquisas em gerenciamento de recursos humanos e gestão da qualidade de vida para a obtenção da longevidade no trabalho. 
8 CONCLUSÃO 

O presente estudo foi idealizado com a finalidade de melhoria das condições de trabalho e saúde dos trabalhadores de enfermagem. Almejou ainda, o atendimento às expectativas governamentais de maior longevidade no trabalho em consonância com o aumento da esperança de vida da população.

Primeiramente, o objetivo foi verificar os índices de capacidade para o trabalho e presenteísmo, bem como, a associação entre os mesmos; assim como a construção de propostas de intervenções junto aos gerentes de enfermagem.

Desenvolvido em hospital público de ensino com trabalhadores ligados diretamente à assistência de enfermagem, obteve-se a participação da maioria $(73,4 \%)$ dos trabalhadores, com destaque para pessoal das unidades de atendimento aos pacientes adultos. Os resultados relativos aos dados quantitativos, identificaram a situação de presenteísmo em 38,9\% dos trabalhadores, sendo o melhor desempenho observado na dimensão física em relação a dimensão psicológica. A avaliação do presenteísmo revelou o esforço desses trabalhadores para finalizar suas tarefas de trabalho, mesmo em decorrência de problemas de saúde física e/ou mental.

Quanto à capacidade para o trabalho, verificou-se bons índices para a maioria, no entanto $38,3 \%$ de capacidade para o trabalho inadequada foi identificado, dado que direcionou o foco da discussão dos resultados para este grupo, segundo as recomendações da literatura explorada sobre a temática.

Dentre os problemas de saúde mais prevalentes encontrados, tanto na avaliação do presenteísmo, quanto da capacidade para o trabalho, foram os distúrbios osteomusculares, gastrointestinais, respiratórios e os distúrbios emocionais como ansiedade e depressão. Portanto, é passível de inferência que o presenteísmo e as incapacidades para o trabalho se manifestam pelo adoecimento dos trabalhadores e se relacionam aos fatores psicossociais e às condições de trabalho.

A associação do presenteísmo e da capacidade para o trabalho foi estatisticamente comprovada e mais percebida pelos trabalhadores com melhor desempenho, que obterem maior prevalência de capacidade para o trabalho adequada do que aqueles com redução do desempenho.

O dado de absenteísmo revelado foi somente em curto período de tempo. A maior relevância dos achados sobre o presenteísmo revela os esforços dos 
trabalhadores para completar as tarefas de trabalho e demonstra o apreço e responsabilidade dos mesmos para com a profissão.

Todavia, o fenômeno do presenteísmo e as incapacidades identificadas chamam a atenção da gestão hospitalar para a vigilância à saúde dos trabalhadores de enfermagem. Trabalhadores adoecidos podem atingir índices elevados de presenteísmo e absenteísmo e prejudicar a qualidade dos serviços de saúde.

Os dados qualitativos captados no grupo focal resultaram em três categorias, nas dimensões individual, gerencial e institucional. Foram elaboradas as propostas de intervenções embasadas em temas que envolvem as mudanças atitudinais do próprio sujeito em relação à sua própria saúde como hábitos de vida saudável e mudança de comportamento, frente às medidas de proteção no ambiente de trabalho.

Por conseguinte, foi consensualizado entre os gerentes a necessidade de reorganização do processo de trabalho e a motivação dos líderes, em prol da cultura de segurança. Foi proposto o planejamento de treinamentos periódicos relativos à saúde e segurança no trabalho, contando com os enfermeiros no papel de multiplicadores.

Dentre as dificuldades encontradas durante a coleta de dados, observouse maior perda de participantes devido à sobrecarga e ao ritmo acelerado de trabalho acarretado pelo programa de incentivo à demissão voluntária, que ocorreu durante a coleta de dados. Esse episódio inédito e histórico na instituição também pode ter causado algum viés de resultado no estudo, em decorrência desse programa ter dado preferências às demissões dos trabalhadores com mais idade e maior tempo de serviço na instituição.

Considera-se, ainda que os gerentes podem contar com a contribuição institucional para a utilização dos recursos da universidade para a melhoria da comunicação intersetorial. Isso pode ocorrer mediante o estabelecimento de ampliação do hospital como campo de estágio, para as faculdades de ciências da sua saúde e afins, que atendam a temática da saúde ocupacional.

Vale ressaltar que as propostas de intervenção, elencadas pelos gerentes, têm potencial para a mudança dessa realidade no cenário de estudo. Também sugerem temas para futuros projetos de pesquisa que contemplem a interdisciplinaridade. 
9 REFERÊNCIAS 



\section{REFERÊNCIAS}

Alavinia SM, Boer AGEM, Van Duivenbooden JC, Frings-Dressen, Burdorf A. Determinants of work ability and its predictive value for dasability. Occupational Medicine. 2009;59:32-37.

Álvares LD, Figueira Júnior A, Deliberato PCP. Indicadores de saúde em trabalhadores de uma indústria de plásticos. Revista Brasileira de Ciências da Saúde. 2010; 8(25):21-31.

Antunes R, Alves Giovanni. As mutações do mundo do trabalho na era da mundialização do capital. Educ. Soc. 2004; 25(87):335-51. Disponível em: http://www.cedes.unicamp.br

Araujo CL, Soares MSM, Silva ACO, Azevedo PR, Carvalho LDP, Gonçalves ACR. Capacidade para o trabalho dos profissionais de enfermagem de uma unidade de terapia intensiva cardiológica. [internet] Rev Pesq. Saúde. 2012;13(3). Disponível: http://www.periodicoseletronicos.ufma.br/index.php/revistahuufma/issue/view/110

AronssonG, Gustafsson K, Dallner M. Sick but yet at work: an empirical study of sickness presenteeism. J Epidemiol. Community Health. 2000;54:502-9.

Bacha AM, Grassiotto OR, Gonçalves SP, Higa R, Fonsechi-Carvasan GA, Machado HC, Cacique DB. Satisfação no trabalho da equipe de enfermagem em um hospital universitário. Rev Bras Enferm. 2015;68(6):1130-8.

Balsanelli AP, Jericó MC. Os reflexos da gestão pela qualidade total em instituições hospitalares brasileiras. Acta Paul Enferm. 2005;18(4):397-402.

Baptista PCP, Tito RS, Carvalho MB. Exposição às cargas psíquicas e os processos de desgaste em trabalhadores de enfermagem. In: Felli VEA, Baptista PCP, organizadoras. Saúde do trabalhador de enfermagem. Barueri, SP: Manole, 2015; p.189-203.

Bethge M., Radoschewski Friedrich Michael 2 and Christoph Gutenbrunner. Effortreward imbalance and work ability: cross-sectional and longitudinal findings from the Second German Sociomedical Panel of Employees. BMC Public Health 2012, $12: 875$.

Brooks A, Hagen SE, Sathyanarayanan S, Schults AB, Edington DW. Presenteeism: Critical Issues. Journal of Occupational \& Environmental Medicine. 2010;55(11):1055-67. 
Boström M, Sluiter JK, Hagberg M. Changes in work situation and work ability in young female and male workers. A prospective cohort study. BMC Public Health 2012, 12:694. http://www.biomedcentral.com/1471-2458/12/694

Brasil. Ministério da Previdência Social. Panorama da Previdência Social Brasileira. 2.ed. Brasília: 2008.p.80.

Calzaretta AV. Presentismo laboral. Ciencia \& Trabajo. 2007; 9(27).

Camelo SHH, Rocha FLR, Mininel VA, Scozzafave MCS. Trabalhadores de saúde: formas de adoecimento e estratégias de promoção à saúde. Revista Eletrônica Gestão \& Saúde. 2014;5(3):2220-29.

Camerino D, Conway PM, Van Der Heijden BIJM, Estryn-Behar M, Consonni D, Gould D, et al. Journal of Advanced Nursing. 2006;56(5):542-52.

Campos GWS. Considerações sobre o processo de administração e gerência de serviços de saúde. In: Campos GWS; Mehy EE; Nunes ED (Orgs). Planejamento sem normas. 2를. São Paulo: HUCITEC; 1994:9-31p.

Cancelliere C, Cassidy JD, Ammendolia C. Côté P. Are workplace health promotion programs effective at improving presenteeism in workers? a systematic review and best evidence synthesis of the literature. BMC Public Health. 2011;11:395.

Carneiro SAM. Saúde do trabalhador público: questão para a gestão de pessoas - a experiência na Prefeitura de São Paulo. Revista do Serviço Público. 2006;57(1):2349.

Carugno M, Pesatori AC, Ferrario M, Bonzini M, Ferrari AL, Silva FJ, et al. Physical and psychosocial risk factors for musculoskeletal disorders in Brazilian and Italian nurses. Cadernos de saúde pública. 2012;28(9):1632-42.

Chiavenato I. Recursos humanos. São Paulo: Atlas; 2000.

Chiesa AM, Ciampone MHT. Princípios gerais para a abordagem de variáveis qualitativas e o emprego da metodologia de grupos focais. In: Associação Brasileira de Enfermagem. A classificação internacional das práticas de enfermagem em saúde coletiva - CIPESC. Brasília: ABEN,1999(Série didática: Enfermagem no SUS).

Chinelli F, Vieira M, Menezes C. Qualificação profissional e trajetórias ocupacionais de trabalhadores técnicos em saúde. In: Martins MIC, Marques AP, Costa NR, Matos A, organizadores. Trabalho em Saúde, Desigualdades e Políticas Públicas. Centro de Investigação em Ciências Sociais (CICS-UM) Universidade do Minho/ Escola Nacional de Saúde Pública Sérgio Arouca; Fundação Oswaldo Cruz - Fiocruz. 2014; 283-292p. 
Chiu M, Wang MJ, Lu C, Pan S, Kumashiro M, Ilamrinen J. Evaluating work ability and quality of life for clinical nurses in Taiwan. Nursing outlook. 2007;55(6):318-26.

Ciconelli RM, Soárez PC, Kowalski CCG, Ferraz MB. The Brazilian Portuguese version of the Work Productivity and Activity Impairment: General Health (WPAI-GH) Questionnaire. Sao Paulo Med. J. [Internet]. 2006 [cited 2016 Apr 19];124( 6 ):325332. Available from: http://www.scielo.br/scielo.php?script=sci_arttext\&pid=S1516$31802006000600005 \& \operatorname{lng}=$ en. http://dx.doi.org/10.1590/S1516-31802006000600005.

Cimiotti JP, Aiken LH, Sloane DM, Wu ES. Nurse staffing, burnout, and health careassociated infection. Am J Infect Control. 2012;40(6): 486-490.

Clark S. Presentees. Sunday Times, 1994, Out 16.

Conselho Federal de Enfermagem. Pesquisa inédita traça o perfil da enfermagem. [internet]. Brasília; 2015. [citado em 2015 mai 6]. Disponível:

http://www.cofen.gov.br/pesquisa-inedita-traca-perfil-da-enfermagem 31258.html

Cook RF, Billings DW, Hersch RK, Back AS, Hendrickson A. A field test of a webbased workplace health promotion program to improve dietary practices, reduce stress, and increase physical activity: randomized controlled trial. J Med Internet Res. 2007;9(2):e17.

Cossi MS, Costa RRO, Medeiros SM, Menezes RMP. Capacidade para o trabalho na equipe de enfermagem inserida no ambiente hospitalar. Revista de Atenção à Saúde. 2015;13(43):68-72.

Costa AFRP. Contributo para o estudo da relação entre o índice de capacidade para o trabalho, o envelhecimento e a ergonomia [Dissertação]. Lisboa. Faculdade de Ciências e Tecnologia, Universidade Nova Lisboa; 2008.

Costa RPO, Cossi MS, Vitor AF, Lira ALBC, Medeiros SM, Cavalcante CAA. Absenteísmo de profissionais de enfermagem que trabalham na rede hospitalar: revisão integrativa da literatura. 2014;15(1):06-13.

Demerouti E, Le Blanc PM, Bakker AB, Schaufeli WB, Hox J. Present but sick: a three-wave study on job demands, presenteeism and burnout. Career Development International. 2009;14(1):50-68.

Elias MA, Navarro VL. A relação entre o trabalho, a saúde e as condições de vida: negatividade e positividade no trabalho das profissionais de enfermagem de um hospital escola. Rev Latino-am Enfermagem. 2006;14(4):517-25.

Estryn-Behar M, Heijden B, Camerino D, Fry C, Le Nezet O, Conway PM, et al. Violence risks in nursing-results from the European 'NEXT' Study. Occupational Medicine; 2008;58:107-114. 
Estryn-Béhar M, Van der Heijden BIJM. Effects of extended work shifts on employee fatigue, health, satisfaction, work/family balance, and patient safety. Work. 2012;41:4283-4290.

Felli VEA. A saúde do trabalhador e o gerenciamento em enfermagem [Tese de Livre docência]. São Paulo: Escola de Enfermagem, Universidade de São Paulo; 2002.

Felli VEA. Condições de trabalho de enfermagem e adoecimento: motivos para a redução da jornada de trabalho para 30 horas. Enfermagem em Foco.

2012;3(4):178-181.

Felli VEA, Mininel VA, Sarquis LMM, ME, Silva FJ, Costa TF, Baptista PCP. Sistema de monitoramento da saúde do trabalhador de enfermagem - Simoste. In: Felli VEA, Baptista PCP, organizadoras. Saúde do trabalhador de enfermagem. Barueri, SP: Manole, 2015; p.204-44.

Felli VEA, Peduzzi M. A qualidade de vida no trabalho e a saúde do trabalhador de enfermagem. In: Kurcgant P, coordenadora. Gerenciamento em enfermagem. Rio de Janeiro: Guanabara-Koogan, 2010; p.1-10.

Felli VEA, Tronchin, DMR. A qualidade de vida no trabalho e a saúde do trabalhador de enfermagem. In: Kurcgant P, coordenadora. Gerenciamento em enfermagem. Rio de Janeiro: Guanabara-Koogan, 2010; p.85-103.

Fernandes JD. Expansion of courses/places for Nursing Graduation and the quality of nurse's education process. Rev Bras Enferm [Internet]. 2012;65(3):397-8.

Available from: http://www.scielo.br/pdf/reben/v65n3/en_v65n3a01.pdf

Fischer FM. Breve histórico desta tradução. In: Tuomi K, Ilmarinen J, Jahkola A, Katajarinne L, Tulkki A. Índice de capacidade para o trabalho. Trad. de Fischer FM. São Carlos: EdUFScar, 2005.

Fischer FM, Borges FNS, Rotenberg L, Latorre MRDO, Soares NS, Santa Rosa PLF, Nagai $R$, Landsbergis $P$. A (in)capacidade para o trabalho em trabalhadores de enfermagem. Rev Bras Med Trab. 2005;3(2):97-103.

Flores-Sandi G. "Presentismo" Potencialidad em accidentes de salud. Acta Med Costarric. 2006:48(1)30-34.

Franco T, Druck G, Seligmann-Silva E. As novas relações de trabalho, o desgaste mental do trabalhador e os transtornos mentais no trabalho precarizado. Rev. bras. Saúde ocup. 2010; 35(122):229-48.

Frota NM, Barros LM, Caldini LN, Araújo TM, Caetano JA. Saúde ocupacional dos profissionais de enfermagem em unidade de terapia intensiva. Enferm Foco. 2013;4(2):115-18. 
Gaidizinski RR. Dimensionamento de pessoal de enfermagem em instituições hospitalares [tese de livre docência]. São Paulo: Escola de Enfermagem, Universidade de São Paulo; 1998.

Gaidzinski RR, Lima AFCL, Soares AVN, Fugulin FMT, Sancinetti TR, Castilho V. Gestão de pessoal de enfermagem e o Sistema de Assistência de Enfermagem. In: Gaidzinski RR, Soares AVN, Lima AFC, Gutierrez BAO, Cruz DALM, Rogenski NMB, et al. Diagnóstico de enfermagem na prática clínica. Porto Alegre: Artmed, 2008. p.47-61.

Golubic R, Milosevic M, Knezevic B, Mustajbegovic J. Work-related stress, education and work ability among hospital nurses. J Adv Nurs. 2009;65(10):2056-66.

Gurgueira GP, Alexandre NMC. Laudos médicos recomendando restrições de trabalho em um hospital universitário no Brasil. Rev. Latino-Am. Enfermagem [online]. 2006;14(4):510-6.

Hyeda A, Handar Z. Avaliação da produtividade na síndrome de burnout. Rev Bras Med Trab;2011;9(2):78-84.

Helleshein EF, Lautert L. Capacidade para o trabalho, características sociodemográficas e laborais de enfermeiros de um hospital universitário. Rev. Latino-Am Enfermagem [online]. 2012; 20(3):[8 telas]. Disponível em: http://www.scielo.br/pdf/rlae/v20n3/pt a13v20n3.pdf

Hemp. P. Presenteeísm: at work - but out of it. Havard Business Riview:2004;82 (10):49-58.

IImarinen J. Towards a longer worklife: Ageing and the qualility worklife in the European Union. Finnish Institute of Occupational Health, 2005. Challenges created by changes in age structurs. p.15-35.

Ilmarinen J. Towards a longer worklife: mmilestones of Finland and Finnish Institute of Occupational Health from 1981-2008. In: ZinkenWK (ed). Utilizing older workers for competitive advantage: the new human resouces frontier. Center of productive Longevity, Bounder (CO), 2008. p.59-71.

IImarinen J, Tuomi K. Past, present and future of work ability. In: Ilmarinen J, Lehtinen S (eds). Past, present and future of work ability. People and Work Research Reports no 65. Edited by Finnish Institute of Occupational Health, Helsinki. 2004, p.1-25. 
Ilmarinen J, Tuomi K, Eskelinen L, Nygård C-H, Huuhtanen P, Klockars M. Background and objectives of the Finnish research project on aging workers in municipal occupations. Scand J Work Environ Health 1991;17(Suppl 1):7-11.

International Stress Management Association (ISMA) - Brasil. Presenteísmo. 2010. Disponível em <http//www.ismabrasil.com.br/> Acesso em 11 de fev de 2014.

Instituto Brasileiro de Geografia e Estatística. Síntese de indicadores sociais: uma análise das condições de vida da população brasileira [Internet]. Rio de Janeiro; 2013. [citado em 11 fev 2016]. Disponível em:

http://biblioteca.ibge.gov.br/visualizacao/livros/liv66777.pdf

John G. Presenteeism in the workplace: A review and research agenda. Journal of Organization Behavior. 2010;31(4):519-42.

Karino ME, Felli VEA, Sarquis LMM, Santana LL, Silva SR, Teixeira RC. Cargas de trabalho e desgastes dos trabalhadores de enfermagem de um hospital-escola. Cienc Cuid saúde. 2015;14(2):1011-18.

Koopman C, Pelletier KR, Murray JF, Sharda CE, Berger ML, Turpin RS, et al. Jounal Occup Environ Med. 2002;44:14-20.

Kujala V, Remes J, Ek H, Tammelin T, Laitinem J. Classification of work ability index among young imployees. Occupational Medicine. 2005;55:399-401.

Kujala V, Tammelin T, Remes J, Vammavaara E, Ek E, Laitinen J. Work ability index of young employees and their sickness absence during the following year. Scand $\mathrm{J}$ Work Environ Health. 2006;32(1):75-84.

Kurcgant $P$, Massarolo MCKB. Cultura e poder nas organizações de saúde. In: Kurcgant P, coordenadora. Gerenciamento em enfermagem. Rio de Janeiro: Guanabara-Koogan, 2010; p.23-33.

Kurcgant P, Tronchin DMR, Melleiro MM, Castilho V, Machado VB, Pinhel I, et al. Indicadores de qualidade e a avaliação do gerenciamento de recursos humanos em saúde. Rev. esc. enferm. USP [Internet]. 2009 Dec [cited 2016 May 10]; 43(spe2): 1168-1173. Available from: http://dx.doi.org/10.1590/S0080-62342009000600004

Lanzoni MM, Meirelles BHS. Liderança do enfermeiro: elemento interveniente na rede de relações do agente comunitário de saúde. Rev Bras Enferm. 2013;66(4): 557-63.

Laurel, AC, Noriega M. Processo de produção e saúde: trabalho e desgaste operário. São Paulo: Hucitec; 1989. Para o estudo da Saúde na sua relação com o processo de produção. p.99-144. 
Lelis CM, Battaus MRB, Freitas FCT, Rocha FLR, Marziale MHP, Robazzi MLCC. Distúrbios osteomusculares relacionados ao trabalho em profissionais de enfermagem: revisão integrativa da literatura. Acta Paul. Enferm. 2012;25(3):477-82.

Letvak S, Buck R. Factors Influencing Work Productivity and Intent to Stay in Nursing. Nursing Economics. 2009;26(3):159-165.

Letvack S, Rhum CJ. The impact of worker health on long term care. Geriatric Nursing. 2010;31(3):165-69.

Lima ACS, Magnago TSBS, Prochnow A, Ceron MDS, Beltrame MT, Greco PBT. Prevalência e características da (in) capacidade para o trabalho de trabalhadores de enfermagem. Rev enferm UFPE on line. 2013;7(8):5143-9.

Machado MH, Filho WA, Lacerda WF, Oliveira E, Lemos W, Wermelinger M, Vieira M, Santos MR, Junior PBS, Justino E, Barbosa C. Características gerais da enfermagem: o perfil sociodemográfico. Enferm. Foco. 2016;7(Esp):09-14.

Magnago TSBS, Lima ACS, Prochnow A, Ceron MDS, Tavares JP,Urbanetto JS. Intensidade da dor musculoesquelética e a (in)capacidade para o trabalho na enfermagem. Rev Latino-am Enfermagem. 2012;20(6):1125-33.

Martins AC. Sintomas osteomusculares relacionados ao trabalho de enfermagem em unidade de terapia intensiva [dissertação]. São Paulo: Escola de Enfermagem, Universidade de São Paulo; 2011.

Martins MIC, Molinaro A. Reestruturação produtiva e seu impacto nas relações de trabalho nos serviços públicos de saúde no Brasil. Ciencia \& Saúde Coletiv. 2013; 18(6):1667-76.

Martinez LF. A esperança é a última a morrer? Capital psicológico positivo e presenteísmo. Comportamento organizacional e Gestão. 2007;13(1):37-54.

Martinez LF, Ferreira Al. Sick at work: Presenteissm among nurses in a Portuguese Public Hospital. Stress Health [online]. 2011; Published online in Wiley Online Library (wileyonlinelibrary.com) DOI: 10.1002/smi.

Martinez MC, Latorre MRDO. Saúde e capacidade para o trabalho em trabalhadores da área administrativa. Rev Saúde Pública. 2006;40(5):851-8.

Martinez MC, Latorre MRDO, Fischer MF. Validação e confiabilidade da versão brasileira do índice de capacidade para o trabalho. Rev Saúde Pública. 2009;43(3):525-32.

Martinez MC, Latorre MRDO, Fischer MF. Capacidade para o trabalho: revisão da literatura. Cienc. Saúde Coletiva. 2010;15(Suppl1):1553-61. 
Matus C. Política, planejamento \& Governo. Brasília: IPEA, 1996.

Mauro MYC, Paz AF, Mauro CCC, Pinheiro MAS, Silva VG. Esc. Anna Nery [internet]. Condições de trabalho da enfermagem nas enfermarias de um hospital universitário. 2010 [cited 2015 Jan 10];14(2):244-252. Available from:

<http://www.scielo.br/scielo.php?script=sci_arttext\&pid=S1414-

$81452010000200006 \&$ Ing=en\&nrm=iso $>$. ISSN 1414-8145.

http://dx.doi.org/10.1590/S1414-81452010000200006.

Mendes ACG, Sá DA, Miranda GMD, Lyra TM, Tavares RAW. Assistência pública de saúde no contexto da transição demográfica brasileira: exigências atuais e futuras. Cad. Saúde Pública. 2012; 28(5):955-64.

Middaugh DJ. Presenteeism: Sick and tired at work. Dermatology nursing. 2007;19(2):172-85.

Minayo MCS. O desafio do conhecimento: pesquisa qualitativa em saúde. 14 ed São Paulo; Hucitec, 2014;p.408.

Mininel VA, Felli VEA. Management initiatives aimed at nursing quality of worklife. Ergonomia IJE\&HF. 2007;29(3-4):273-6.

Mininel VA, Felli VEA, Silva EJ, Torri Z, Abreu AP, Branco MTA. Cargas de trabalho, processos de desgaste e absenteísmo-doença em enfermagem. Rev. Latino-Am. Enfermagem. 2013;21(6):1290-7.

Moreira PSV, Silvino ZR, Cortez EA. Avaliação da capacidade para o trabalho: estratégia de cuidado para a enfermagem. Rev enferm UFPE on line. 2015;9(4):7202-6.

Nigeliskii C, Lautert L. Estresse laboral e capacidade para o trabalho de enfermeiros de um grupo hospitalar. Rev. Latino-Am. Enfermagem [internet]. Maio-jun 2011[24 jan. 2014]; 19(3): [08 telas]. Disponível em:

http://www.scielo.br/pdf/rlae/v19n3/pt 21.pdf

Oliveira AGB, Marcon SR, Conciani ME, Oliveira JRT. Qualidade de vida entre trabalhadores de enfermagem de um hospital universitário. Revista espaço para a saúde. 2014;15(1):06-13.

Pai DD, Lautert L, Krug JS. Psicodinâmica e saúde mental do trabalhador de enfermagem: ritmo acelerado e intensificação do fazer. Enfermagem em foco. 2011; 2(1):38-43.

Palha CD. O presenteísmo em enfermagem [Dissertação]. Porto, Portugal. Escola Superior de Enfermagem do Porto, 2014 
Pan American Heath Organization (PAHO). [homepage on internet]. Washington; 2006. [cited 2016 January 20]. Observatory of Human Resources.[about 1 screen]. Available from: http://www.obervatoriorh.org/Toronto/29SetAgenda PT.pdf

Pasa TS, Magnago TSBS, Silva RM, Cervo AS, Beck CLC, Viero NC. Riscos ergonômicos para trabalhadores de enfermagem ao movimentar e remover pacientes. Rev Enferm UFSM. 2015;5(1)92-102.

Paschoalin HC. Presente no trabalho mesmo doente: o presenteísmo na enfermagem [tese]. Rio de Janeiro: Escola de Enfermagem Ana Nery, Universidade Federal do Rio de Janeiro; 2012.

Paschoalin HC, Griep RH, Lisboa MTL. A produção científica sobre o presenteísmo na enfermagem e suas repercussões no cuidado. Rev APS. 2012;15(3):306-11.

Paschoalin HC, Griep RH, Lisboa MTL, Mello, DCB. Adaptação transcultural e validação do Stanford Presenteeism Scale para avaliação do presenteismo. Rev Latino-Am. Enfermagem. 2013;21(1):388-95.

Pillete PC. Presenteeism in Nursing: A clear and present danger to productivity. 2005;35(6):300-303.

Pontes AGV, Rigotto RM. Saúde do Trabalhador e Saúde Ambiental: potencialidades e desafios da articulação entre universidade, SUS e movimentos sociais. Rev. bras. saúde ocup. [Internet]. 2014 Dec [cited 2016 May 18]; 39( 130 ): 161-174. Available from: http://www.scielo.br/scielo.php?script=sci_arttext\&pid=S0303$76572014000200161 \&$ Ing=en. http://dx.doi.org/10.1590/0303-7657000077113.

Prochnow A, Magnago TSBS, Urbanetto JS, Beck CLC, Lima SBS, Greco PBT. Capacidade para o trabalho na enfermagem: relação com demandas psicológicas e controle sobre o trabalho. Rev. Latino-Am. Enfermagem. 2013;21(6):1298-305.

Queiroz DL, Souza JC. Qualidade de vida e capacidade para o trabalho de profissionais de enfermagem. Psicol inf. 2012;16(16):103-26.

Reilly MC, Zbrozek A, Dukes EM. The validity and reproducibility of a work productivity and activity impairment instrument. Pharmacoeconomics. 1993;4(5):35365.

Reinadt EL, Fischer FM. Barreiras às intervenções relacionadas à saúde do trabalhador do setor saúde no Brasil. Rev Panam Salud Publica. 2009;25(5):411-7.

Renner JS, Taschetto DVR, Baptista GL, Basso CR. Qualidade de vida e satisfação no trabalho: a percepção dos técnicos de enfermagem que atuam em ambiente hospitalar. Rev Min Enferm. 2014;18(2): 440-6. 
Ribeiro RP, Martins JT, Marziale MHP, Robazzi MLCC. Adoecer pelo trabalho na enfermagem: uma revisão integrativa. Rev Esc Enferm USP. 2012;46(2):495-504.

Rio de Janeiro, Governo do Estado. Lei no 6296; Dispõe sobre a atenção à saúde ocupacional dos profissionais de enfermagem. 2012 [Internet]. Disponível em: http://alerjln1.alerj.rj.gov.br/contlei.nsf/bc008ecb13dcfc6e03256827006dbbf5/d0423c ea0f63e60783257a4b0057e271?OpenDocument

Rocha SSM, Felli VEA. Saúde de trabalhador de enfermagem sob a ótica da gerência. Rev Bras Enferm. 2004;57(4):453-8.

Rongen A, Robroek SJW, Van Der Heijden BIJM, Schouteten R, Hasselorn HM, Burdorf A. Influence of work related characteristics and work ability on changing employer or leaving the profession among nursing staff. Journal of nursing management. 2013; online: DOI:10.1111/jonm. 12066.

Rogenski NMB. O sistema de enfermagem na divisão de enfermagem cirúrgica. In: Gaidzinski RR, Soares AVN, Lima AFC, Gutierrez BAO, Cruz DALM, Rogenski NMB, et al. Diagnóstico de enfermagem na prática clínica. Porto Alegre: Artmed, 2008. p.127-184.

Roja R. Enfoque del presentismo em empresas de salud. Ciencia \& Trabajo. 2007;9(24):64-8.

Rotenberg L, Griep RH, Fischer FM, Fonseca MJM, Landsbergis P. Working at night and work ability among nursing personne: when precarious employment makes the difference. Int Arch Occup Environ Health. 2009;82:877- 85.

Sancinetti TR. Soares AVN, Lima AFC, Santos NC, Melleiro MM, Fugulin FMT, et al. Taxa de absenteísmo da equipe de enfermagem como indicador de gestão de pessoas. Rev Esc Enferm. 2011; 45(4):1007-12.

Santana LL. Propostas de intervenções à saúde dos trabalhadores apoiadas em indicadores [Dissertação]. Curitiba: Departamento de Enfermagem, Setor de Ciências da Saúde, Universidade Federal do Paraná; 2013.

Sápia T, Felli VEA, Ciampone MHT. Problemas de saúde de trabalhadores de enfermagem em ambulatórios pela exposição à cargas fisiológicas. Acta Paul Enferm 2009;22(6):808-13.

Sasaki SFS. Trabalho bancário e fatores associados ao presenteísmo e ao absenteísmo [dissetação]. São Paulo: Faculdade de Saúde Pública, Universidade de São Paulo; 2013.

Santos MA. A reestruturação produtiva e seus impactos na saúde do trabalhador. Rev Serviço Social e Sociedade: Trabalho e saúde, n82, Ed Cortez: São Paulo, 2005. 
Shikiar R, Halpern MT, Rentz AM, Khan ZM. Development of the Health and Work Questionnaire (HWQ): an instrument for assessing workplace productivity in relation to worker health. Work. 2004;22(3):219-29.

Silva VEAF. O desgaste do trabalhador de enfermagem: estudo da relação trabalho de enfermagem e a saúde do trabalhador [tese]. São Paulo: Escola de Enfermagem, Universidade de São Paulo;1996.

Silva FJ. A capacidade para o trabalho e a fadiga entre trabalhadores de enfermagem [Dissertação]. São Paulo: Escola de enfermagem, Universidade de São Paulo; 2011.

Silva FJ, Felli VEA, Martinez MC, Mininel VA. A fadiga em trabalhadores de enfermagem, o presenteísmo e a (in)capacidade para o trabalho. In: Saúde do trabalhador de enfermagem. Felli VEA, Baptista PCP, organizadoras. Baruei, SP: Manoelle. 2015, 289-305p.

Silva FJ, Felli VEA, Martinez MC, Mininel VA, Ratier APP. Association between work ability and fatigue in Brazilian nursing workers. Work. 2016;53:225-32.

Silva SM. Retorno ao trabalho: a vivência dos trabalhadores de enfermagem com distúrbios osteomusculares relacionados ao trabalho (DORT) [Dissertação]. São Paulo: Escola de enfermagem, Universidade de São Paulo; 2012.

Soric M, Golubic R, Milosevic M, Juras K, Mustajbegovic J. Shift Work, Quality of Life and Work Ability among Croatian Hospital Nurses. Coll. Antropol. 2013;37(2): 379384.

Teixeira LP, Casanova EG, Silva TASM. Occupational diseases in nursing - When the work is sick. Revista Pró-UniverSUS. 2014;05(2):19-24.

Telles ACM, Baptista PCP, Vasconcelos LHS, Bernardes CL, Ratier APP. Promoção da qualidade de vida no trabalho: relato de experiência de um workshop envolvendo os trabalhadores de enfermagem. Cogitare Enferm. 2015;20(3):626-31.

Tito, RS. Burnout e transtornos mentais comuns nos trabalhadores de enfermagem que assistem crianças com cardiopatia grave [Dissertação]. São Paulo: Escola de enfermagem, Universidade de São Paulo; 2013.

Tompa E, Dolinschi R, Natale J. Economic evaluation of a participatory ergonomics intervention in textile plant. Applied Ergonomics. 2013; 44(3):408-7.

Tuomi K, Ilmarinen J, Jahkola A, Katajarinne L, Tulkki A. Índice de capacidade para o trabalho. Trad. de Frida Marina Fischer (Coord.). São Carlos: EdUFSCar, 2005. p.7-52. 
Umann J, Guido LZ, Silva RM. Estresse, coping e presenteísmo em enfermeiros que assistem pacientes críticos e potencialmente críticos. Rev Esc Enferm USP. 2014; 48(5):891-8.

Umann J, Guido LA, Grazziano ES. Presenteísmo em enfermeiros hospitalares. Rev. Latino-am Enfermagem. 2012;20(1):159-166.

Universidade de São Paulo. Hospital Universitário da Universidade de São Paulo. Departamento de Enfermagem. Serviço de Apoio Educacional. Quadro de pessoal completo. São Paulo, 2016.

Universidade de São Paulo. Reitoria, Relação preliminar dos servidores classificados no PIDV. [internet]. São Paulo; 2015. [citado em 2016 fev 5]. Disponível:

http://www.imprensaoficial.com.br/PortallO/DO/GatewayPDF.aspx?pagina=2\&cadern o=Executivo\%20I\&data=14/01/2015\&link=/2015/executivo\%20secao\%20i/janeiro/14/ pag 0053 1ON57NPQF7S5AeDON8F99MNMAQR.pdf

Van den Berg TI, Robroek SJ, Plat JF, Koopmanschap MA, Burdorf A. The importance of job control for workers with decreased work ability to remain productive at work. Int Arch Occup Environ Health. 2011;84(6):705-12.

Vanni K, Virtanen P, Luukkaala T, Nygar C. Relationship between perceived work ability and productivity loss. Internation Journal of Occupational Safety and Ergonimics (JOSE). 2012; 18(3):299-309.

Vasconcelos SP, Fischer FM, Reis AOA, Moreno CRC. Fatores associados à capacidade para o trabalho e percepção de fadiga em trabalhadores de enfermagem da Amazônia Ocidental. Rev Bras Epidemiol. 2011; 14(4):688-97.

Vasconcelos SP, Marqueze E, Gonçalves L, Lemos L, Araújo L, Fischer FM, Moreno $\mathrm{CRC}$. Morbidity among nursing personnel and its association with working conditions and work organization. Work. 2012;41(sup1):3732-7.

Vegian CFL. Capacidade para o trabalho entre profissionais de um serviço de atendimento pré-hospitalar móvel urgência [dissertação]. Campinas: Faculdade de Ciências Médicas, Universidade Estadual de Campinas; 2010.

Versa GLGS, Matsuda LM. Situação profissional da equipe de enfermagem intensivista em um hospital de ensino. Rev enferm UERJ. 2014; 22(3):409-15.

Viero, NC, Greco PBT Magnago TSBS, Scalcon CB, Prochnow A, et al. Redução da capacidade para o trabalho e a relação da morbidade dos trabalhadores de enfermagem. Revista Contexto \& Saúde. 2011; 10(20):1305-10.

Vineburgh MT. Books essays and review. Interpersonal and Biological Process. 2007;70(1):80-3. 
APÊNDICES 



\section{APÊNDICE A - Dados Sociodemográficos e Profissionais}

Assinale uma opção nos itens abaixo:

Sexo: $1 \square$ Feminino $2 \square$ Masculino

Idade: anos

Estado conjugal atual:
$1 \square$ Solteiro(a)
$2 \square$ Casado(a) $3 \square$ Vive com companheiro(a)
$4 \square$ Separado(a)/divorciado(a)
$5 \square$ Viúvo(a)

Escolaridade: (assinalar o nível mais elevado)
$1 \square$ Fundamental
$2 \square$ Médio
$3 \square$ Superior

Renda familiar líquida:
$1 \square 1500-3000$
$2 \square 3001-4500$
$3 \square 4501-6000$
$4 \square 6001 \mathrm{ou}+$

Tempo de trabalho na Instituição: anos e na profissão:

Função: $1 \square$ Enfermeiro $2 \square$ Téc. Enfermagem $3 \square$ Aux. Enfermagem Setor onde trabalha:

Turno de trabalho: $1 \square$ Manhã $2 \square$ Tarde $\quad 3 \square$ Noite

Tempo de trajeto de (ida e volta) para o trabalho: $\mathrm{h}$

№ de vínculos empregatícios: $1 \square$ único $2 \square$ duplo $\quad 3 \square$ triplo $\quad 4 \square$ outro

№ Número total de horas trabalhadas na semana: $\mathrm{h}$

Caso possua restrição de atividades de trabalho, assinale com $X$ nas seguintes opções:

$\square$ Observação e anotação no prontuário do paciente

$\square$ Administração de medicamentos

$\square$ Curativos

$\square$ Transferência de pacientes para o leito, maca e/ ou cadeira

$\square$ Higienização de pacientes em alta-dependência para os cuidados de enfermagem 
$\square$ Encaminhamento de pacientes em maca/ e ou cadeira de rodas ente as unidades

$\square$ Outro. Qual 


\section{APÊNDICE B - Termo de Consentimento Livre e Esclarecido}

Estimado(a) Senhor(a):

Eu, Fabio José da Silva, aluno de Pós-Graduação (doutorado) da Escola de Enfermagem da Universidade de São Paulo, desenvolvendo a pesquisa intitulada "A Capacidade para o trabalho e o presenteísmo entre trabalhadores de enfermagem", sob a orientação da Prof $^{\underline{a}}$ Dr $^{\mathrm{a}}$ Vanda Elisa Andres Felli.

Este estudo, do tipo epidemiológico de recorte transversal, com abordagem quanti-qualitativa dos dados, tem como objetivos: Analisar a associação entre capacidade para o trabalho e presenteísmo entre trabalhadores de enfermagem, como subsídio para o gerenciamento de recursos humanos e propor medidas preventivas, junto aos gerentes de enfermagem, para a melhoria da capacidade para o trabalho e a redução do presenteísmo. E, para que consiga atingir este objetivo, contamos com sua participação nas reuniões de grupo focal que serão filmadas/ gravadas e transcritas para análise temática.

Em caso de aceite na participação dessa pesquisa, você terá total liberdade para retirar o seu consentimento em qualquer fase do trabalho.

Esclareço que serão respeitados os preceitos éticos, garantindo sigilo total e anonimato quanto aos dados confidenciais envolvidos na pesquisa, procurando deixá-lo (a) informado (a) sobre metodologia que deverá ser utilizada. Estarei disponível para sanar dúvidas que possam surgir durante o andamento da pesquisa.

Esclareço também que não haverá ajuda para o transporte e alimentação, pois a pesquisa realizada será no próprio local de trabalho, em horário previamente agendado, e somente após a autorização da Instituição e aprovação do Comitê de Ética e Pesquisa. Neste sentido serão respeitadas as dinâmicas das suas atividades, procurando não ocasionar grandes interferências ou interrupções das mesmas.

Rubrica do participante Rubrica do pesquisador 
Se você tiver alguma dúvida em relação ao estudo ou queira falar conosco para obter informações sobre o andamento do mesmo, pode entrar contato a qualquer momento pelo telefone (11) 30919494 ou (11) 996575101, bem como, pelo endereço: Rua Cotoxó, 449 Vila Pompéia, São Paulo/SP, CEP 05020-000, ou ainda pelo endereço eletrônico: fabiojoseph@usp.br. Também deixo a disposição o contato do Comitê de Ética do Ética em Pesquisa do Hospital do HU-USP: Av. Prof. Lineu Prestes no 2565 - Cidade Universitária - CEP 055088-900 - São Paulo/SP e, do Comitê de Ética em Pesquisa da Escola de Enfermagem da Universidade de São Paulo: Av. Dr. Enéas de Carvalho Aguiar, 419 - CEP 05403-000 - São Paulo/SP. Email: edipesq@usp.br.Tel: (11)3061-7548.

Muito obrigado pela sua atenção, disponibilidade e interesse.

Fabio José da Silva

Após ter lido e compreendido as informações acima, eu concordo em participar da pesquisa e estou ciente dos meus direitos como sujeito participante e acredito que os mesmos serão respeitados.

Declaro também que estou recebendo uma cópia deste documento assinado concomitantemente com o pesquisador.

São Paulo, de de 2015.

Sujeito de pesquisa 


\section{APÊNDICE C - Doenças auto-referidas no ICT}

Tabela 20 - Distribuição ( $n^{\circ}$ e \%) dos trabalhadores de enfermagem segundo doenças referidas, São Paulo, 2015.

\begin{tabular}{|c|c|c|c|c|}
\hline \multirow[t]{2}{*}{ Doença/agravo } & \multicolumn{2}{|c|}{ Opinião própria } & \multicolumn{2}{|c|}{$\begin{array}{l}\text { Diagnóstico } \\
\text { médico }\end{array}$} \\
\hline & no & $\%$ & no & $\%$ \\
\hline 01. Lesão nas costas & 98 & 25,9 & 61 & 16,1 \\
\hline 02. Lesão nos braços/mãos & 79 & 20,8 & 77 & 20,3 \\
\hline 03. Lesão nas pernas/pés & 57 & 15,0 & 41 & 10,8 \\
\hline 04. Lesão em outras partes do corpo & 20 & 5,3 & 23 & 6,1 \\
\hline 05. Doença na parte superior das costas & 75 & 19,8 & 28 & 7,4 \\
\hline 06. Doença da parte inferior das costas & 66 & 17,4 & 32 & 8,4 \\
\hline 07. Dor nas costas que se irradia para a perna & 56 & 14,8 & 29 & 7,7 \\
\hline $\begin{array}{l}\text { 08. Doença musculoesquelética afetando os } \\
\text { membros }\end{array}$ & 54 & 14,2 & 31 & 8,2 \\
\hline 09. Artrite reumatóide & 4 & 1,1 & 6 & 1,6 \\
\hline 10. Outra doença musculoesquelética & 6 & 1,6 & 9 & 2,4 \\
\hline 11. Hipertensão arterial & 21 & 5,5 & 36 & 9,5 \\
\hline 12. Doença coronariana, dor no peito & 3 & 0,8 & 3 & 0,8 \\
\hline 13. Infarto do miocárdio, trombose coronariana & 1 & 0,3 & 1 & 0,3 \\
\hline 14. Insuficiência cardíaca & 0 & 0,0 & 0 & 0,0 \\
\hline 15. Outra doença cardiovascular & 7 & 1,8 & 6 & 1,6 \\
\hline 16. Infecções repetidas no trato respiratório & 33 & 8,7 & 32 & 8,4 \\
\hline 17. Bronquite crônica & 3 & 0,8 & 5 & 1,3 \\
\hline 18. Sinusite crônica & 28 & 7,4 & 25 & 6,6 \\
\hline 19. Asma & 10 & 2,6 & 13 & 3,4 \\
\hline 20. Enfisema & 0 & 0,0 & 0 & 0,0 \\
\hline 21. Tuberculose pulmonar & 0 & 0,0 & 0 & 0,0 \\
\hline 22. Outra doença respiratória & 10 & 2,6 & 9 & 2,4 \\
\hline 23. Distúrbio emocional severo & 10 & 2,6 & 16 & 4,2 \\
\hline 24. Distúrbio emocional leve & 138 & 36,4 & 38 & 10,0 \\
\hline 25. Problema ou diminuição na audição. & 22 & 5,8 & 12 & 3,2 \\
\hline 26. Doença ou lesão da visão & 23 & 6,1 & 27 & 7,1 \\
\hline
\end{tabular}


(continuação)

\section{Doença/agravo}

27. Doença neurológica

28. Outra doença neurológica ou dos sentidos

29. Pedras ou doença da vesícula biliar

30. Doença do pâncreas ou do fígado

31. Úlcera gástrica ou duodenal

32. Gastrite ou irritação duodenal

33. Colite ou irritação do cólon

34. Outra doença digestiva

35. Infecção das vias urinárias

36. Doença dos rins

37. Doença nos genitais e aparelho

38. Outra doença geniturinária

39. Alergia, eczema

40. Outra erupção

41. Outra doença de pele

42. Tumor benigno

43. Tumor maligno (câncer)

44. Obesidade

45. Diabetes

46. Bócio ou outra doença da tireoide

47. Outra doença endócrina ou metabólica

48. Anemia

49. Outra doença do sangue

50. Defeito de nascimento

51. Outro problema ou doença

\section{Diagnóstico médico}

\section{Opinião própria}

n으

22

$\%$

no

$\%$

1

5,8

23

6,1

$\begin{array}{llll}1 & 0,3 & 1 & 0,3\end{array}$

$\begin{array}{llll}10 & 2,6 & 12 & 3,2\end{array}$

$\begin{array}{llll}1 & 0,3 & 3 & 0,8\end{array}$

$\begin{array}{llll}8 & 2,1 & 10 & 2,6\end{array}$

$34 \quad 9,0 \quad 31 \quad 8,2$

$\begin{array}{llll}3 & 0,8 & 8 & 2,1\end{array}$

$\begin{array}{llll}11 & 2,9 & 11 & 2,9\end{array}$

$\begin{array}{llll}24 & 6,3 & 27 & 7,1\end{array}$

$\begin{array}{llll}11 & 2,9 & 13 & 3,4\end{array}$

$\begin{array}{llll}9 & 2,4 & 11 & 2,9\end{array}$

$\begin{array}{llll}3 & 0,8 & 5 & 1,3\end{array}$

$\begin{array}{llll}21 & 5,5 & 27 & 7,1\end{array}$

$\begin{array}{llll}4 & 1,1 & 3 & 0,8\end{array}$

$\begin{array}{llll}6 & 1,6 & 13 & 3,4\end{array}$

$\begin{array}{llll}6 & 1,6 & 12 & 3,2\end{array}$

$\begin{array}{llll}1 & 0,3 & 5 & 1,3\end{array}$

$\begin{array}{llll}46 & 12,1 & 30 & 7,9\end{array}$

$\begin{array}{llll}9 & 2,4 & 14 & 3,7\end{array}$

$15 \quad 4,0 \quad 24 \quad 6,3$

$\begin{array}{llll}4 & 1,1 & 10 & 2,6\end{array}$

$\begin{array}{llll}7 & 1,8 & 13 & 3,4\end{array}$

$2 \quad 0,5 \quad 5 \quad 1,3$

$\begin{array}{llll}0 & 0,0 & 5 & 1,3\end{array}$

$\begin{array}{llll}5 & 1,3 & 11 & 2,9\end{array}$




\section{APÊNDICE D - Etapas da modelagem múltipla para análises das associações entre capacidade para o trabalho e presenteísmo:}

A modelagem múltipla incluiu todas as variáveis que apresentaram valor do $p<0,20$ na análise bivariada. Os passos estão descritos a seguir e os resultados apresentados na Tabela B.

O modelo 1 inclui a variável presenteísmo. Em seguida, no modelo 2 foi incluída a variável faixa etária. A faixa etária " $\geq 35,0$ e $<45,0$ anos" foi considerada a categoria de referência por ser aquela com maior percentual de trabalhadores com capacidade para o trabalho adequada. A categoria etária " $\geq 45,0$ anos" não apresentou significância estatística e foi retirada da modelagem. O modelo 3 repetiu a análise anterior excluindo esta categoria etária, e como resultado houve ajuste do OR e do intervalo de confiança para as duas variáveis em relação aos resultados das análises biivariadas.

Na sequência foi incluída a variável setor de trabalho. Neste modelo 4 a categoria composta pelo Centro Cirúrgico, Centro Obstétrico e Pediatria foi considerada a categoria de referência por ser aquela com maior percentual de trabalhadores com capacidade para o trabalho adequada. A categoria composta pelos setores Alojamento Conjunto, Berçário, Clínica Cirúrgica, Imagem e Endoscopia, UTI Adulto e UTI Pediátrica não apresentou significância estatística e foi retirada da modelagem. $O$ modelo 5 repetiu a análise anterior excluindo esta categoria etária, e como resultado houve ajuste do OR e do intervalo de confiança para as duas variáveis em relação aos resultados das análises bivariadas e também para o modelo anterior.

O modelo 6 incluiu a variável renda familiar, que apresentou significância estatística e ajuste do OR e de seu intervalo de confiança em relação ao modelo bivariado. Houve discreta elevação do OR e dos intervalos de confiança das demais variáveis, que mantiveram a significância estatística. A variável renda familiar foi mantida na modelagem.

Na sequência foi incluída a variável turno de trabalho. Neste modelo 7 o turno da noite foi considerado como categoria de referência por ser aquela com maior percentual de trabalhadores com capacidade para o trabalho adequada. O turno da manhã ganhou significância estatística e o turno da tarde perdeu significância estatística. Esta inversão em relação aos modelos bivariados sugere sobreajuste do modelo. No modelo 8 foi retirado o turno da tarde, e o turno da manhã também perdeu a significância estatística. Esta variável foi retirada da modelagem. 
No modelo 9 foi incluída a variável sexo, que não apresentou significância estatística e foi retirada da análise.

$\mathrm{Na}$ sequência foi incluída a variável Divisão de Enfermagem. Neste modelo 10 a Enfermagem Cirúrgica foi considerada a categoria de referência por ser aquela com maior percentual de trabalhadores com capacidade para o trabalho adequada. Nenhuma categoria desta variável apresentou associação estatisticamente significativa e retirou a significância da variável setor de trabalho. Por isso, foi retirada da modelagem.

Finalmente, apesar de não apresentar associação estatisticamente significativa com a capacidade para o trabalho, a variável sexo foi reintroduzida no modelo como variável de ajuste (modelo 9). Neste modelo o presenteísmo permaneceu associado à capacidade para o trabalho, independente das demais variáveis (faixa etária, setor de trabalho, renda familiar e sexo). Este modelo não apresentou mudanças importantes nos parâmetros (OR, intervalo de confiança e valor do p) em relação ao último modelo considerado (modelo 6). O teste de Hosmer-Lemeshow indicou boa adequação do modelo $\left(\chi^{2}=4,091 ; p=0,769\right)$.

Tabela 21 - Descrição das etapas de modelagem múltipla dos fatores associados à capacidade para o trabalho em Trabalhadores de Enfermagem, identificados por meio da análise de regressão logística, São Paulo, 2015.

(continua)

\begin{tabular}{|c|c|c|c|c|c|}
\hline Modelo & Variável & Categoria & OR aj & $\begin{array}{c}\text { IC } 95 \% \text { (OR } \\
\text { aj) }\end{array}$ & $p^{*}$ \\
\hline \multirow[t]{2}{*}{1} & Presenteísmo & Melhor desempenho & 1,00 & & \\
\hline & & Redução do desempenho & 5,56 & {$[3,03 ; 20,21]$} & $<0,001$ \\
\hline \multirow[t]{5}{*}{2} & Presenteísmo & Melhor desempenho & 1,00 & & \\
\hline & & Redução do desempenho & 5,45 & {$[2,93 ; 10,12]$} & $<0,001$ \\
\hline & Faixa etária & $\geq 35,0$ e $<45,0$ anos & 1,00 & & \\
\hline & & $<35$ anos & 2,69 & {$[1,50 ; 4,83]$} & 0,001 \\
\hline & & $\geq 45,0$ anos & 1,58 & {$[0,91 ; 2,74]$} & 0,102 \\
\hline \multirow[t]{4}{*}{3} & Presenteísmo & Melhor desempenho & 1,00 & & \\
\hline & & Redução do desempenho & 5,30 & {$[2,87 ; 9,79]$} & $<0,001$ \\
\hline & Faixa etária & $\geq 35,0$ e $<45,0$ anos & 1,00 & & \\
\hline & & $<35$ anos & 2,05 & {$[1,27 ; 3,30]$} & 0,003 \\
\hline
\end{tabular}


(continua)

\begin{tabular}{|c|c|c|c|c|c|}
\hline Modelo & Variável & Categoria & OR aj & $\begin{array}{l}\text { IC 95\% (OR } \\
\text { aj) }\end{array}$ & p * \\
\hline \multirow[t]{7}{*}{4} & Presenteísmo & Melhor desempenho & 1,00 & & \\
\hline & & Redução do desempenho & 5,13 & {$[2,74 ; 9,62]$} & $<0,001$ \\
\hline & Faixa etária & $\geq 35,0$ e $<45,0$ anos & 1,00 & & \\
\hline & & $<35$ anos & 1,98 & {$[1,22 ; 3,22]$} & 0,006 \\
\hline & $\begin{array}{l}\text { Setor de } \\
\text { trabalho }\end{array}$ & $\begin{array}{l}\text { Centro Cirúrgico, Centro } \\
\text { Obstétrico, Pediatria }\end{array}$ & 1,00 & & \\
\hline & & $\begin{array}{l}\text { Alojamento Conjunto, } \\
\text { Berçário, Clínica Cirúrgica, } \\
\text { Imagem e Endoscopia, } \\
\text { UTI Adulto, UTI Pediátrica }\end{array}$ & 1,82 & {$[0,97 ; 3,42]$} & 0,064 \\
\hline & & $\begin{array}{l}\text { Ambulatório, Clínica } \\
\text { Médica, Pronto Socorro } \\
\text { Adulto, Pronto Socorro } \\
\text { Infantil }\end{array}$ & 2,96 & {$[1,51 ; 5,79]$} & 0,002 \\
\hline \multirow[t]{6}{*}{5} & Presenteísmo & Melhor desempenho & 1,00 & & \\
\hline & & Redução do desempenho & 4,96 & {$[2,67 ; 9,32]$} & $<0,001$ \\
\hline & Faixa etária & $\geq 35,0$ e $<45,0$ anos & 1,00 & & \\
\hline & & $<35$ anos & 2,01 & {$[1,24 ; 3,25]$} & 0,005 \\
\hline & $\begin{array}{l}\text { Setor de } \\
\text { trabalho }\end{array}$ & $\begin{array}{l}\text { Centro Cirúrgico, Centro } \\
\text { Obstétrico, Pediatria }\end{array}$ & 1,00 & & \\
\hline & & $\begin{array}{l}\text { Ambulatório, Clínica } \\
\text { Médica, Pronto Socorro } \\
\text { Adulto, Pronto Socorro } \\
\text { Infantil }\end{array}$ & 1,91 & {$[1,19 ; 3,08]$} & 0,007 \\
\hline \multirow[t]{7}{*}{6} & Presenteísmo & Melhor desempenho & 1,00 & & \\
\hline & & Redução do desempenho & 5,22 & {$[2,77 ; 9,84]$} & $<0,001$ \\
\hline & Faixa etária & $\geq 35,0$ e $<45,0$ anos & 1,00 & & \\
\hline & & $<35$ anos & 2,23 & {$[1,36 ; 3,66]$} & 0,002 \\
\hline & $\begin{array}{l}\text { Setor de } \\
\text { trabalho }\end{array}$ & $\begin{array}{l}\text { Centro Cirúrgico, Centro } \\
\text { Obstétrico, Pediatria }\end{array}$ & 1,00 & & \\
\hline & & $\begin{array}{l}\text { Ambulatório, Clínica } \\
\text { Médica, Pronto Socorro } \\
\text { Adulto, Pronto Socorro } \\
\text { Infantil }\end{array}$ & 1,95 & {$[1,20 ; 3,15]$} & 0,007 \\
\hline & $\begin{array}{l}\text { Renda familiar } \\
\text { líquida }\end{array}$ & $6.001,00$ ou mais & 1,00 & & \\
\hline
\end{tabular}


(continua)

\begin{tabular}{|c|c|c|c|c|c|}
\hline Modelo & Variável & Categoria & OR aj & $\begin{array}{l}\text { IC } 95 \% \text { (OR } \\
\text { aj) }\end{array}$ & $p^{*}$ \\
\hline \multirow[t]{11}{*}{7} & \multirow[t]{2}{*}{ Presenteísmo } & Melhor desempenho & 1,00 & & \\
\hline & & Redução do desempenho & 5,40 & {$[2,85 ; 10,25]$} & $<0,001$ \\
\hline & \multirow[t]{2}{*}{ Faixa etária } & $\geq 35,0$ e $<45,0$ anos & 1,00 & & \\
\hline & & $<35$ anos & 2,28 & {$[1,36 ; 3,82]$} & 0,002 \\
\hline & \multirow[t]{2}{*}{$\begin{array}{l}\text { Setor de } \\
\text { trabalho }\end{array}$} & $\begin{array}{l}\text { Centro Cirúrgico, Centro } \\
\text { Obstétrico, Pediatria }\end{array}$ & 1,00 & & \\
\hline & & $\begin{array}{l}\text { Ambulatório, Clínica } \\
\text { Médica, Pronto Socorro } \\
\text { Adulto, Pronto Socorro } \\
\text { Infantil }\end{array}$ & 1,86 & {$[1,14 ; 3,04]$} & 0,013 \\
\hline & \multirow{2}{*}{$\begin{array}{l}\text { Renda familiar } \\
\text { líquida }\end{array}$} & $6.001,00$ ou mais & 1,00 & & \\
\hline & & Até $6.000,00$ & 2,15 & {$[1,34 ; 3,44]$} & 0,001 \\
\hline & \multirow[t]{3}{*}{ Turno } & Noite & 1,00 & & \\
\hline & & Manhã & 1,93 & {$[1,09 ; 3,41]$} & 0,024 \\
\hline & & Tarde & 1,60 & {$[0,90 ; 2,85]$} & 0,111 \\
\hline \multirow[t]{10}{*}{8} & \multirow[t]{2}{*}{ Presenteísmo } & Melhor desempenho & 1,00 & & \\
\hline & & Redução do desempenho & 5,38 & {$[2,84 ; 10,17]$} & $<0,001$ \\
\hline & \multirow[t]{2}{*}{ Faixa etária } & $\geq 35,0$ e $<45,0$ anos & 1,00 & & \\
\hline & & $<35$ anos & 2,43 & {$[1,46 ; 4,04]$} & 0,001 \\
\hline & \multirow[t]{2}{*}{$\begin{array}{l}\text { Setor de } \\
\text { trabalho }\end{array}$} & $\begin{array}{l}\text { Centro Cirúrgico, Centro } \\
\text { Obstétrico, Pediatria }\end{array}$ & 1,00 & & \\
\hline & & $\begin{array}{l}\text { Ambulatório, Clínica } \\
\text { Médica, Pronto Socorro } \\
\text { Adulto, Pronto Socorro } \\
\text { Infantil }\end{array}$ & 1,84 & {$[1,13 ; 2,99]$} & 0,014 \\
\hline & \multirow{2}{*}{$\begin{array}{l}\text { Renda familiar } \\
\text { líquida }\end{array}$} & $6.001,00$ ou mais & 1,00 & & \\
\hline & & Até $6.000,00$ & 2,12 & {$[1,33 ; 3,39]$} & 0,002 \\
\hline & \multirow[t]{2}{*}{ Turno } & Noite & 1,00 & & \\
\hline & & Manhã & 1,53 & {$[0,94 ; 2,504]$} & 0,870 \\
\hline
\end{tabular}


(continuação)

\begin{tabular}{|c|c|c|c|c|c|}
\hline Modelo & Variável & Categoria & OR aj & $\begin{array}{l}\text { IC 95\% (OR } \\
\text { aj) }\end{array}$ & $p^{*}$ \\
\hline \multirow[t]{10}{*}{9} & \multirow[t]{2}{*}{ Presenteísmo } & Melhor desempenho & 1,00 & & \\
\hline & & Redução do desempenho & 5,18 & {$[2,75 ; 9,77]$} & $<0,001$ \\
\hline & \multirow[t]{2}{*}{ Faixa etária } & $\geq 35,0$ e $<45,0$ anos & 1,00 & & \\
\hline & & $<35$ anos & 2,25 & {$[1,37 ; 3,71]$} & 0,001 \\
\hline & \multirow[t]{2}{*}{$\begin{array}{l}\text { Setor de } \\
\text { trabalho }\end{array}$} & $\begin{array}{l}\text { Centro Cirúrgico, Centro } \\
\text { Obstétrico, Pediatria }\end{array}$ & 1,00 & & \\
\hline & & $\begin{array}{l}\text { Ambulatório, Clínica } \\
\text { Médica, Pronto Socorro } \\
\text { Adulto, Pronto Socorro } \\
\text { Infantil }\end{array}$ & 2,02 & {$[1,24 ; 3,27]$} & 0,005 \\
\hline & \multirow{2}{*}{$\begin{array}{l}\text { Renda familiar } \\
\text { líquida }\end{array}$} & $6.001,00$ ou mais & 1,00 & & \\
\hline & & Até $6.000,00$ & 2,08 & {$[1,30 ; 3,31]$} & 0,002 \\
\hline & \multirow[t]{2}{*}{ Sexo } & Feminino & 1,00 & & \\
\hline & & Masculino & 0,54 & {$[0,260 ; 1,11]$} & 0,093 \\
\hline \multirow[t]{13}{*}{10} & \multirow[t]{2}{*}{ Presenteísmo } & Melhor desempenho & 1,00 & & \\
\hline & & Redução do desempenho & 5,28 & {$[0,78 ; 9,95]$} & $<0,001$ \\
\hline & \multirow[t]{2}{*}{ Faixa etária } & $\geq 35,0$ e $<45,0$ anos & 1,00 & & \\
\hline & & $<35$ anos & 2,24 & {$[1,36 ; 3,71]$} & 0,002 \\
\hline & \multirow[t]{2}{*}{$\begin{array}{l}\text { Setor de } \\
\text { trabalho }\end{array}$} & $\begin{array}{l}\text { Centro Cirúrgico, Centro } \\
\text { Obstétrico, Pediatria }\end{array}$ & 1,00 & & \\
\hline & & $\begin{array}{l}\text { Ambulatório, Clínica } \\
\text { Médica, Pronto Socorro } \\
\text { Adulto, Pronto Socorro } \\
\text { Infantil }\end{array}$ & 1,70 & {$[0,92 ; 3,13]$} & 0,090 \\
\hline & \multirow{2}{*}{$\begin{array}{l}\text { Renda familiar } \\
\text { líquida }\end{array}$} & $6.001,00$ ou mais & 1,00 & & \\
\hline & & Até $6.000,00$ & 2,02 & {$[1,27 ; 3,23]$} & 0,003 \\
\hline & \multirow{5}{*}{$\begin{array}{l}\text { Divisão de } \\
\text { Enfermagem }\end{array}$} & Enfermagem Cirúrgica & 1,00 & & \\
\hline & & Enfermagem Clínica & 1,23 & {$[0,58 ; 2,63]$} & 0,591 \\
\hline & & Pacientes Externos & 1,42 & {$[0,60 ; 3,37]$} & 0,428 \\
\hline & & Enfermagem Pediátrica & 1,06 & {$[0,48 ; 2,33]$} & 0,880 \\
\hline & & $\begin{array}{l}\text { Enfermagem Obstétrica e } \\
\text { Ginecológica }\end{array}$ & 1,17 & {$[0,55 ; 2,51]$} & 0,681 \\
\hline
\end{tabular}

* $p$ da categoria aj = ajustada 

ANEXOS 



\section{ANEXO 1 - Índice de Capacidade para o trabalho}

Este questionário foi elaborado pelo Instituto de Saúde Ocupacional da Finlândia, Helsinki; traduzido e adaptado por pesquisadores das seguintes universidades: Faculdade de Saúde Pública da Universidade de São Paulo: Departamento de Saúde Ambiental; Universidade Federal de São Carlos: Departamento de enfermagem; Faculdade de Ciências Médicas da UNICAMP: Departamento de Medicina Preventiva e Social.

Por favor, preencha o questionário cuidadosamente, respondendo todas as questões com um círculo entorno da alternativa que melhor reflete sua opinião ou escrevendo sua resposta em local apropriado.

1. Suponha que sua melhor capacidade para o trabalho tem um valor igual a 10 pontos

Circule um número na escala de zero a dez, que designe quantos pontos você daria para sua capacidade atual:

$\begin{array}{lllllllllll}0 & 1 & 2 & 3 & 4 & 5 & 6 & 7 & 8 & 9 & 10\end{array}$

Estou

incapaz para

Estou em minha melhor capacidade para o trabalho o trabalho

2. Como você classificaria sua capacidade atual para o trabalho em relação às exigências físicas do mesmo? (ex.: fazer esforço físico com partes do corpo).

Muito boa

Boa

Moderada

Baixa

Muito baixa 
3. Como você classificaria sua capacidade atual para o trabalho em relação às exigências mentais de seu trabalho? (ex.: interpretar fatos, resolver problemas, decidir a melhor forma de fazer.)

Muito boa 5

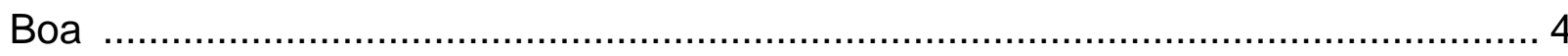

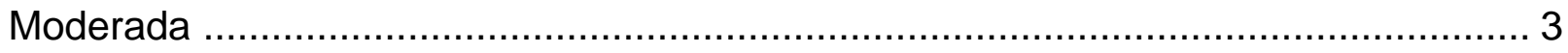

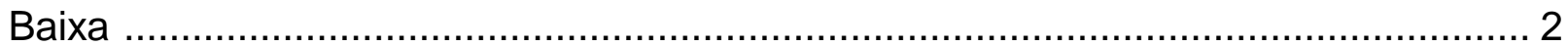

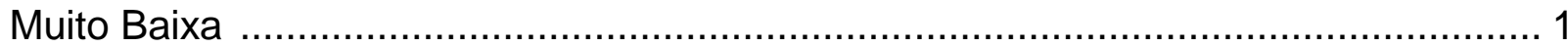

4. Em sua opinião quais das lesões por acidentes ou doenças citadas abaixo você possui atualmente? Marque também aquelas que foram confirmadas pelo médico.

Em minha
opinião $\quad \begin{gathered}\text { Diagnóstico } \\ \text { médico }\end{gathered}$

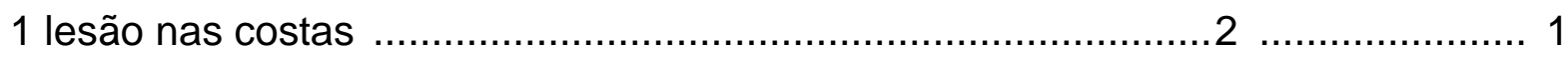

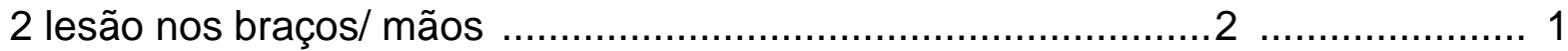

3 lesão nas pernas/ pés .................................................................... 1

4 lesão em outras partes do corpo ……....................................

Onde? Que tipo de lesão?

5 doença da parte superior das costas

ou região do pescoço, com dores frequentes ........................... $2 \ldots \ldots \ldots \ldots \ldots \ldots \ldots . . .11$

6 doença da parte inferior das costas

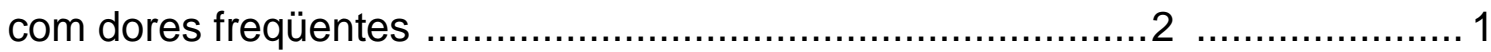

7 dor nas costas que se irradia para a perna (ciática) ................. $2 \ldots \ldots \ldots \ldots \ldots \ldots \ldots . . .11$

8 doença músculo-esquelética que afeta membros

(braços e pernas) com dores frequentes ..............................

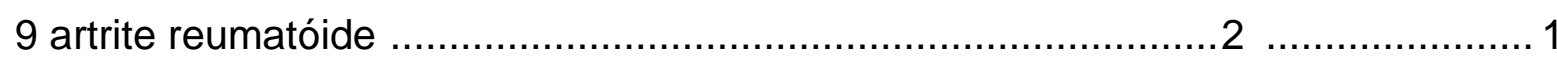

10 outra doença músculo esquelética ...........................................................

Qual?

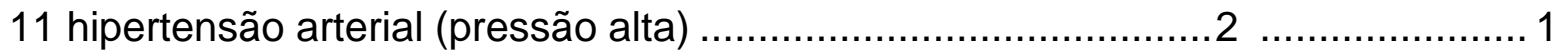

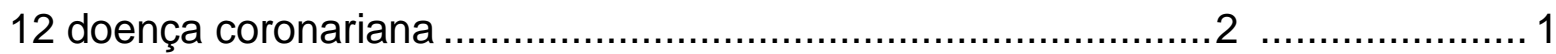

13 infarto do miocárdio, trombose coronariana .................................................. 1

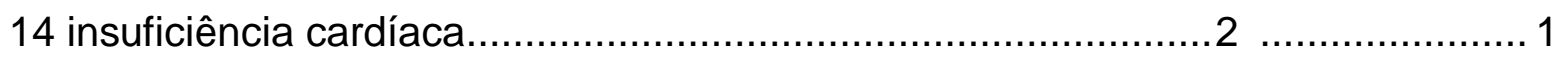


15 outra doença cardiovascular

2 1

Qual?

16 infecções repetidas do trato respiratório

(inclusive amidalite, sinusite aguda, bronquite aguda) ............ 2 …................... 1

17 bronquite crônica .................................................................................

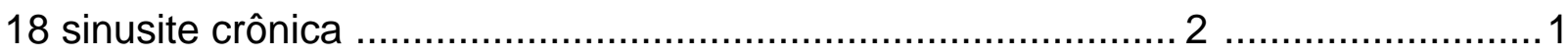

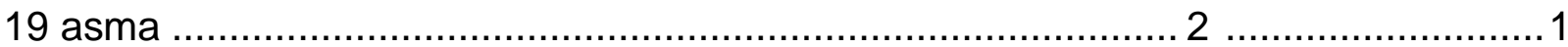

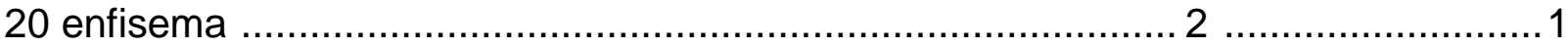

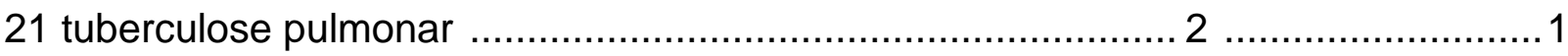

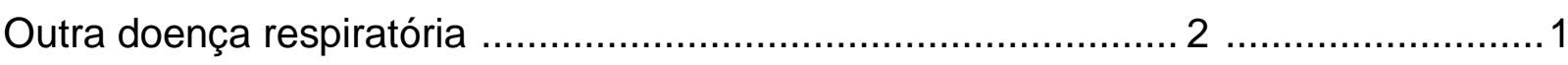

Qual?

23 distúrbios emocionais severo (depressão severa) ................. 2 ......................... 1

24 distúrbio emocional leve, tensão,

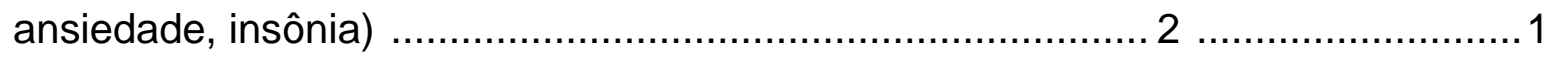

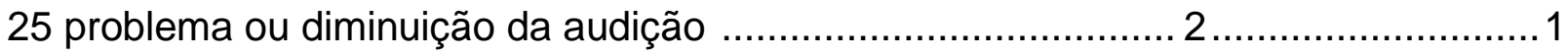

26 doença ou lesão da visão (não assinale

se apenas usa óculos e/ou lentes de contato ……..........................................

27 doença neurológica (acidente vascular

cerebral, neuralgia, enxaqueca, epilepsia ............................. 2 ...................... 1

28 outra doença neurológica ou dos

órgãos dos sentidos

2 1

Qual?

29 pedras ou doenças da vesícula biliar .........................................................

30 doença do pâncreas ou do fígado .............................................................1

31 úlcera gástrica ou duodenal ...................................................................... 2

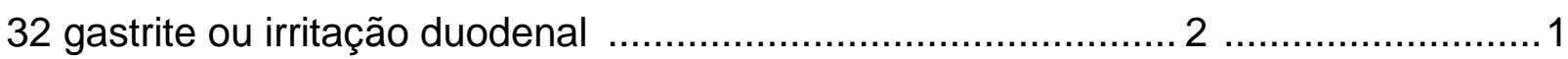

33 colite ou irritação do cólon ...................................................................... 2

34 outra doença digestiva ..............................................................................

Qual?

35 infecções das vias urinárias 


\section{Em minha \\ Diagnóstico \\ opinião médico}

37 doença nos genitais e aparelho reprodutor

(problema nas trompas ou na próstata........................................................ 1

38 outra doença geniturinária ……….................................... 2 ...................... 1

Qual?

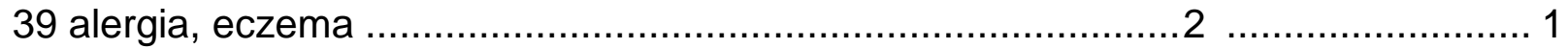

40 outra erupção cutânea .......................................................................... 1

Qual?

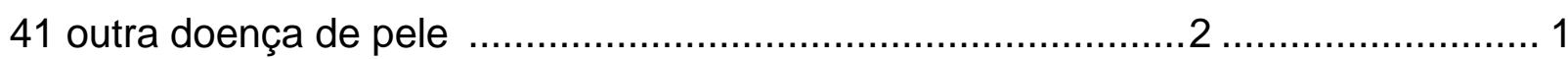

Qual?

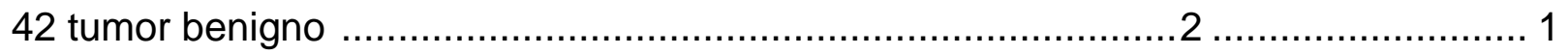

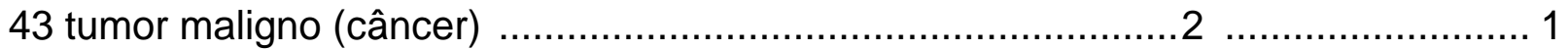

Qual?

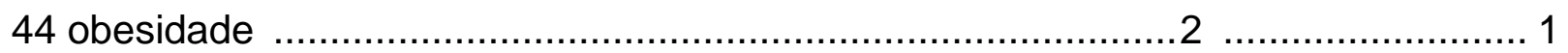

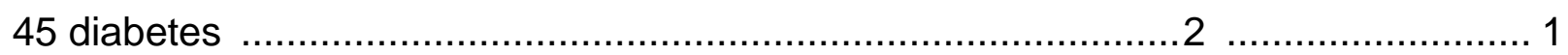

46 bócio ou outra doença da tireóide ........................................................... 1

47 outra doença endócrina ou metabólica ....................................................... 1

Qual?

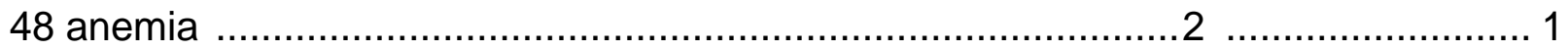

49 outra doença do sangue …................................................................ 1

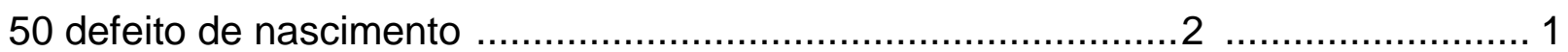

Qual?

51 outro problema ou doença ..................................................................... 1

Qual? 
5. Sua lesão ou doença é um impedimento para seu trabalho atual? (Você pode marcar mais de uma nesta pergunta).

Não há impedimento/Eu não tenho doenças 6

Eu sou capaz de fazer meu trabalho, mas ele me causa alguns sintomas 5 Algumas vezes preciso diminuir meu ritmo de trabalho ou mudar meus métodos de trabalho 4

Frequentemente preciso diminuir meu ritmo de trabalho ou mudar meus métodos de trabalho 3

Por causa de minha doença sinto-me capaz de trabalhar apenas em tempo parcial 2

Em minha opinião estou totalmente incapacitado para trabalhar 1

6. Quantos dias inteiros você esteve fora esteve fora por causa de problemas de saúde, consulta médica ou para exame durante os últimos 12 meses?

Nenhuma 5

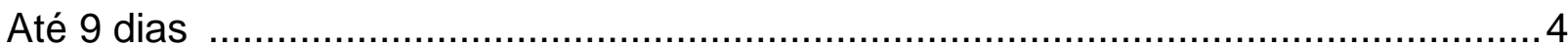

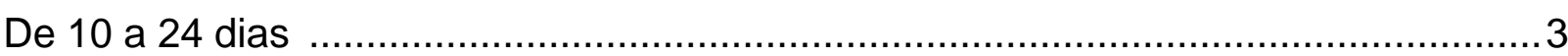

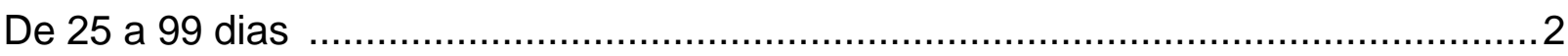

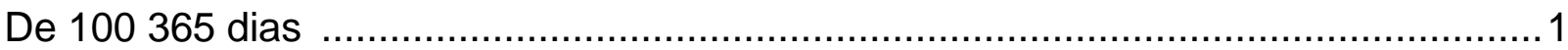

7. Considerando sua saúde, você acha que será capaz de, daqui a 2 anos, fazer seu trabalho atual?

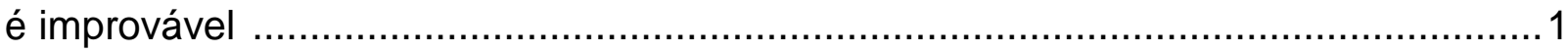

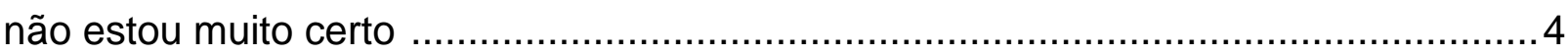

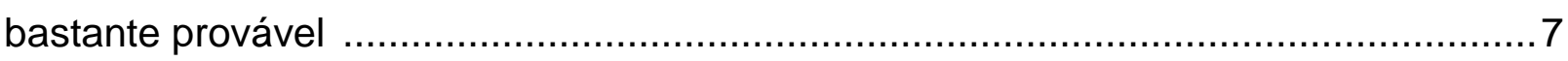

8. Recentemente você tem conseguido apreciar suas atividades diárias?

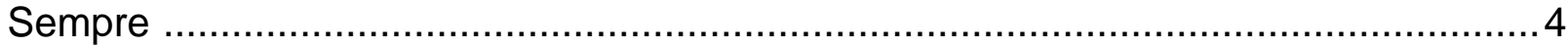

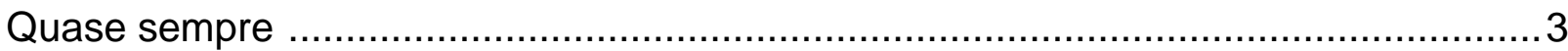

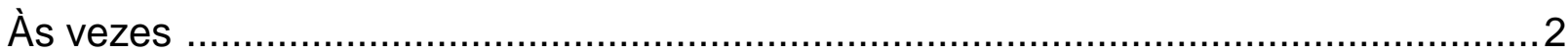

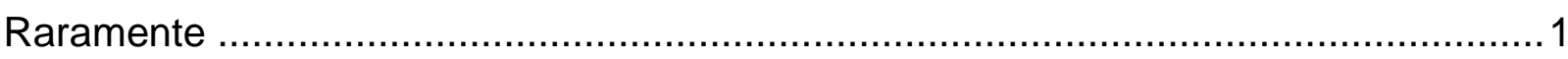

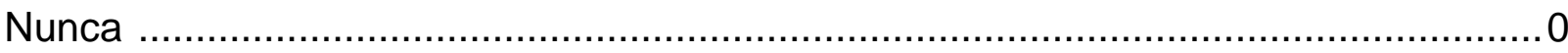


9. Recentemente você tem se sentido ativo e alerta?

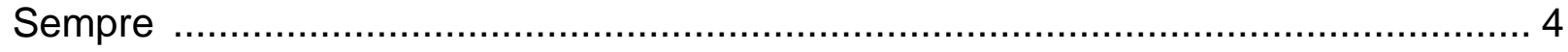

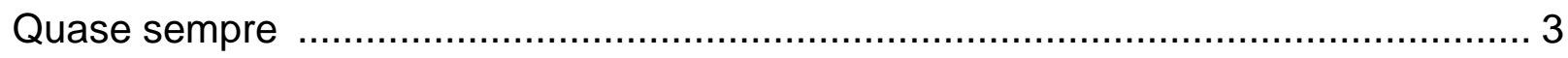

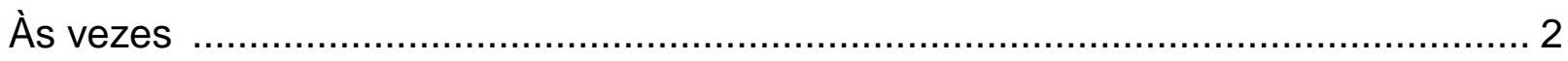

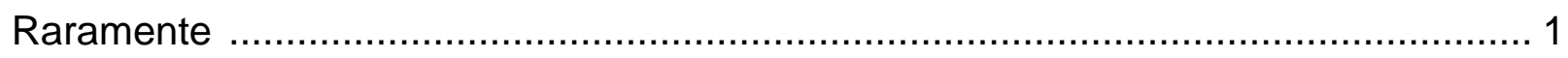

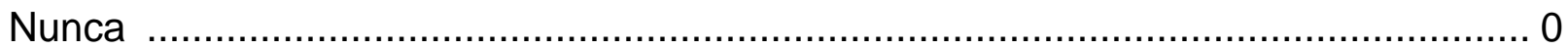

10. Recentemente você tem se sentido cheio de esperança para o futuro?

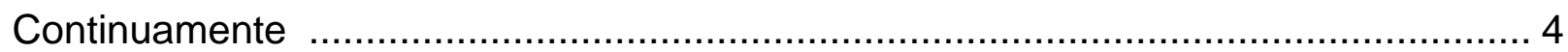

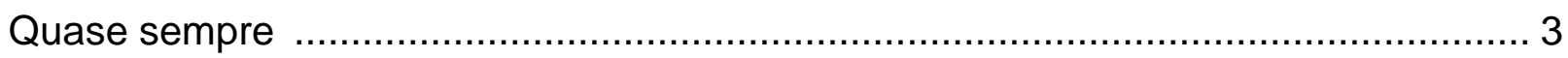

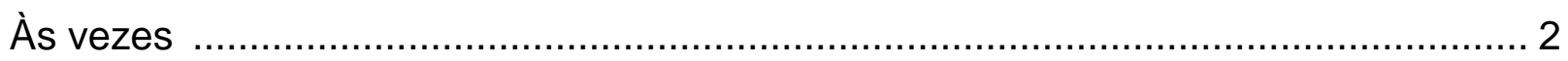

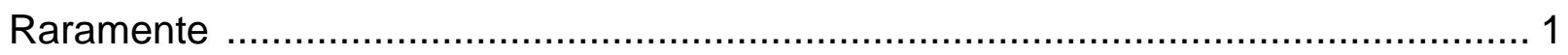

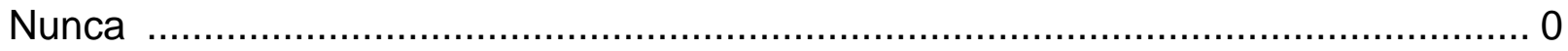




\section{ANEXO 2 - Escala de Presenteísmo de Stanford (SPS-6)}

Você se manteve trabalhando com algum problema de saúde nos últimos trinta dias?

$\square$ Sim. Qual?

$\square$ Não. Sendo esta a sua resposta, você não precisa responder a esta escala.

\begin{tabular}{|c|c|c|c|c|c|}
\hline & $\begin{array}{c}\text { Eu } \\
\text { discordo } \\
\text { totalmente }\end{array}$ & $\begin{array}{l}\text { Eu discordo } \\
\text { parcialmente }\end{array}$ & $\begin{array}{l}\text { Não } \\
\text { concord } \\
\text { o nem } \\
\text { discordo }\end{array}$ & $\begin{array}{l}\text { Eu concordo } \\
\text { parcialmente }\end{array}$ & $\begin{array}{c}\text { Eu } \\
\text { concordo } \\
\text { totalment } \\
\text { e }\end{array}$ \\
\hline $\begin{array}{l}1 \text { Devido ao meu } \\
\text { problema de saúde, } \\
\text { foi muito difícil lidar } \\
\text { com estresse no } \\
\text { trabalho? }\end{array}$ & 1() & 2() & 3() & 4() & 5() \\
\hline $\begin{array}{l}2 \text { Apesar do meu } \\
\text { problema de saúde, } \\
\text { conseguiu terminar } \\
\text { as tarefas difíceis no } \\
\text { trabalho }\end{array}$ & 1() & 2() & 3() & 4() & 5() \\
\hline $\begin{array}{l}3 \text { Devido ao meu } \\
\text { problema de saúde, } \\
\text { não pude ter prazer } \\
\text { no trabalho. }\end{array}$ & 1() & 2() & 3() & 4() & 5() \\
\hline $\begin{array}{l}4 \text { Me senti sem } \\
\text { ânimo para terminar } \\
\text { algumas tarefas no } \\
\text { trabalho devido ao } \\
\text { problema de saúde. }\end{array}$ & 1() & 2() & 3() & 4() & 5() \\
\hline $\begin{array}{l}5 \text { No trabalho, } \\
\text { consegui me } \\
\text { concentrar em } \\
\text { minhas metas apesar } \\
\text { de meu problema de } \\
\text { saúde. }\end{array}$ & 1() & 2() & 3() & 4() & 5() \\
\hline $\begin{array}{l}6 \text { Apesar de meu } \\
\text { problema de saúde, } \\
\text { tive energia } \\
\text { suficiente para } \\
\text { terminar o meu } \\
\text { trabalho. }\end{array}$ & 1() & 2() & 3() & 4() & 5() \\
\hline
\end{tabular}


ANEXO 3 - Parecer Consubstanciado do CEP - EEUSP

\begin{tabular}{|c|c|c|c|c|}
\hline$\equiv E$ & ESCOLA DE ENFERMAGEM DA \\
UNIVERSIDADE DE SÃO \\
ENFERMAGEM
\end{tabular}

\section{PARECER CONSUBSTANCIADO DO CEP}

\section{DADOS DO PROJETO DE PESQUISA}

Titulo da Pesquisa: Capacidade para o trabalho e presenteismo em trabalhadores de enfermagem: propostas de intervençōes gerenciais

Pesquisador: VANDA ELISA ANDRES FELLI

Área Temática:

Versäo: 3

CAAE: 33481114.5 .0000 .5392

Instituiçăo Proponente: Escola de Enfermagem da USP

Patrocinador Principal: Financiamento Próprio

\section{DADOS DO PARECER}

Número do Parecer: 843.983

Data da Relatoria: 20/10/2014

\section{Apresentaçăo do Projeto:}

O aperfeiçoamento das politicas de saúde e segurança do trabalho estão entre os desafios da década dos recursos humanos em saúde $e$, com o aumento da expectativa de vida da populaçăo e a inversão da pirámide populacional, os trabalhadores tendem a permanecer por mais tempo no mercado de trabalho, demandando por boas condições de trabalho e saúde, tanto no plano individual, como das organizaçōes e da própria sociedade. A hipótese deste estudo é que existe associaçāo entre o presenteismo e a capacidade inadequada para o trabalho e que essa problemática pode ser melhorada por meio de estrategias de gerenciamento de recursos humanos. Estudo transversal de abordagem quanti-qualitativa a ser desenvolvido no Hospital Universitário da USP. A população será composta por todos os trabalhadores da assistência de enfermagem (enfermeiros, técnicos e auxiliares) nos três turnos de trabalho (manhã, tarde e noite)(694 participantes). Utilizará os seguintes instrumentos de coleta de dados; questionário sobre dados sóciodemográficos e profissionais dos participantes; Indice de baixos salários e o Stanford Presenteeism Scale - 6 (SPS-6). Haverá tambèm um grupo focal com 14 enfermeiros chefes das seçōes de enfermagem com seguinte queståo norteadora: Que intervençø̃es são indicadas para a melhoria da capacidade para o trabalho e do presenteismo entre os trabalhadores de enfermagem? Critério de Inclusão:trabalhadores com pelo menos seis meses

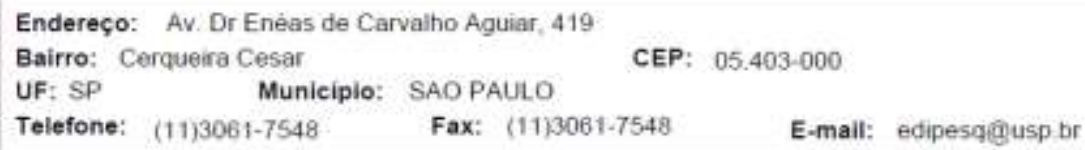




\section{EE UNIVERSIDADE DE SÃO PAULO - EEUSP

de trabalho na instituição e/ou que nâo tenham se afastado nas duas últimas semanas que antecederem a coleta de dados; estar trabalhando na assisténcia direta aos pacientes no momento da coleta de dados. Critério de Exclusão: enfermeiros lotados nas áreas administrativas, técnicos/ auxiliares de enfermagem que trabalham junto ao gerenciamento de materiais nas unidades assistenciais e atendentes de enfermagem por não prestarem assistência direta aos pacientes.

\section{Objetivo da Pesquisa:}

Objetivo Primário:

Avaliar os indices de capacidade para o trabalho e de presenteismo entre os trabalhadores de enfermagem. Objetivo Secundário:

Propor intervençס̃es gerenciais para a prevenção do presenteismo e das incapacidades para o trabalho.

\section{Avaliaçăo dos Riscos e Beneficios:}

Riscos minimos, provável desconforto ao responder aos instrumentos de coleta Indice de baixos salários e o Stanford Presenteeism Scale - 6 (SPS-6).

Beneficios: Elucidação da problemática que impacta na saúde dos trabalhadores e na economia $e$ contribuição para o gerenciamento de recursos humanos.

\section{Comentários e Considerações sobre a Pesquisa:}

Trata-se de um projeto de doutorado.

Consideraçōes sobre os Termos de apresentação obrigatória:

Atendeu a solicitação de inclusão dos contatos da instituição proponente no TCLE. TCLE adequado.

\section{Recomendaçōes:}

Substituir o termo "cópia" por "via" no TCLE.

Conclusōes ou Pendências e Lista de Inadequações:

Pendencias resolvidas.

Situação do Parecer:

Aprovado

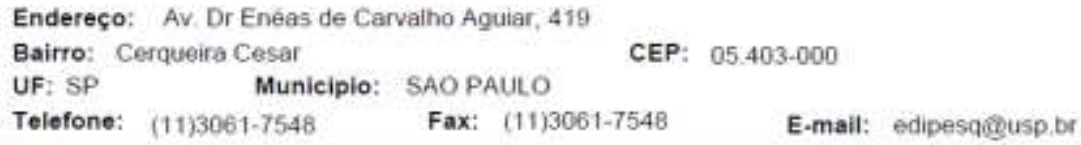




\section{EE . एSIP ESCOLA DE ENFERMAGEM DA UNIVERSIDADE DE SÃO PAULO - EEUSP \\ PAULO-EEUSP}

Continuação do Parecer 843.983

\section{Necessita Apreciação da CONEP:}

Năo

Consideraçōes Finais a critério do CEP:

A aprovação do Comitê de Ética em Pesquisa da EEUSP não substitui a autorização da instituição coparticipante para o inicio da pesquisa.

O CEP EEUSP informa que há necessidade de registro dos relatórios: parcial e final da pesquisa, na Plataforma Brasil.

Assinado por:

Ruth Natalia Teresa Turrini

(Coordenador)

Endereço: Av. Dr Eneas de Carvalho Aguiar, 419 


\section{ANEXO 4 - Aprovação do Comitê de Ética em Pesquisa do HU-USP}

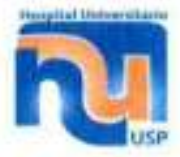

Săo Paulo, 02 de dezembro de 2014.

$I^{\text {mava(a) }} \cdot S^{\text {r(a) }}$.

Dra. Vanda Elisa Andres Felli

Departamento de Orientação Profissional da Escola de Enfermagem

UNIVERSIDADE DE SÃO PAULO

REFERENTE: Projeto de Pesquisa "Capacidade para o trabalho e presenteísmo em trabalhadores de enfermagem: proposta de intervenções gerenciais"

Pesquisador(a) responsável: Dra. Vanda Elisa Andres Felli

Pesquisador Executante: Fabio José da Silva

CAAE: 33481114.5 .3001 .0076

Registro CEP-HU/USP: $1435 / 14$

Prezado(a) Senhor(a)

O Comitê de Ética em Pesquisa do Hospital Universitário da Universidade de São Paulo, em reunião ordinária realizada no dia 28 de novembro de 2014 , analisou o Projeto de Pesquisa acima citado, considerando-o como APROVADO, bem como o seu Termo de Consentimento Livre e Esclarecido.

Lembramos que cabe ao pesquisador elaborar e apresentar a este Comitê, relatórios parciais e final, de acordo com a Resolução $n^{\circ} 466 / 2012$ do Conselho Nacional de Saúde, inciso XI.2, letra " d".

O primeiro relatório está previsto para 28 de maio de 2015.

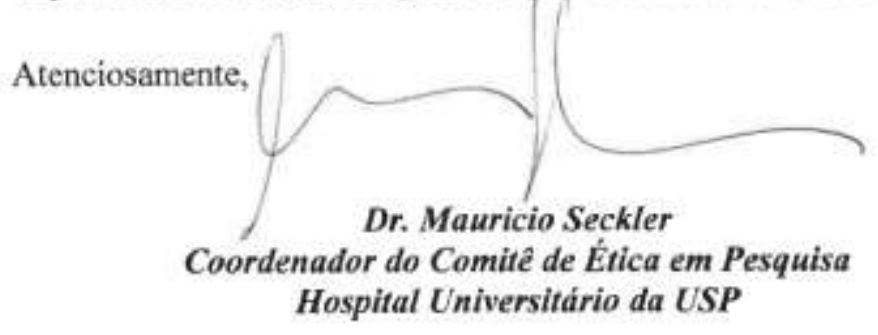

COMITÉ DE ËTCA EM PESOUISA DO HOSPTTAL UNIVERSTTARIO DA USP Aveaida Professor Lineu Prestes, 2565 - Cidsde Universitíria - 05505.000 SAo Paulo - SP

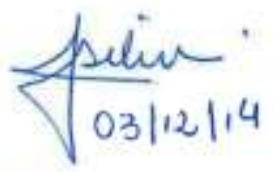
Telit (11) 3691-9457 - E-mail: cep/nhu-11sp.her 